\title{
F- and H-Area Seepage Basins Water Treatment System Process Optimization and Alternative Chemistry lon Exchange/Sorbent Material Screening Clearwell Overflow Study
}

by

S. M. Serkiz

Westinghouse Savannah River Company

Savannah River Site

RECEIVED

Aiken, South Carolina 29808

S. H. Reboul

This paper was prepared in connection with work done under the above contract number with the U. S. Department of Energy. By acceptance of this paper, the publisher and/or recipient acknowledges the U. S. Government's right to retain a nonexclusive, royalty-free license in and to any copyright covering this paper, along with the right to reproduce and to authorize others to reproduce all or part of the copyrighted paper. 


\section{DISCLAIMER}

This report was prepared as an account of work sponsored by an agency of the United States Government. Neither the United States Government nor any agency thereof, nor any of their employees, makes any warranty, express or implied, or assumes any legal liability or responsibility for the accuracy, completeness, or usefulness of any information, apparatus, product or process disclosed, or represents that its use would not infringe privately owned rights. Reference herein to any specific commercial product, process or service by trade name, trademark, manufacturer, or otherwise does not necessarily constitute or imply its endorsement, recommendation, or favoring by the United States Government or any agency thereof. The views and opinions of authors expressed herein do not necessarily state or reflect those of the United States Government or any agency thereof.

This report has been reproduced directly from the best available copy.

Available for sale to the public, in paper, from: U.S. Department of Commerce, National Technical Information Service, 5285 Port Royal Road, Springfield, VA 22161

phone: (800) 553-6847

fax: (703) 605-6900

email: orders@ntis.fedworld.gov

online ordering: http://www.ntis.gov/ordering.htm

Available electronically at http://www.doe.gov/bridge

Available for a processing fee to U.S. Department of Energy and its contractors, in paper, from: U.S. Department of Energy, Office of Scientific and Technical Information, P.O. Box 62, Oak Ridge, TN 37831-0062

phone: (865)576-8401

fax: (865)576-5728

email: reports@adonis.osti.gov 


\section{DISCLAIMER}

Portions of this document may be illegible in electronic image products. Images are produced from the best available original document. 
WSRC-TR-99-00020

Revision 0
Keywords: $F$ and $H$ Seepage Basins, groundwater treatment, treatability study, ion exchange, strontium, technetium, uranium, iodine

Retention: Permanent

\section{F- and H-Area Seepage Basins Water Treatment System \\ Process Optimization and Alternative Chemistry Ion Exchange/Sorbent Material Screening Clearwell Overflow Study (U)}

January 18, 1999

S. M. Serkiz, 773-43A

Steven M. Sertey 1-18-99

S. H. Reboul, 730-2B

Hcate H. Reboul 1-26-99

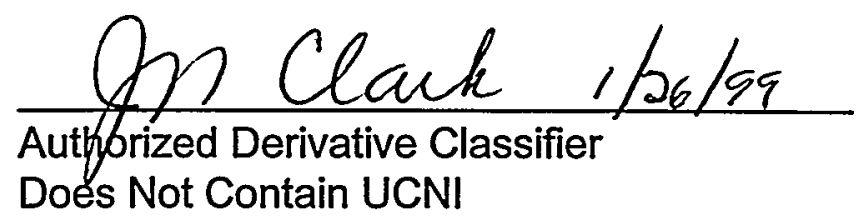

Savannah River Technology Center

Westinghouse Savannah River Company

Aiken, SC 29808 


\section{Table of Contents}

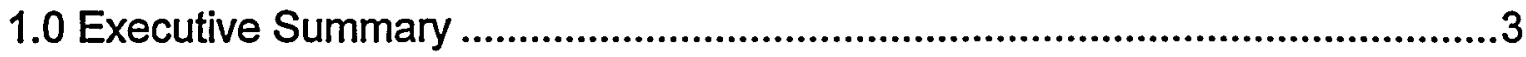

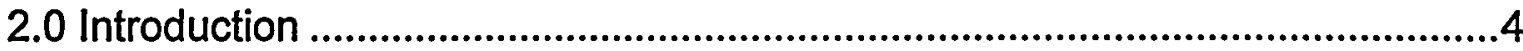

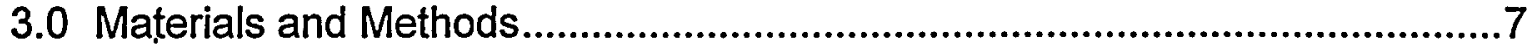

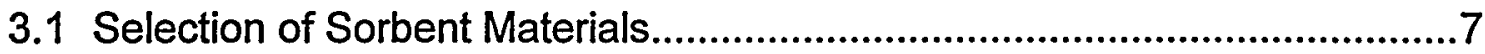

3.2 Clearwell Sample Collection and Characterization......................................8

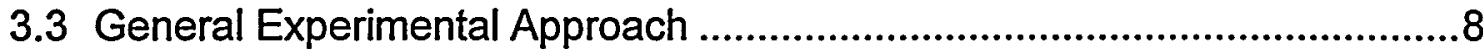

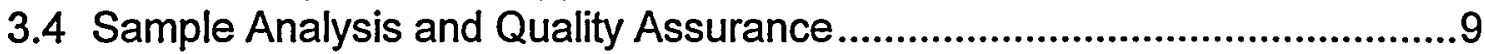

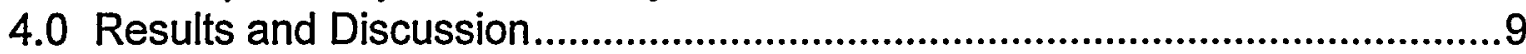

4.1 Influent Characterization (Column Blank Test Results) ............................11

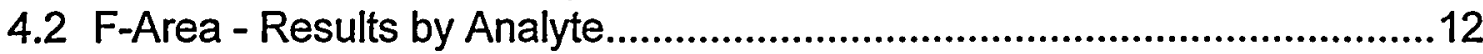

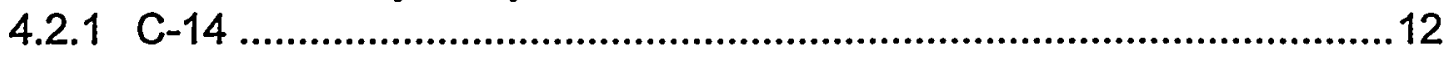

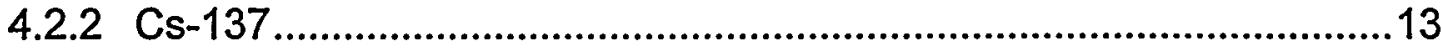

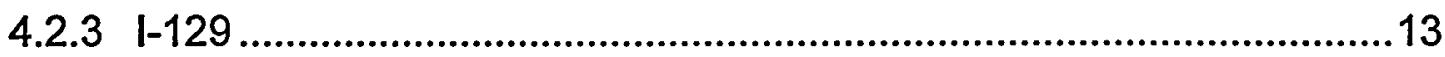

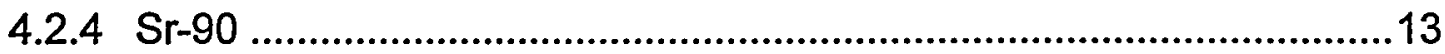

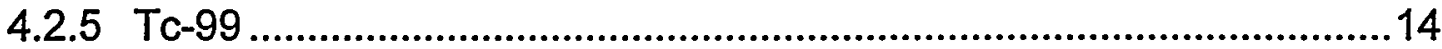

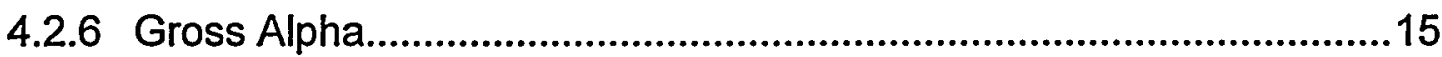

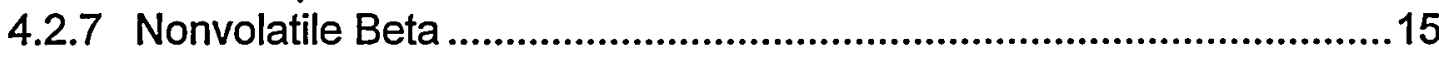

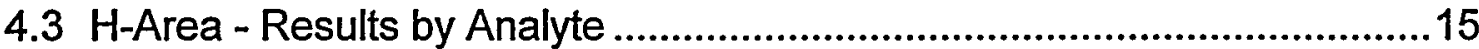

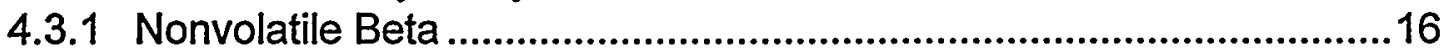

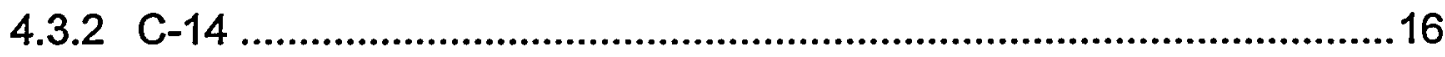

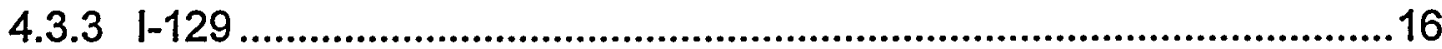

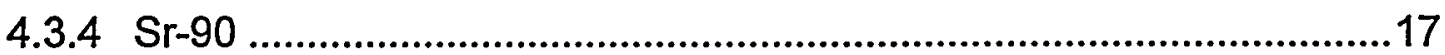

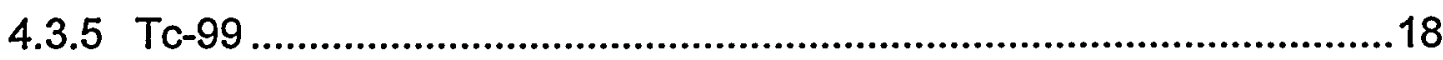

4.4 Post-Test Photographic Documentation .....................................................18

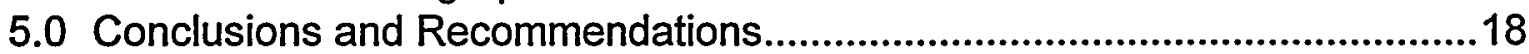

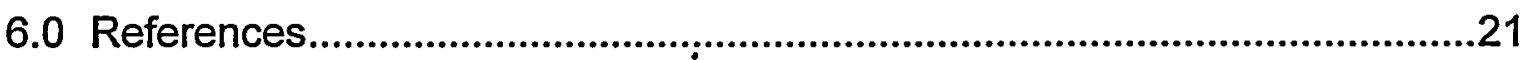

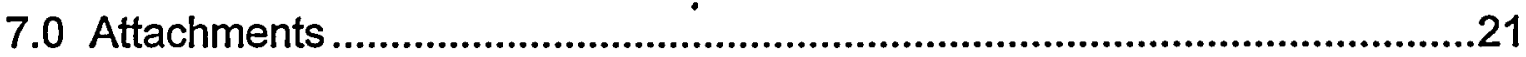

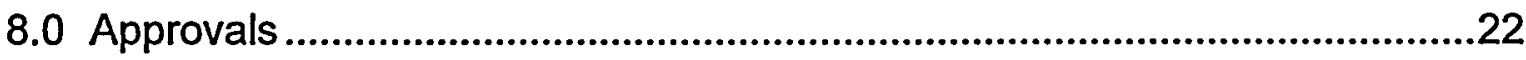




\subsection{Executive Summary}

During startup of the water treatment units (WTUs) at the F-and H-Area Seepage Basins several system performance deficiencies have been encountered in meeting the contract performance specifications. These deficiencies have included not consistently meeting effluent quality not be and frequent changeouts of sorbent/exchange media.

This study investigated alternative ion exchange/sorbent materials and polishing chemistries designed to remove specific radionuclides (e.g., C-14, Tc-99, Sr-90, and $\mathrm{I}-129)$ not removed during the neutralization/precipitation/clarification process.

Generally, the experimental approach for this study consisted of passing clearwell water from both the F-and H-Area WTUs through a series of small-scale columns each packed with one of 14 different sorbent materials. Effluent water from these experiments was analyzed for specific radionuclides (C-14, Tc-99, Sr-90, and I129), gross activities (gross alpha and nonvolatile beta), hazardous constituents (RCRA metals), and major stable cations (iron and aluminum). Analysis of timedependent concentration data was used to determine the contaminant breakthrough characteristics of each sorbent material.

The results of this study indicate that significant improvements to the water polishing chemistry over the current design, both in terms of costs and operations, can be made using commercially available ion exchange materials. In general, relative sorbent effectiveness was similar for clearwell samples from both areas.

The following are the major findings and recommendations resulting from this study.

1. A number of sorbents were found to be substantially more effective in removing Sr-90 than the SIR600 zeolite specified or chosen by ADTECHS. In the short term, ADTECHS' SIR600 zeolite should be replaced with the inexpensive commercial water softening resin CG8. The implementation of the more highly cross-linked cation resins (AG50Wx12, AG50W $\times 8, A G M P-50$ ) and the titanic oxide $\mathrm{Sr}$-Treat material should be evaluated based on additional laboratory data.

2. Removal for the anionic radionuclides (I-129, Tc-99, and C-14) was problematic.

- In samples from both areas, $1-129$ was not removed by activated carbon, the material chosen by ADTECHS for $1-129$ removal. It is recommended that this sorbent be removed from the WTUs due to its ineffectiveness in $1-$ 129 removal and its potential for biofouling of the injection wells. In general, the more highly cross-linked anion resins were more effective in I- 
129 removal than either the DOWEX21K (the anion exchange material chosen by ADTECHS) or the activated carbon.

- Two anion exchange resins (AG1X8 and Reillex HQL) appear to remove Tc-99 more effectively than DOWEX21K (than the anion exchange resin chosen by ADTECHS). In F-Area, none of the sorbent materials were capable of reducing effluent activities for Tc-99 to below about $40 \mathrm{pC} / \mathrm{L}$ (inadequate DF).

- None of the sorbent materials effectively removed C-14. If C-14 removal is necessary, airsparging should be used rather than ion exchange.

3. Because the current operating practice for resin/sorbent materials is to dispose of these materials after a single breakthrough cycle and many of these resins are capable of being regenerated multiple times, an evaluation of the feasibility and cost effectiveness of resin regeneration should be conducted.

4. The chemical form of many of the constituents targeted for removal in this system are sensitive to redox changes (e.g., I, Tc, and $U$ ) and no monitoring or control of the redox conditions of the WTUs is currently being completed. It is recommended that the redox of the system be monitored.

5. A thorough mass balance of contaminants as they pass through neutralization/precipitation/clarification process should be conducted and these results compared to effectiveness of resin polishing of the groundwater without reverse osmosis and chemical treatment.

\subsection{Introduction}

During startup of the water treatment units (WTUs) at the F- and H-Area Seepage Basins several problems have been encountered in meeting the contract performance specifications. These problems have included (Peer Review Panel, 1998):

- effluent water quality not being consistently met;

- system design flow rates are not being achieved;

- secondary waste criteria are not being met; and

- the system reliability has been poor.

Additionally, a recent independent peer review panel (Peer Review Panel, 1998) indicated that there was "considerable uncertainty regarding whether or not the existing chemistry can be optimized or if an alternative chemistry is more appropriate." They further recommended that bench-scale treatability testing be conducted to evaluate alternative processes and/or optimize the current process.

This study investigated alternative ion exchange/sorbent materials and polishing chemistries designed to remove of specific radionuclides (e.g., C-14, Tc-99, Sr90 , and I-129) not removed during the neutralization/precipitation/clarification 
process. For simplicity, this report will use the terms ion exchange material and sorbent material synonymously, even though the term ion exchange describes a specific sorption mechanism.

When alternative chemistries are tested, this new process or combination of processes must be capable of meeting effluent water quality requirements for all constituents of concern (COCs). A summary of the primary COCs at each area is given in Table 1 . In this table, the COCs are categorized as either $\alpha$-emitters, $\beta$ emitters, stable metals, or organics. Also given in this table are the average and maximum concentrations activities, and acceptance limits (i.e., reinjection standards) for the COCs at each site area. As shown in Table 1, alpha-emitting COCs include isotopes of Ra, Th, $\mathrm{U}, \mathrm{Am}$, and $\mathrm{Cm}$; beta-emitters include $\mathrm{C}-14$, Co-60, Ni-63, Sr-90, Tc-99, I-129, Cs-137, and Ra-228; stable metals include Ni, - $\mathrm{Cd}, \mathrm{Hg}$, and $\mathrm{Pb}$; and a single organic, trichloromethane. Because gross alpha and nonvolatile beta measurements represent the sum of several alpha and beta emitting radionuclides, water treatment processes designed to reduce these gross measurements have to target the contributing radionuclides in order to be effective. During startup testing of the WTUs, removal of alpha and/or beta emitters was insufficient in the majority of system tests. Residual alpha emitters included U-238, U-234, Cm-244, Am-241, Th-230, and Ra-226. Beta emitters remaining after treatment included nonvolatile $\mathrm{Sr}-90, \mathrm{Y}-90$ (Y-90 is in secular equilibrium with $\mathrm{Sr}-90$ ), and $\mathrm{Ra}-228$, as well as potentially volatile $\mathrm{C}-14, \mathrm{Tc}-99$, and $\mathrm{l}-129$.

Generally, the experimental approach for this study consisted of passing clearwell water from both the F-and H-Area WTUs through a series of small-scale columns each packed with a different sorbent material. Effluent water from these experiments was analyzed for specific radionuclides (C-14, Tc-99, Sr-90, and I129 , gross activities (gross alpha and nonvolatile beta); hazardous constituents (RCRA metals), and major cations (iron and aluminum). Analysis of timedependent concentration data was used to determine the contaminant breakthrough characteristics of each sorbent material.

Because this is primarily a screening study, additional bench-scale studies are necessary to optimize the process and to collect design/cost data on the alternative sorbents. 
Table 1

Contaminants Requiring Removal from $\mathrm{F}$ and $\mathrm{H}$ Area Groundwaters (Concentration data from Attachment 4 of Specification M-SPP-G-00194)

\begin{tabular}{|c|c|c|c|c|c|}
\hline \multirow[b]{2}{*}{ Area } & \multirow{2}{*}{$\begin{array}{l}\text { Contaminant } \\
\text { Type and Units }\end{array}$} & \multirow{2}{*}{$\begin{array}{l}\text { Contaminant } \\
\text { Identification }\end{array}$} & \multicolumn{3}{|c|}{ Concentrations } \\
\hline & & & Average & Maximum & Acceptance Limit \\
\hline$F$ & $\alpha$-emitter, $\mathrm{pCi} / \mathrm{L}$ & Gross $\alpha$ & 541 & 2070 & 15 \\
\hline " & " & $\mathrm{U}-238$ & 425 & 1600 & 15 for $\alpha$ sum \\
\hline $\bar{n}$ & $\bar{n}$ & U-234 & 188 & 420 & 15 for $\alpha$ sum \\
\hline $\bar{n}$ & $"$ & $\mathrm{Ra}-226$ & 39 & 556 & 5 for Ra sum \\
\hline $\bar{n}$ & $"$ & $\mathrm{Am}-241$ & $\overline{33}$ & 220 & 15 for $\alpha$ sum \\
\hline $\bar{n}$ & $\bar{n}$ & Th-228 & 31 & 350 & 15 for $\alpha$ sum \\
\hline $\bar{n}$ & $\overline{7}$ & Th-230 & 23 & 85 & 15 for $\alpha$ sum \\
\hline$n$ & $\bar{n}$ & U-235 & 13 & 49 & 15 for $\alpha$ sum \\
\hline$n$ & $n$ & $\mathrm{Cm}-244$ & 11 & 59 & 15 for $\alpha$ sum \\
\hline $\bar{n}$ & $n$ & Am-243 & 10 & $\overline{33}$ & 15 for $\alpha$ sum \\
\hline$n$ & $"$ & $\mathrm{Cm}-246$ & 8 & 15 & 15 for $\alpha$ sum \\
\hline$n$ & $n$ & Th-232 & 3 & 11 & 15 for $\alpha$ sum \\
\hline$n$ & $\beta$-emitter, pCi/L & Nonvolatile $\beta$ & 1817 & 5220 & 50 \\
\hline 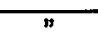 & " & Sr-90 & 402 & 970 & 8 \\
\hline $\bar{n}$ & $"$ & Tc-99 & 159 & 350 & 50 for $\beta$ sum \\
\hline $\bar{n}$ & $\pi$ & Cs-137 & 100 & 982 & 50 for $\beta$ sum \\
\hline $\bar{n}$ & $\bar{n}$ & $1-129$ & 66 & 270 & 50 for $\beta$ sum \\
\hline $\bar{n}$ & 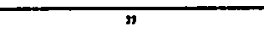 & C-14 & 53 & 100 & 50 for $\beta$ sum \\
\hline$\pi$ & " & Ra-228 & 47 & 170 & 5 for Ra sum \\
\hline $\bar{n}$ & Metal, $\mu \mathrm{g} / \mathrm{L}$ & Cadmium & 7.8 & 37 & 5 \\
\hline $\bar{n}$ & n & Lead & 38 & 1095 & 50 \\
\hline$n$ & $"$ & Mercury & 0.63 & 7.4 & 2 \\
\hline$n$ & $n$ & Nickel & 50 & 334 & 200 \\
\hline $\bar{n}$ & Organic, $\mu \mathrm{g} / \mathrm{L}$ & Dichloromethane & 2.6 & 31 & 5 \\
\hline $\mathrm{H}$ & $\alpha$-emitter, $\mathrm{pCi} / \mathrm{L}$ & Gross $\alpha$ & 30 & 612 & 15 \\
\hline$n$ & $n$ & Th-230 & 43 & 220 & 15 for $\alpha$ sum \\
\hline$n$ & $n$ & Th-228 & 20 & 140 & 15 for $\alpha$ sum \\
\hline $\bar{y}$ & $\bar{n}$ & $\mathrm{Ra}-226$ & 17 & 50 & 5 for Ra sum \\
\hline $\bar{y}$ & $n$ & U-238 & 15 & 60 & 15 for $\alpha$ sum \\
\hline $\bar{n}$ & $\beta$-emitter, pCi/L & Nonvolatile $\beta$ & 1970 & 16000 & 50 \\
\hline$n$ & $n$ & $\mathrm{Sr}-90$ & 1901 & 4900 & 8 \\
\hline$n$ & $n$ & $\mathrm{C}-14$ & 348 & 1500 & 50 for $\beta$ sum \\
\hline $\bar{n}$ & $n$ & Tc-99 & 110 & 340 & 50 for $\beta$ sum \\
\hline$n$ & $n$ & Ra-228 & 86 & 830 & 5 for Ra sum \\
\hline $\bar{n}$ & $n$ & Co-60 & 82 & 320 & 50 for $\beta$ sum \\
\hline$n$ & $n$ & $\mathrm{Ni}-63$ & 82 & 140 & 50 for $\beta$ sum \\
\hline$n$ & $"$ & $1-129$ & 23 & 110 & 50 for $\beta$ sum \\
\hline $\bar{n}$ & Metal, $\mu \mathrm{g} / \mathrm{L}$ & Mercury & 2.4 & 16 & 2 \\
\hline$n$ & $n$ & Lead & 8.3 & 130 & 50 \\
\hline$"$ & Organic, $\mu \mathrm{g} / \mathrm{L}$ & Dichloromethane & 3.1 & 44 & 5 \\
\hline
\end{tabular}




\subsection{Materials and Methods}

This section describes the materials and methods used to evaluate ion exchange/sorbent materials for use in polishing radionuclides from clearwell water at the F\&H WTUs. Included in this section are: the selection of sorbent materials, collection and characterization of process water samples, the experimental approach, and sample analyses/quality assurance.

\subsection{Selection of Sorbent Materials}

Exchange materials evaluated in this testing were selected based on the results of the literature review. Concurrence from appropriate Environmental Restoration Department/Environmental Restoration Engineering technical representatives on the selected materials was also obtained. A literature review of supplier information (e.g., recommendation of flow rates, exchange capacity, and application), material safety data sheets, existing WTU performance data, trade journal data, DOE site experience, and cost data were used in this evaluation process. As a baseline, sorbent materials currently used by ADTECHs in the WTUs were also evaluated.

The selected sorbent materials are listed in Table 2 and fall into four categories: (1) those used in the current system, (2) materials targeting Sr removal, (3) commercial anion resins, and (4) commercial cation resins.

\begin{tabular}{|c|c|c|}
\hline Material & Comments & Size \\
\hline SIR600 & ADTECHS's Zeolite for Cation Removal & $\sim 16-30$ Mesh \\
\hline DOWEX21K & ADTECHS's Anion Resin 4\% Crosslinked & 16-30 Mesh \\
\hline Activated Carbon & ADTECHS's lodine Removal & Powder \\
\hline$\overline{G C 8}$ & $\begin{array}{l}\text { ResinTech Commercial Water Softener } \\
\text { for Sr Removal }\end{array}$ & 16-50 Mesh \\
\hline Sr Treat & Titanic Oxide for Sr Removal & $0.30-0.85 \mathrm{~mm}$ \\
\hline Chelex20 & Chelating Cation Resin & 20-50 Mesh \\
\hline$\overline{A G 1 \times 2}$ & Biorad Anion 2\% Crosslinked & 100-200 Mesh \\
\hline AG1x8 & Biorad Anion 8\% Crosslinked & 200-400 Mesh \\
\hline Reillex HQL & Reilly Anion & 30-60 Mesh \\
\hline Powered Iron & Redox/Sorption Removal Actinides and Tc & $>100$ Mesh \\
\hline Monosodium Titanate & Sr Removal & Powder \\
\hline AGMP.50 & Biorad Cation Macroporous & $200-400$ Mesh \\
\hline AG50W $\times 8$ & Biorad Cation 8\% Crosslinked & 100-200 Mesh \\
\hline AG50W $\times 12$ & Biorad Cation $12 \%$ Crosslinked & 100-200 Mesh \\
\hline Experimental Blank & Glass Wool Column Plugs & Not Applicable \\
\hline
\end{tabular}




\subsection{Clearwell Sample Collection and Characterization}

ER personnel collected and transported clearwell overflow water from each of the WTUs to SRTC. Samples were collected on 8/18/98 and 7/6/98 for the F-and HArea WTUs, respectively. The samples were unpreserved and stored at room temperature prior to analysis. Prior to sampling, the WTUs had been in operation for a minimum of 16 hours.

Experimental blanks were conducted with each set of column tests and allowed for the characterization of the clearwell samples. These experimental blanks consisted of glass wool packing in disposable $20-\mathrm{mL}$ plastic columns. Effluent samples from these columns were collected and analyzed by an outside certified contract lab to provide characterization of the clearwell overflow. A more detailed description of the experimental approach is provided below in Section 3.3.

\subsection{General Experimental Approach}

The source of influent water for these tests was clarifier overflow from each of the $\mathrm{F}$ - and H-Area WTUs. Influent retention times on the sorbent material were approximately two minutes and column effluent samples were collected in sequential one-liter aliquots. To determine contaminant breakthrough, effluent samples from both the experimental blank column (glass wool plugs) and sorbent test columns were analyzed for the radionuclides of interest (including C-14, Tc99 , Sr-90, 1-129, gross alpha, and nonvolatile beta).

All bench-scale testing was conducted using established test methods and the general approach contained in the following procedures.

- ASTM D 1782-91, "Test Methods for Operating Performance of Particulate Cation-Exchange Materials"

- ASTM D 2187-94, "Standard Test Methods for Physical and Chemical Properties of Particulate Ion Exchange Resins"

Because this study was designed for a rapid screening of the performance of a large number of sorbent materials rather than a characterization of these materials, modifications to the field conditions and ASTM procedures (column dimensions, mass of sorbent, and flow rate) were necessary.

A schematic of the experimental setup is presented in Figure 1 and the experimental protocols were as follows: 
1. Ten $\mathrm{mL}$ of sorbent material were placed into disposable $20 \mathrm{~mL}$ plastic columns with small glass wool plugs on the top and bottom of sorbent. In one column for every test set, two small glass wool plugs were placed in a column and run as an experimental blank. Fourteen-gauge silicone tubing was used to transfer the influent from the sample carboy, through the pump, and into the bottom of the column.

2. Influent flow rate was run at $5 \mathrm{~mL} / \mathrm{min} \pm 5 \%(0.25 \mathrm{~mL} / \mathrm{min}$ out of $5 \mathrm{~mL} / \mathrm{min})$ and record flow rate from each column.

3. Columns were conditioned by washing each with a minimum of $100-\mathrm{mL}$ DI water at a flow rate of $5 \mathrm{~mL} / \mathrm{min}$.

4. Tubing was placed into influent sample and sorbent materials were back eluted at a flow rate of $5 \mathrm{~mL} / \mathrm{min}$. Twenty sequential 1- $\mathrm{L}$ samples were collected for each sorbent material and the experimental blank.

5. Sequential 1-L aliquots were submitted to an offsite certified laboratory for appropriate analyses (Sr-90, I-129, Tc-99, C-14, gross alpha, nonvolatile beta, RCRA metals, iron, and aluminum) (see Table 3 for specific analyses by sorbent and WTU sample).

6. Photographs were taken of used sorbent materials to document visual evidence of column fouling.

\subsection{Sample Analysis and Quality Assurance}

GEL Laboratories of Charleston, SC analyzed effluent samples under contract $A B 80091 \mathrm{~N}$ with WSRC. Details of analytical procedures and QA requirements for these analyses are contained in this contract. Standard QA practices were utilized to maximize usefulness of the experimental data. This included: a) use of an accredited analytical laboratory; b) routine submittal of experimental blanks; and c) submittal of experimental replicates. The SRTC Conduct of R\&D Manual was employed for this work and a Hazard Screening Checklist was completed.

\subsection{Results and Discussion}

The results of ion exchange/sorbent material screening for clearwell water collected from the WTUs at both the F-and H-Area Seepage Basins are presented in this section. Column effluent concentrations/activities and photographic documentation were completed as a part of these experiments and form the basis for evaluation of sorbent performance.

Analytical results of column effluent concentrations/activity are reported in a tabular summary for each sorbent material or experimental blank for clearwell samples from each of the WTUs in Appendix A. Included in these tables are the: 
sample ID, analyte, average bedvolume, result qualifier, analytical result, accuracy (reported at $2 \sigma$ ), and the units of the analysis. The average bedvolume is calculated as the volume of influent passed through the column in liters minus 0.5 liters to account for mixing of effluent into the one-liter final sample volume all divided by the resin/sorbent volume in liters (0.010L for these experiments).

Graphs of bedvolume versus activity for all radioactive analytes were developed to evaluate column breakthrough and are included in Appendix B.

\begin{tabular}{|c|c|c|}
\hline \multicolumn{3}{|c|}{ Table 3 - Analyte List By Sorbent and Area } \\
\hline WTU & Sorbent & Analyses \\
\hline F-Area & Blank $A$ and $B$ & $\begin{array}{l}\text { Gross Alpha, Nonvolatile Beta, C-14, Cs-137, l-129, Sr-90, } \\
\text { Tc-99, RCRA Metals }\end{array}$ \\
\hline F-Area & Activated Carbon & $\begin{array}{l}\text { Gross Alpha, Nonvolatile Beta, C-14, Cs-137, l-129, Sr-90, } \\
\text { Tc-99, RCRA Metals }\end{array}$ \\
\hline F-Area & AG1-X2 & $\begin{array}{l}\text { Gross Alpha, Nonvolatile Beta, C-14, I-129, Tc-99, RCRA } \\
\text { Metals }\end{array}$ \\
\hline F-Area & AG1-X8 & $\begin{array}{l}\text { Gross Alpha, Nonvolatile Beta, C-14, I-129, Tc-99, RCRA } \\
\text { Metals }\end{array}$ \\
\hline F-Area & AG50W $\times 12$ & Gross Alpha, Nonvolatile Beta, Cs-137, Sr-90, RCRA Metals \\
\hline F-Area & AG50W $\times 8$ & Gross Alpha, Nonvolatile Beta, Cs-137, Sr-90, RCRA Metals \\
\hline F-Area & AGMP50 & Gross Alpha, Nonvolatile Beta, Cs-137, Sr-90, RCRA Metals \\
\hline F-Area & CG8 & Gross Alpha, Nonvolatile Beta, Cs-137, Sr-90, RCRA Metals \\
\hline F-Area & Chelex 20 & Gross Alpha, Nonvolatile Beta, Cs-137, Sr-90, RCRA Metals \\
\hline F-Area & DOWEX21K & $\begin{array}{l}\text { Gross Alpha, Nonvolatile Beta, C-14, Cs-137, I-129, Sr-90, } \\
\text { Tc-99, RCRA Metals }\end{array}$ \\
\hline F-Area & Monosodium Titanate & Gross Alpha, Nonvolatile Beta, Cs-137, Sr-90, RCRA Metals \\
\hline F-Area & Reillex HQL & $\begin{array}{l}\text { Gross Alpha, Nonvolatile Beta, C-14, 1-129, Tc-99, RCRA } \\
\text { Metals }\end{array}$ \\
\hline F-Area & SIR600 Zeolite & $\begin{array}{l}\text { Gross Alpha, Nonvolatile Beta, C-14, Cs-137, l-129, Sr-90, } \\
\text { Tc-99, RCRA Metals }\end{array}$ \\
\hline F-Area & SR Treat & Gross Alpha, Nonvolatile Beta, Cs-137, Sr-90, RCRA Metals \\
\hline H-Area & Blank $A$ and $B$ & Gross Alpha, Nonvolatile Beta, C-14, I-129, Sr-90, Tc-99, Al, Fe \\
\hline H-Area & Activated Carbon & Gross Alpha, Nonvolatile Beta, C-14, 1-129, Sr-90, Tc-99, Al, Fe \\
\hline H-Area & $A G 1-X 2$ & Gross Alpha, Nonvolatile Beta, C-14, I-129, Sr-90, Tc-99, Al, Fe \\
\hline H-Area & AG1-X8 & Gross Alpha, Nonvolatile Beta, C-14, I-129, Sr-90, Tc-99, Al, Fe \\
\hline H-Area & AG50W $\times 12$ & Gross Alpha, Nonvolatile Beta, C-14, I-129, Sr-90, Tc-99, Al, Fe \\
\hline H-Area & AG50W $\times 8$ & Gross Alpha, Nonvolatile Beta, C-14, 1-129, Sr-90, Tc-99, Al, Fe \\
\hline H-Area & AGMP50 & Gross Alpha, Nonvolatile Beta, C-14, l-129, Sr-90, Tc-99, Al, Fe \\
\hline H-Area & CG8 & Gross Alpha, Nonvolatile Beta, C-14, I-129, Sr-90, Tc-99, Al, Fe \\
\hline H-Area & Chelex 20 & Gross Alpha, Nonvolatile Beta, C-14, 1-129, Sr-90, Tc-99, Al, Fe \\
\hline H-Area & DOWEX21K & Gross Alpha, Nonvolatile Beta, C-14, I-129, Sr-90, Tc-99, Al, Fe \\
\hline H-Area & Iron Powder & Gross Alpha, Nonvolatile Beta, C-14, I-129, Sr-90, Tc-99, Al, Fe \\
\hline H-Area & Monosodium Titanate & Gross Alpha, Nonvolatile Beta, C-14, I-129, Sr-90, Tc-99, Al, Fe \\
\hline H-Area & Reillex HQL & Gross Alpha, Nonvolatile Beta, C-14, I-129, Sr-90, Tc-99, Al, Fe \\
\hline H-Area & SIR600 Zeolite & Gross Alpha, Nonvolatile Beta, C-14, 1-129, Sr-90, Tc-99, Al, Fe \\
\hline H-Area & SR Treat & Gross Alpha, Nonvolatile Beta, C-14, I-129, Sr-90, Tc-99, Al, Fe \\
\hline
\end{tabular}




\subsection{Influent Characterization (Column Blank Test Results)}

Blank concentrations, averaged over both blank runs and all effluent samples, for both F- and H-Area WTU clearwell influent are summarized by analyte in Tables 4 and 5. Average concentrations from Tables 4 and 5 that do not meet the relevant acceptance limits in Table 1 are shaded. For the F-Area WTU clearwell sample, analytes that do not meet the acceptance criteria are gross alpha, nonvolatile beta (i.e., gross beta), C-14 (sum of beta), 1-129 (sum of beta), Sr-90, and Tc-99 (sum of beta). H-Area WTU acceptance criteria are not met for nonvolatile beta (i.e., gross beta), C-14 (sum of beta), Sr-90, and Tc-99 (sum of beta). Even though the acceptance criteria apply at the effluent tank, those analytes not meeting the acceptance criteria in the clearwell are the primary focus of the remaining data analysis. Average RCRA metals concentrations for F-Area WTU clearwell blank samples were below acceptance limits and, therefore, further data analysis of these constituents was not conducted.

For the F-Area clearwell blanks, there is an obvious outlier for Sr-90 in Blank B at an average bedvolume of 1050 . The result for this analysis was $-0.0356 \mathrm{pC}_{\mathrm{i}} / \mathrm{L}$, where the other three $\mathrm{Sr}-90$ analyses averaged $264+/-31 \mathrm{pC} / \mathrm{l}$. Not including this $\mathrm{Sr}-90$ outlier, variability for the analytes exceeding acceptance criteria among the blank samples were about 15 and 20 percent, respectively, for the $\mathrm{F}$ - and $\mathrm{H}$ Area clearwell samples. Of this total variability about 5 percent can be attributed to analytical error and the remainder is thought to be due to sample heterogeneity and/or aging.

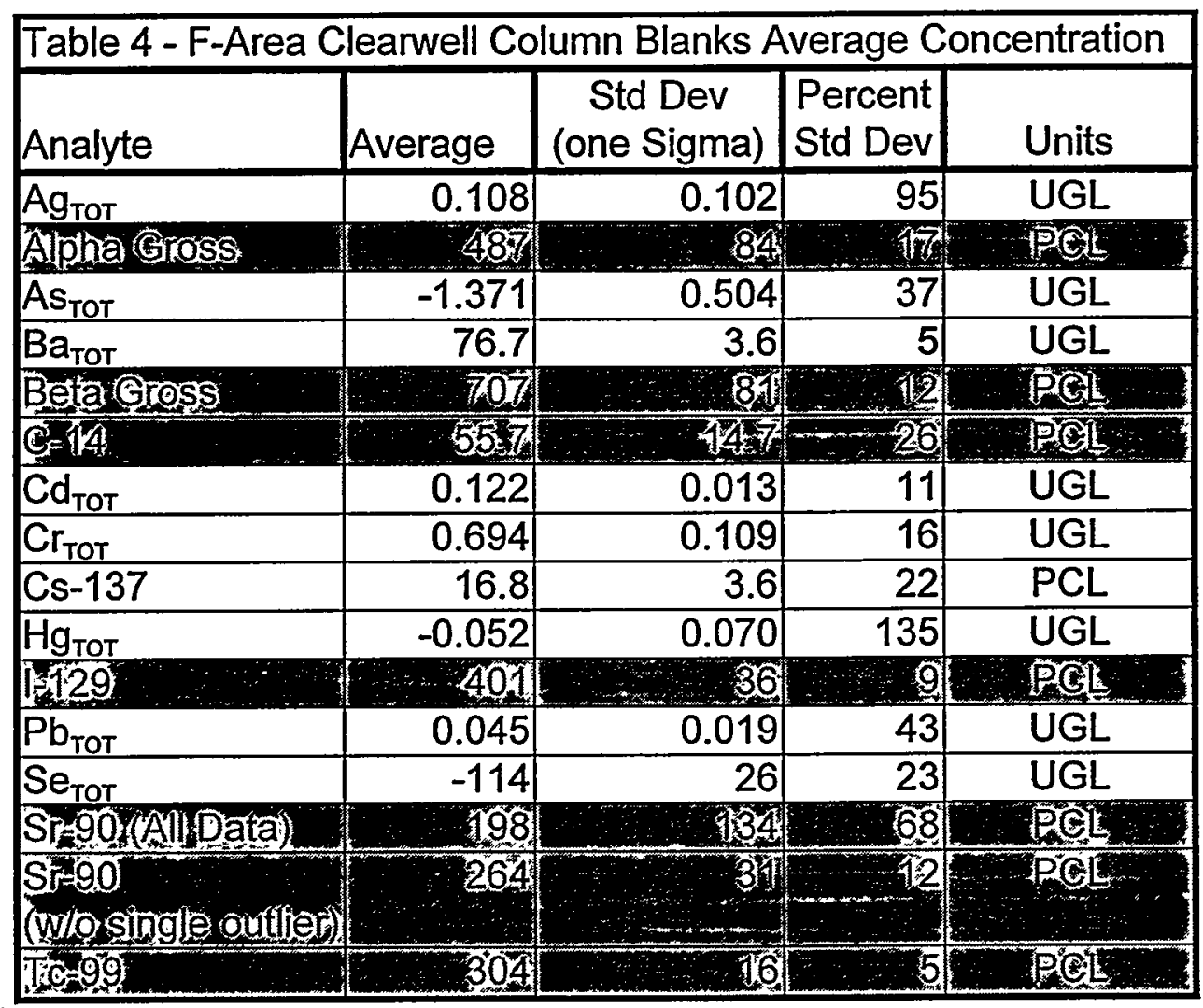




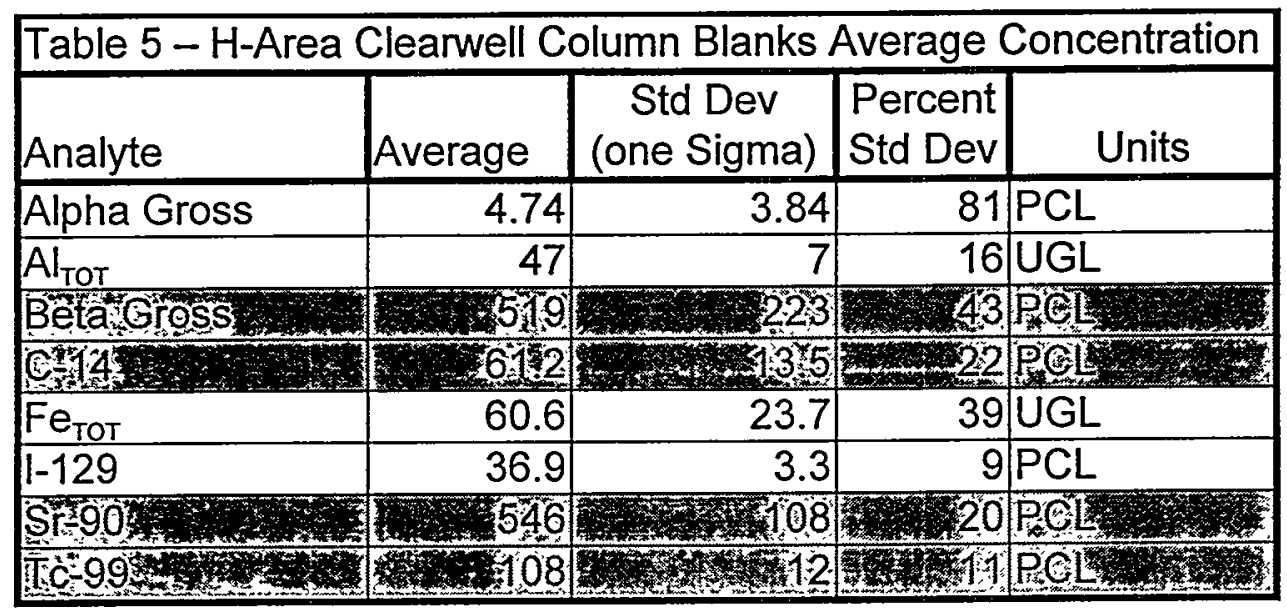

\subsection{F-Area - Results by Analyte}

For the F-Area WTU clearwell sample, analytes that did not meet the acceptance criteria were C-14 (sum of beta), I-129 (sum of beta), Sr-90, and Tc-99 (sum of beta), gross alpha, nonvolatile beta (i.e., gross beta). The results of each of these analytes and $\mathrm{Cs}-137$ for the range of sorbent materials tested are addressed by individual analyte in this section.

\subsubsection{C-14}

C-14 analyses of clearwell overflow effluent for all sorbent materials evaluated are summarized in Figure B8. The results of recent tests of H-Area WTU water suggest that the carbon in this system is in the inorganic form and'can be effectively removed via acidification and air sparging (report to be published). The anion exchange resins were largely ineffective in removing $\mathrm{C}-14$ from clearwell overflow samples. The best removal, only a DF 2, for C-14 was observed for the Dowex $21 \mathrm{~K}$ resin, where decontamination factor (DF) is defined as the ratio of the concentration or activity of the influent to that of the effluent.

At the $\mathrm{pH}$ of the clearwell samples $(\sim 8)$, the predominant specie for inorganic carbon will be the bicarbonate anion $\left(\mathrm{HCO}_{3}^{-}\right.$) (Stumm and Morgan, 1981). Being monovalent, $\mathrm{HCO}_{3}{ }^{-}$is generally less effectively removed by anion exchange resins than would the divalent carbonate $\left(\mathrm{CO}_{3}{ }^{2}\right)$ anion. The carbonate anion is the dominant specie only above $\mathrm{pH} 10$. If $\mathrm{C}-14$ removal via ion exchange is required it is recommended that this exchange reaction be carried out at $\mathrm{pH}$ values of around 10.5 . 
Cs-137 activities in clearwell samples used in this study averaged $16.8 \mathrm{pC} / \mathrm{l}$ and were, therefore, below the acceptance criteria of sum of beta less than $50 \mathrm{pC} / \mathrm{L}$. This suggests that expending exchange capacity to remove Cs-137 may not be the most efficient method of operating the F-Area WTU. Existing process chemistry data should be reviewed to ensure that Cs-137 activities measured in this study are representative of Cs-137 activities observed during system operation.

Cs-137 analyses of clearwell overflow effluent for all sorbent materials evaluated are summarized in Figure B11. The best removal, a DF 5, for Cs-137 was observed for the SIR600 zeolite. If Cs-137 removal is determined to be important, it is recommended that other, less expensive, sorbent materials with a high affinity for Cs (e.g., Duolite ARC-359, mica, and vermiculite) be evaluated as a potential replacement for the SIR600 zeolite.

\section{$4.2 .3 \quad 1-129$}

I-129 analyses of clearwell overflow effluent for all sorbent materials are summarized in Figure B12. Of these materials, the AG1x8, Reillex HQL, and Dowex $21 \mathrm{~K}$ anion resins were the only materials that were effective in removing I129. The AG1X2 resin ( $2 \%$ crosslinkage) was ineffective for $\mathrm{I}-129$ removal. DF values were as high as $\sim 50$ and DF for $A G 1 \times 8>$ Reillex $H Q L>$ Dowex $21 \mathrm{~K}$. Breakthrough of $\mathrm{I}-129$, however, occurred after only few hundred bedvolumes.

The precise chemical form of the $1-129$ in these systems is not known. Because $1-129$ was removed only by anionic resins and is unaffected by the activated carbon and zeolite, it is highly probable that iodine is in an inorganic and anionic form. If the majority of the $1-129$ does not currently exist as iodide, then reduction of the iodine to iodide is expected to enhance the removal effectiveness.

Recommendations regarding the $1-129$ removal process include: (1)conduct lab studies on the affect of redox potential on iodine removal; (2) remove activated carbon from the treatment system due to its lack of effectiveness in iodine removal and its source of organic carbon (potential injection well fouling problems (Serkiz and Thibault, 1998)); and (3) evaluate effectiveness of other sorbent materials (e.g., organic clays and silver impregnated activated carbon) for I-129 removal.

\subsubsection{Sr-90}

Sr-90 analyses of clearwell overflow effluent for all sorbent materials evaluated are summarized in Figure B15 and for the Sr-specific sorbents in Figure B16. The most effective sorbents where AG50Wx12, AG50Wx8, AGMP-50, CG8, SIR600 zeolite, and Sr Treat. The maximum DF value was at least 15 and similar for 
AG50W $\times 12, A G 50 W \times 8, A G M P-50, C G 8$, and Sr Treat. The DF for SIR600 zeolite used in the ADTECHs design is $\sim 5$. Breakthrough of Sr-90, above 24 $\mathrm{pC} / \mathrm{l}$ ( 3 times the regulatory limit to account for permeate dilution), occurred before 400 bedvolumes for the SIR600 zeolite, about at 800 bedvolumes for the CG8 resin, and does not occur for AG50Wx12, AG50Wx8, AGMP-50, or Sr Treat up to 1300 bedvolumes.

Based on these data, it is recommended that: (1) SIR600 zeolite be replaced with CG8 resin, based the lower resin cost of this; (2) conduct additional laboratory studies on AG50Wx12, AG50Wx8, AGMP-50, CG8 and Sr Treat to determine Sr90 breakthrough; and (3) once breakthrough has been determined for the resins in Item (2), conduct an economic analysis of Sr removal based on, at a minimum, resin cost and expected operating life (from breakthrough studies). If Cs-137 removal is required by polishing to meet reinjection requirements, then a lesser amount of the SIR600 zeolite, or a suitable substitute, will have to be included in the polishing system (see discussion in Section 4.2.4).

\subsubsection{Tc-99}

Tc-99 analyses of clearwell overflow effluent for all sorbent materials are summarized in Figure B19. Of these materials, the activated carbon, $A G 1 \times 2$, AG1x8, Reillex HQL, and Dowex $21 \mathrm{~K}$ were the only materials that removed Tc-99 in these experiments. Of these resins, $A G 1 \times 8$ and Reillex $H Q L$ anion resins gave the highest DF ( 6) and this value did not change as a function of number of bedvolumes during the experiment. The activated carbon, AG1x2, and Dowex $21 \mathrm{~K}$ materials all initially had similar DF to the $A G 1 \times 8$ and Reillex HQL anion resins. Their performance, however, degraded significantly (to a DF of 1 and complete breakthrough) over the course of the test.

The precise chemical form of the Tc-99 in these systems is not known. Under the redox conditions found in the groundwater, Tc-99 should exist as Tc(VII) as the $\mathrm{TcO}_{4}^{-}$specie (Serkiz, $1995 \mathrm{Memo}$ ). After RO concentration and iron addition, it is possible that all or a fraction of Tc(VII) is reduced to $\mathrm{Tc}(\mathrm{IV})$ as the $\mathrm{TcO}(\mathrm{OH})_{\mathrm{x}}$ where the number of hydroxides present $(x)$ is dependent on $\mathrm{pH}$. Because anion resins are initially effective in removing about 80 percent of the Tc-99, it is probable that the majority of the Tc-99 is as pertechnetate anion $\left(\mathrm{TcO}_{4}{ }^{-}\right)$. The result that none of the sorbent materials were capable of reducing effluent activities to below about $40 \mathrm{pC} / \mathrm{l}$, suggests that some fraction of the Tc is present in a non-pertechnetate form.

Recommendations regarding the Tc-99 removal process include: (1) lab studies on the effect of redox potential on Tc-99 removal (e.g., examine anion exchange under oxidizing condition); (2) additional laboratory studies should be conducted on AG1x8 and Reillex HQL to determine Tc-99 breakthrough; and (3) once breakthrough has been determined for the resins in Item (2), conduct an 
economic analysis of Tc removal based on, at a minimum, resin cost and expected life (from breakthrough studies).

\subsubsection{Gross Alpha}

Gross alpha in F-Area groundwater is thought to be the result of contributions from isotopes of $\mathrm{U}, \mathrm{Ra}, \mathrm{Am}, \mathrm{Th}, \mathrm{Cm}$ with the majority of the alpha activity resulting from U-238 and U-234 (see Table 1). In the absence of carbonate and in oxidizing systems, uranium is predicted to be dominated by the $\mathrm{UO}_{2}(\mathrm{OH})_{3}-$ specie at a pH of 8 and in the presence of as little as $5 \mathrm{mg} \mathrm{C/l}$ (as carbonate) the dominant specie at a pH of 8 is predicted to be $\mathrm{UO}_{2}\left(\mathrm{CO}_{3}\right)_{2}{ }^{2-}$ (Langmuir, 1979). Given the speciation of uranium coming from the clearwell, uranium removal should be greatest for anion exchange materials. Conversely, at low $\mathrm{pH}$ values, where uranium is expected to exist as the cation $\mathrm{UO}_{2}{ }^{2+}$, a cation exchange resin would be expected to be more effective at uranium removal.

Gross alpha analyses of clearwell overflow effluent for all sorbent materials evaluated are summarized in Figure B1 and for the most effective sorbents in Figure B2. The greatest gross alpha reduction was observed for conventional anion exchange resins (Dowex $21 \mathrm{~K}, A G 1 \times 2$, and $A G 1 \times 8$ ) and the chelating resin Chelex 20.

\subsubsection{Nonvolatile Beta}

The nonvolatile beta contributors in F-Area groundwater are primarily $\mathrm{Sr}-90 / \mathrm{Y}-90$ and to a lesser extent Cs-137 and Ra-228. It should be noted that C-14, Tc-99, and $\mathrm{I}-129$ are volatile beta contributors that do not contribute to the nonvolatile beta activity. The nonvolatile beta radionuclides are in a wide variety of cationic valence states $\left(\mathrm{Sr}^{+2}, \mathrm{Y}^{+3}, \mathrm{Cs}^{+}\right.$, and $\left.\mathrm{Ra}^{+2}\right)$. Therefore, a single exchange/sorbent material would not be expected to be completely effective at reducing nonvolatile beta activity from these waters:

Nonvolatile beta analyses of clearwell overflow effluent for all sorbent materials evaluated are summarized in Figure B4 and for the strontium-specific sorbents in Figure B5. Based upon the screening results for $\mathrm{Sr}-90$ (primary nonvolatile beta contributor), process knowledge, and field experience, these nonvolatile beta data are suspect and not thought to provide meaningful information.

\subsection{H-Area - Results by Analyte}

For the H-Area WTU clearwell sample, analytes that did not meet the acceptance criteria were nonvolatile beta (i.e., gross beta), C-14 (sum of beta), Sr-90, and Tc- 
99 (sum of beta). The results of each of these analytes and I-129 for the range of sorbent materials tested are addressed by individual analyte in this section.

\subsubsection{Nonvolatile Beta}

Beta contributors in H-Area groundwater include Sr-90, Y-90, Tc-99, I-129, C-14, Co-60, Ni-63 and Ra-228. These radionuclides are in a wide variety of chemical forms from anionic (e.g., Tc and I) to cationic (e.g., Sr, Co, and Ni). Therefore, a single exchange/sorbent material would not be expected to be completely effective at reducing nonvolatile beta activity form these waters.

Nonvolatile beta analyses of clearwell overflow effluent for all sorbent materials evaluated are summarized in Figure B6 and for the most effective sorbents in Figure B7. The most effective sorbents where those that target $\mathrm{Sr}$ removal (AG50W $\times 12, A G 50 W \times 8, A G M P-50, C G 8$, SIR600 zeolite, and Sr Treat). This is consistent with the highest proportion of the beta activity being associated with Sr-90 in secular equilibrium with Y-90. Of these sorbents: (1) ADTECHS' strontium sorbent SIR600 zeolite exhibited some breakthrough (above detection limit but below acceptance criteria of $50 \mathrm{pC} / \mathrm{L}$ ) between 600 and 1000 bedvolumes; and (2) AG50Wx12, AG50W $88, A G M P-50, C G 8$, and $\mathrm{Sr}$ Treat did not exhibit any sign of breakthrough to almost 1600 bedvolumes.

\subsubsection{C-14}

C-14 analyses of clearwell overflow effluent for all sorbent materials evaluated are summarized in Figure B9 and for anion resins and activated carbon in Figure $B 10$. The results of recent tests of $\mathrm{H}$-Area WTU water suggest that the carbon in this system is in the inorganic form and can be effectively removed via acidification and air sparging (report to be published). The anion exchange resins were largely ineffective in removing $\mathrm{C}-14$ from clearwell overflow samples.

As stated previously, at the $\mathrm{pH}$ of the clearwell samples $(\sim 8)$, the predominant specie for inorganic carbon will be the bicarbonate anion $\left(\mathrm{HCO}_{3}{ }^{-}\right)$(Stumm and Morgan, 1981). Being monovalent, $\mathrm{HCO}_{3}{ }^{-}$is generally less effectively removed by anion exchange resins than would the divalent carbonate $\left(\mathrm{CO}_{3}{ }^{2-}\right)$ anion. The carbonate anion is the dominant specie only above $\mathrm{pH} 10$. If $\mathrm{C}-14$ removal via ion exchange is required it is recommended that this exchange reaction be carried out at $\mathrm{pH}$ values of around 10.5 .

\subsection{3 $\quad \mathrm{I}-129$}

I-129 analyses of clearwell overflow effluent for all sorbent materials are summarized in Figure B13 and for anion resins and activated carbon in Figure $B 14$. Consistent with the results from the F-Area clearwell screening, AG1x8, Reillex HQL, and Dowex $21 \mathrm{~K}$ anion resins were the most effective materials for 
removing l-129 (the AG1X2 resin ( $2 \%$ crosslinkage) was less effective). DF values for these three resins were initially $\sim 5$ and over the entire test $D F$ for AG1x8> Reillex HQL>Dowex 21K. Unlike the F-Area testing, early breakthrough of $\mathrm{I}-129$ does not occur for these three resins. Breakthrough for Dowex $21 \mathrm{~K}$ occurred at about 1200 bedvolumes and for AG1x8 and Reillex HQL it has not occurred at the end of the test ( 1800 bedvolumes).

The precise chemical form of the $1-129$ in these systems is not known. Because I-129 was removed only by anionic resins and is unaffected by the activated carbon and zeolite, it is highly probable that iodine is in an inorganic and anionic form.

Recommendations regarding the $1-129$ removal process include: (1) conduct lab studies on the affect of redox potential on iodine removal; (2) activated carbon from the treatment system due to its lack of effectiveness in iodine removal and its source of organic carbon (potential injection well fouling problems (Serkiz and Thibault, 1998)); (3) conduct additional laboratory studies on AG1x8, Reillex HQL, and Dowex $21 \mathrm{~K}$ to determine $\mathrm{I}-129$ breakthrough; and (4) once breakthrough has been determined for the resins in Item (3), conduct an economic analysis of I-129 removal based on, at a minimum, resin cost and expected operating life (from breakthrough studies). Before removal of the activated carbon material, its usefulness in Tc-99 removal should be evaluated against its affect on injection water quality and ineffective $1-129$ removal.

\subsubsection{Sr-90}

Sr-90 analyses of clearwell overflow effluent for all sorbent materials evaluated are summarized in Figure B17 and for the Sr-specific sorbents in Figure B18. Like the F-Area screening results, the most effective sorbents where AG50Wx12, AG50Wx8, AGMP-50, CG8, SIR600 zeolite, and Sr Treat. Maximum DF value was 100 and similar for AG50Wx12, AG50Wx8, AGMP-50, CG8, and Sr Treat. The DF for SIR600 zeolite used in the ADTECHs design varies from $\sim 100$ to 10 over the course of the experiment. Breakthrough of Sr-90, above $24 \mathrm{pC} / \mathrm{lL}$ (3 times the regulatory limit to account for permeate dilution), occurred between 800 and 1400 bedvolumes for the SIR600 zeolite, between 1300 and 1900 bedvolumes for $A G 50 W \times 8$, and does not occur for AG50Wx12, AGMP-50, CG8 resin, or $\mathrm{Sr}$ Treat up to 1300 bedvolumes.

Based on these data, it is recommended that: (1) replace SIR600 zeolite with CG8 resin, based on the lower cost of this resin and greater operation life for $\mathrm{Sr}$ removal; (2) conduct additional laboratory studies on AG50Wx12, AG50Wx8, AGMP-50, CG8 and Sr Treat to determine Sr-90 breakthrough; and (3) once breakthrough has been determined for the resins in Item (2), conduct an economic analysis of $\mathrm{Sr}$ removal based on, at a minimum, resin cost and expected operating life (from breakthrough studies). 


\subsubsection{Tc-99}

Tc-99 analyses of clearwell overflow effluent for all sorbent materials are summarized in Figure B20 and for anion resin, iron powder, and activated carbon in Figure 21. Of these materials, the activated carbon, AG1x2, AG1x8, iron powder, Reillex HQL, and Dowex $21 \mathrm{~K}$ were the only materials that removed Tc99 in these experiments. The iron powder column clogged after about 500 bedvolumes and testing of this material was stopped. The remaining five materials exhibited similar behavior with minimum DF of 6 that did not change significantly over the course of the testing.

Recommendations regarding the Tc-99 removal process include: (1) conduct additional laboratory studies on activated carbon, $A G 1 \times 2, A G 1 \times 8$, Reillex HQL, and Dowex 21 to determine Tc-99 breakthrough; (2) once breakthrough has been determined for the resins in Item (1), conduct an economic analysis of Tc removal based on, at a minimum, resin cost and expected life (from breakthrough studies); and (3) evaluate the addition of iron powder to the flocculation tank as a means of promoting heterogeneous floc growth and Tc removal via chemical reduction.

\subsection{Post-Test Photographic Documentation}

Digital photographs of the columns were taken after completion of the clearwell overflow sorbent screening experiments and are included as Appendix $\mathrm{C}$. Visual inspection of these photos indicates that some fouling is occurring in on these sorbent materials (up to about one-third of the column length) after about 1900 bedvolumes. This fouling is red in color and is thought to be resulting from iron precipitation. Determination of the elemental composition and character of the fouling precipitates could be completed to further evaluate the fouling of these sorbent materials in future phases of this work.

\subsection{Conclusions and Recommendations}

The results of this study indicate that significant improvements in the water polishing chemistry over the current design, both in terms of costs and operations, can be made using commercially available ion exchange materials.

In general, sorbent effectiveness was similar for clearwell samples from both areas. Specific conclusions for each nuclide examined are summarized below.

Alpha activity is above the performance specification for the F-Area clearwell sample only and the majority of this activity is from U-238 and U-234. Under the conditions found in the clearwell, uranium should be present as anionic species (e.g., $\mathrm{UO}_{2}(\mathrm{OH})_{3}{ }^{-}$or $\left.\mathrm{UO}_{2}\left(\mathrm{CO}_{3}\right)_{2}{ }^{2-}\right)$. Consistent with this speciation, greatest gross 
alpha reduction was observed for conventional anion exchange resins (Dowex $21 \mathrm{~K}, \mathrm{AG} 1 \times 2$, and $A G 1 \times 8$ ) and the chelating resin Chelex 20.

The total beta activity for both areas is dominated by $\mathrm{Sr}-90$ in secular equilibrium with Y-90. Lesser beta contributors include: (1) Volatile Tc-99, I-129, and C-14; (2) nonvolatile Ra-228; and (3) Cs-137 (nonvolatile) for F Area. These radionuclides are in a wide variety of chemical forms from anionic (e.g., Tc and I) to cationic (e.g., Sr and $\mathrm{Cs}$ ) and, therefore, a single exchange/sorbent material would not be expected to be completely effective at reducing all beta activity from these waters. As would be expected, those sorbents that are effective at removing Sr-90 are also effective in reducing nonvolatile beta activity.

A number of sorbents were found to be substantially more effective in removing Sr-90 than the SIR600 zeolite chosen by ADTECHS. The best performers (no breakthrough at the equivalent of over two weeks of operation at full flow) were the more highly cross-linked cation resins (AG50Wx12, AG50Wx8, AGMP-50) and the titanic oxide $\mathrm{Sr}$-Treat material. Additionally, the inexpensive commercial water softening resin CG8 provided significantly better $\mathrm{Sr}-90$ removal than the SIR600 zeolite.

For this study, the most problematic removal was observed for the anionic radionuclides (I-129, TC-99, and $\mathrm{C}-14)$. In water samples from both areas, $\mathrm{I}-129$ was not removed by activated carbon, but was removed to some degree by the commercial anion resins (AG1X8, Reillex HQL, and Dowex 21K). For these anionic resins, F-Area clearwell water showed I-129 breakthrough after only the equivalent of a few days of full-flow operations and for $\mathrm{H}$-Area clearwell water it was between one and two weeks. Like l-129, Tc-99 was most effectively removed by the commercial anion resins (AG1x2, AG1x8, Reillex HQL, and Dowex $21 \mathrm{~K}$ ). For F-Area water none of the sorbent materials were capable of reducing Tc-99 effluent activities to below about $40 \mathrm{pC} / \mathrm{L}$ (inadequate DF) and some fraction of the Tc (c. $20 \%$ ) appears non-anionic. Several of the resins did not reach breakthrough at the equivalent of several weeks of full-flow operations (for both areas). For 1-129 and Tc-99, the removal effectiveness by anion exchange resin appeared to increase with the degree of resin cross-linkage. All of the sorbents evaluated were largely ineffective for $\mathrm{C}-14$ removal.

Based on historical data, Cs-137 activity is expected to be problematic only for $F$ Area and activities for the water used in this study was below the acceptance criteria of sum of beta less than $50 \mathrm{pC} / \mathrm{L}$. This suggests that expending exchange capacity to remove Cs-137 may not be the most efficient method of operating the F-Area WTU.

As a result of reviewing the $\mathrm{F}$ - and $\mathrm{H}$-Area WTU operations and evaluating data from this study several general recommendations regarding the polishing chemistry of this system have been developed. Because the current operating practice for resin/sorbent materials is to dispose of these materials after a single breakthrough cycle and many of these resins are capable of being regenerated multiple times, an evaluation of the feasibility and cost effectiveness of resin 
regeneration should be conducted. Also, because the chemical form of many of the constituents targeted for removal in this system are sensitive to redox changes (e.g., I, Tc, and $U$ ) and no monitoring or control of the redox conditions of the WTUs is currently being completed, it is recommended that the redox of the system be monitored at a minimum in the clearwell, coming into the polishing system, and in the injection tank. Lastly, neutralization/precipitation/clarification process may be having limited benefit, especially at the H-Area WTU, in removing COCs. A thorough mass balance of contaminants as they pass through neutralization/precipitation/clarification process should be conducted and these results compared to effectiveness of resin polishing of the groundwater without reverse osmosis and chemical treatment.

Recommendations for polishing of specific radionuclides in clearwell water are as follows.

\section{Gross Alpha}

Gross alpha activities do not require treatment in H-Area clearwell water. For FArea groundwater the majority of the alpha activity is expected to be due to isotopes of uranium. Uranium activities should be measured in clearwell to confirm that gross alpha activity is due to uranium. If the alpha activity is due to uranium, then efforts should be made to optimize precipitation/flocculation chemistry to remove uranium prior to polishing stage of the process.

\section{Sr-90}

Replace SIR600 zeolite with CG8 resin (lower cost and better Sr Removal) and determine $\mathrm{Sr}-90$ breakthrough for the most effective resins (AG50Wx12, AG50Wx8, AGMP-50, and Sr Treat) and complete cost analysis.

\section{$1-129$}

Remove activated carbon from the treatment units, because of its ineffectiveness for removing $\mathrm{l}-129$ and its effects as a probable source of biological fouling (note: before removal in H-Area evaluate its efficacy in Tc-99 removal). Conduct optimization studies on the effect of redox potential on iodine removal. For $\mathrm{H}$ Area water determine breakthrough for AG1x8 and Reillex HQL and complete cost analysis. Evaluate effectiveness of other iodine-specific sorbents, such as silver impregnated activated carbon.

\section{Tc-99}

Because necessary DFs are not being achieved for Tc-99 in F-Area water, additional studies on the effect of redox potential on Tc-99 removal are needed. Additionally, Tc-99 breakthrough for AG1 188 and Reillex HQL, and cost analysis needs to be completed. 
C-14

If $\mathrm{C}-14$ removal is necessary, airsparging should be used rather than ion exchange.

Cs-137

Confirm that Cs-137 activities measured in F Area for this study are representative of Cs-137 activities observed during system operation.

\subsection{References}

Langmuir, D. 1979. Uranium Solution-Mineral Equilibria at Low-Temperatures with Application to Sedimentary Ore Deposits. Geochim. Cosmochim. Acta 42:547-569.

Peer Review Panel. February 1998. Review of Water Treatment Units for the F and $H$ Area Seepage Basins Groundwater prepared for the Westinghouse Savannah River Corp., Savannah River Site.

Serkiz, S. M. 1995. Memo to John Pierpoint and John Adams. "Follow-up to the Adtechs Vendor Meeting on 10-11-95 - Issues Regarding the Groundwater Treatment System for the F\&H Area Seepage Basins Remediation (U)" Westinghouse Savannah River Company Internal Memo SRTC-WED-95-0211, Aiken, SC.

Serkiz, S. M. and Thibault, J. J. 1998. Characterization of Solids Collected from $\mathrm{H}$-Area Injection Wells and Injection Tank Chemistry From Both F- and H-Area Water Treatment Units (WTUs). Westinghouse Savannah River Site Report WSRC-TR-98-00442, Aiken, SC.

Stumm W. and Morgan, J.J. (1981). Aquatic Chemistry. Wiley \& Sons, New York.

\subsection{Attachments}

Appendix A - Analytical Results by Experimental Blank or Sorbent Material Appendix B - Graphs of Bedvolume versus Activity by Analyte Appendix C - Post Test Column Photographs 


\subsection{Approvals}

\section{Peer Review}
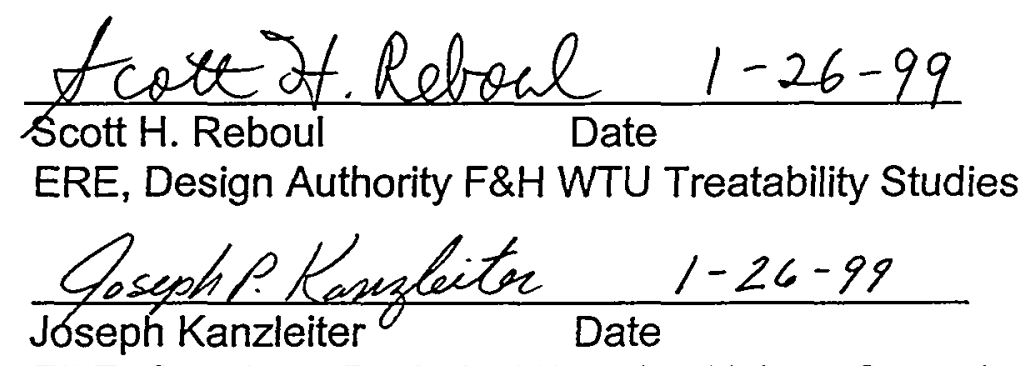

ERE, Cognizant Technical Function H-Area Groundwater Treatment Unit

\section{Approvals}

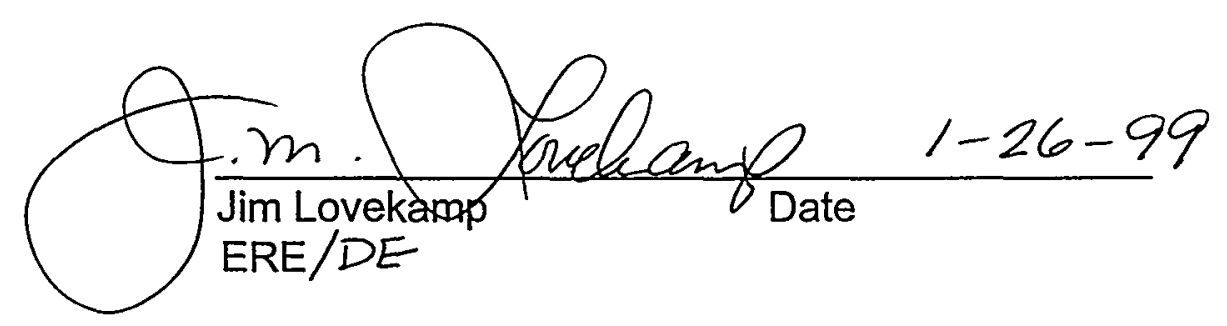

\section{Distribution:}

W. E. Stevens, $773 \mathrm{~A}$

Lynn V. Ehrke, 730-2B

Timothy W. Lewis, 730-2B w/o Attachments

Sean R. Bohrer, 730-2B

Michael J. Hartz, 730-2B w/o Attachments

Bruce G. Schappell, 730-2B

D. B. Moore-Shedrow, 773A w/o Attachments

Tom Butcher, 773-43A

STRCMPT file, 773-A
Tech. Info. Mgmt, 703-43A

Edward M. McNamee, 730-2B Alvin A. Siddall, 730-2B James M. Lovekamp, 730-2B James M. Clark, 730-2B Joseph P. Kanzleiter , 730-2B Scott Reboul, 730-2B Walter Tamosaitis, 773A 
Figure 1 - Experimental Schematic (Not to Scale)

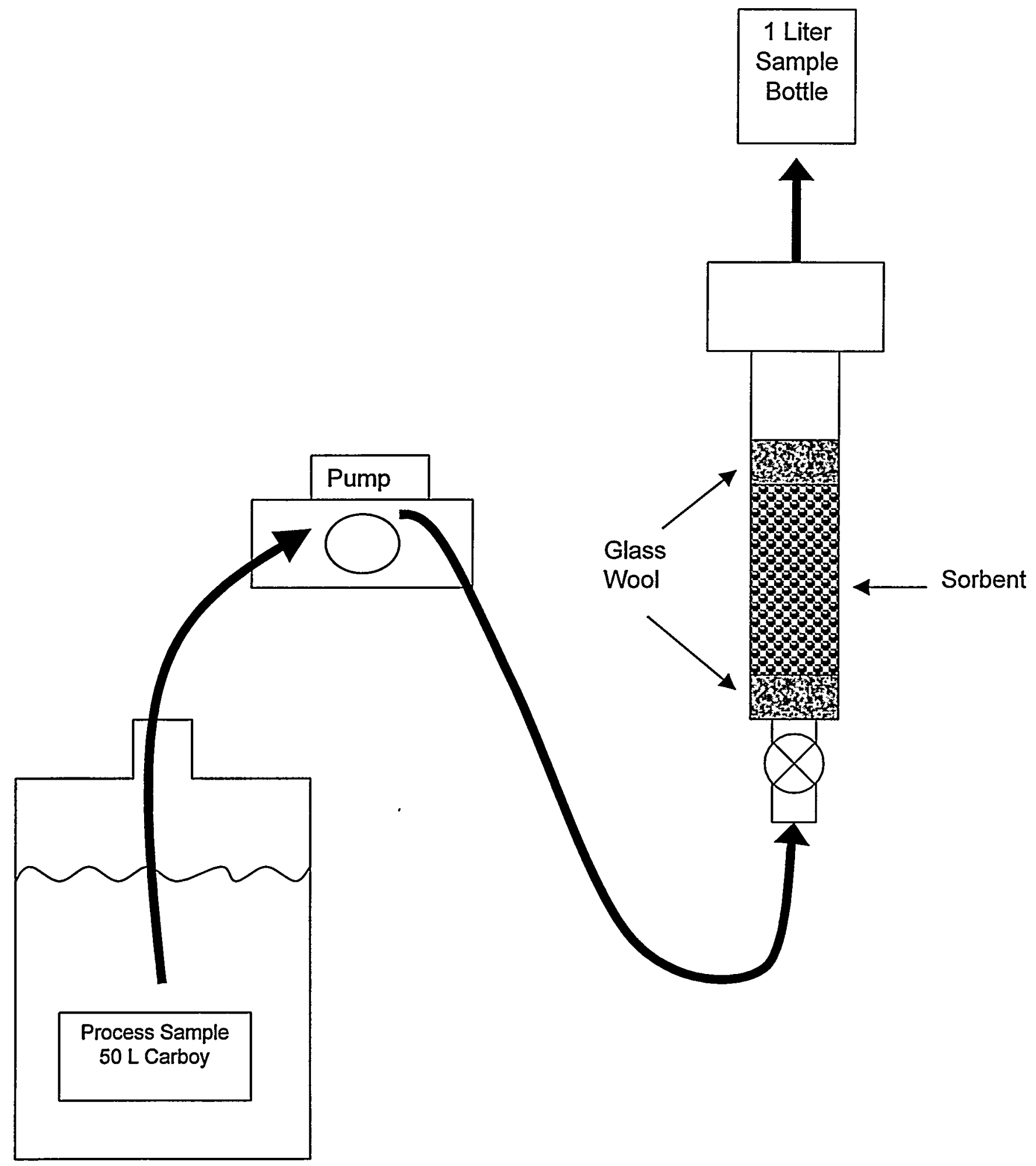


Appendix A

Analytical Results by Experimental Blank or Sorbent Material 


\begin{tabular}{|c|c|c|c|c|c|c|}
\hline \\
\hline \multicolumn{7}{|c|}{$\frac{\text { F-Area WTU Clearwell }}{\text { Blank A }}$} \\
\hline & & & & & & \\
\hline SRS sample ID & Analyte & Avg Bedvol & Anal Oual & Anal Result & Accuracy & Result Units \\
\hline FCO 06A-05 & AGTOT & 450 & & 0.247 & NA & UGL \\
\hline FCO 06A-12 & AGTOT & 1150 & & 0.102 & NR & UGL \\
\hline FCO06A-01 & ALPHAG & 50 & & 453 & 108 & PCL \\
\hline FCO 06A-08 & ALPHAG & 750 & & 441 & 111 & PCL \\
\hline FCO 06A-11 & ALPHAG & 1050 & & 356 & 102 & PCL \\
\hline FCO 06A-18 & ALPHAG & 1750 & & 556 & 125 & PCL \\
\hline FCO 06A-05 & ASTOT & 450 & & -0.705 & NR & UGL \\
\hline FCO 06A-12 & ASTOT & 1150 & & -1.28 & NR & UGL \\
\hline FCO 06A-05 & BATOT & 450 & & 74.6 & NR & UGL \\
\hline FCO 06A-12 & BATOT & 1150 & & 81.7 & NR & UGL \\
\hline FCO 06A-01 & BETAG & 50 & & 685 & 109 & PCL \\
\hline FCO06A-08 & BETAG & 750 & & 743 & 115 & PCL \\
\hline FCO 06A-11 & BETAG & 1050 & & 693 & 117 & $P C L$ \\
\hline FCO 06A-18 & BETAG & 1750 & & 802 & 119 & $\mathrm{PCl}$ \\
\hline FCO 06A-02 & C14 & 150 & & 41.3 & 4.78 & $\mathrm{PCL}$ \\
\hline FCO $06 A-03$ & C14 & 250 & & 46.7 & 4.9 & PCL \\
\hline FCO 06A-06 & C14 & 550 & & 70.2 & 5.28 & PCL \\
\hline FCO 06A-07 & C 14 & 650 & & 69.9 & 5.52 & $\mathrm{PCL}$ \\
\hline FCO 06A-16 & C14 & 1550 & & 46.2 & 4.89 & $P C L$ \\
\hline FCO 06A-17 & C.14 & 1650 & & 42.2 & 5.65 & PCL \\
\hline FCO $06 \mathrm{~A}-05$ & CDTOT & 450 & & 0.135 & NR & $\mathrm{UGL}$ \\
\hline FCO 06A-12 & CDTQT & 1150 & & 0.125 & NR & UGL \\
\hline FCO $06 A-05$ & CRTOT & 450 & & 0.686 & NR & UGL \\
\hline FCO $06 A-12$ & CRTOT & 1150 & & 0.547 & NR & $\mathrm{UGL}$ \\
\hline FCO $06 A-09$ & $\operatorname{CS137}$ & 850 & & 22 & 6.42 & PCL \\
\hline FCO 06A-10 & CS137 & 950 & & 14.6 & 7.92 & PCL \\
\hline FCO $06 A-13$ & CS137 & 1250 & & 20.9 & 7.21 & PCL \\
\hline FCO 06A-14 & CS137 & 1350 & & 12.7 & 5 & PCL \\
\hline FCO 06A-05 & HGTOT & 450 & & 0.0456 & NR & UGL \\
\hline FCO Q6A-12 & HGTOT & 1150 & & -0.1 & NR & UGL \\
\hline FCO $06 A-02$ & 1129 & 150 & $\mathbf{J}$ & 398 & 52.7 & PCL \\
\hline FCO $06 \mathrm{~A}-03$ & 1129 & 250 & $J$ & 444 & 66 & PCL \\
\hline FCO 06A-06 & 1129 & 550 & $\mathrm{~J}$ & 456 & 64.1 & PCL \\
\hline FCO $06 A-07$ & 1129 & 650 & $\mathrm{~J}$ & 370 & 56.7 & PCL \\
\hline FCO $06 \mathrm{~A}-16$ & 1129 & 1550 & 2 & 410 & 69.1 & PGL \\
\hline FCO $06 \mathrm{~A}-17$ & 1129 & 1650 & $\mathrm{~J}$ & 403 & 63.2 & PCL \\
\hline FCO $06 A-05$ & PBTOT & 450 & & 0.066 & NR & UGL \\
\hline FCO 06A-12 & PBTOT & 1150 & & 0.024 & NR & UGL \\
\hline FCO 06A-05 & SETOT & 450 & & -76.8 & NR & UGL \\
\hline FCO 06A-12 & SETOT & 1150 & & -118 & NR & UGL \\
\hline FCO 06A-04 & SR90 & 350 & & 237 & 28.8 & PCL \\
\hline FCO 06A-15 & SR90 & 1450 & & 257 & 31.3 & PCL \\
\hline FCO 06A-05 & TC99 & 450 & & 301 & 13.6 & $\mathrm{PCL}$ \\
\hline FCO 06A-12 & TC99 & 1150 & & 326 & 14 & PCL \\
\hline
\end{tabular}

Notes: $J=L T$ reporting limit

NR $=$ Not Reported

$\mathrm{U}=\mathrm{LT}$ detection limit

$\mathrm{C}=$ lab control sample not met

$\mathrm{R}=\mathrm{ICP}$ interference check not met $\mathrm{V}=$ lab blank contaminated

$E=$ value between sample specific $E Q L$ and detection limit

Accuracy Reported at $2 \delta$

Page $\mathrm{A} 2$ of $\mathrm{A} 39$

WSRC-TR-99-00020, Rev. 0 


\begin{tabular}{|c|c|c|c|c|c|c|}
\hline \multicolumn{7}{|c|}{ F-Area WTU Clearwell } \\
\hline Blank 8 & & & & & & \\
\hline & & & & & & \\
\hline SAS Sample ID & Analyte & Avg Bedvol & Anal Qual & Anal Result & Accuracy & Result Units \\
\hline FCO 06B.05 & AGTOT & 450 & & 0.002 & NR & UGL \\
\hline FCO 06B-12 & AGTOT & 1150 & & 0.081 & NR & UGL \\
\hline FCO 06B-01 & ALPHAG & 50 & & 457 & 115 & PCL \\
\hline FCO $06 \mathrm{~B}-08$ & ALPHAG & 750 & & 602 & 129 & $\mathrm{PCL}$ \\
\hline FCO 06B-15 & ALPHAG & 1450 & & 543 & 118 & $\mathrm{PCL}$ \\
\hline FCO 06B-05 & ASTOT & 450 & & -1.64 & NA & UGL \\
\hline FCO06B-12 & ASTOT & 1150 & & -1.86 & NA & UGL \\
\hline FCO $06 B-05$ & BATOT & 450 & & 73.6 & NA & UGL \\
\hline FCO 06B-12 & BATOT & 1150 & & 76.7 & NR & UGL \\
\hline FCO 068.01 & BETAG & 50 & & 620 & 109 & PCL \\
\hline FCO 06B-08 & BETAG & 750 & & 599 & 109 & PCL \\
\hline FCO 06B-15 & BETAG & 1450 & & 804 & 117 & $P C L$ \\
\hline FCO 06B-02 & C14 & 150 & & 65 & 8.4 & $P C L$ \\
\hline FCO 06B-03 & C14 & 250 & & 56.9 & 9.3 & $\overline{P C L}$ \\
\hline FCO 06B.09 & C14 & 850 & & 35.5 & 17.3 & $\mathrm{PCL}$ \\
\hline FCO 06B-10 & $\mathrm{C} 14$ & 950 & & 61.1 & 9.16 & PCL \\
\hline FCO $06 \mathrm{~B}-16$ & $\mathrm{C} 14$ & 1550 & & 48.8 & 8.41 & PCL \\
\hline FCO 06B-17 & C14 & 1650 & & 84.8 & 9.32 & PCL \\
\hline FCO 06B-05 & CDTOT & 450 & & 0.103 & NR & UGL \\
\hline FCO $06 \mathrm{~B}-12$ & CDTOT & 1150 & & 0.123 & NR & UGL \\
\hline FCO 06B-05 & CRTOT & 450 & & 0.741 & NR & UGL \\
\hline FCO 06B-12 & CRTOT & 1150 & & 0.802 & NA & UGL \\
\hline FCO 06B-06 & CS137 & 550 & & 13.6 & 4.17 & $\overline{P C L}$ \\
\hline FCO 06B-07 & CS137 & 650 & & 14.8 & 5.49 & $P C L$ \\
\hline FCO $06 \mathrm{~B}-13$ & CS137 & 1250 & & 20.2 & 5.31 & $\mathrm{PCL}$ \\
\hline FCO 06B-14 & C\$137 & 1350 & & 15.9 & 5.24 & PCL \\
\hline FCO 06B.05 & HGTOT & 450 & & -0.0471 & NR & UGL \\
\hline FCO 06B-12 & HGTOT & 1150 & & -0.106 & NR & UGL \\
\hline FCO 06B-02 & 1129 & 150 & $\mathrm{~J}$ & 371 & 44.4 & PCL \\
\hline FCO 06B.03 & 1129 & 250 & $\mathrm{~J}$ & 368 & 43.5 & PCL \\
\hline FCO 06B-09 & 1129 & 850 & 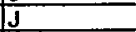 & 379 & 44.4 & PCL \\
\hline FCO 06B-10 & $\longdiv { 1 1 2 9 }$ & 950 & $j$ & 468 & 55.5 & PCL \\
\hline FCO 06B-16 & 1129 & 1550 & $J$ & 369 & 43.6 & $P C L$ \\
\hline$F C 006 B-17$ & 1129 & 1650 & $j$ & 377 & 44.1 & PCL \\
\hline FCO 06B.05 & PBTOT & 450 & & 0.055 & NR & UGL \\
\hline FCO 06B-12 & PBTOT & 1150 & & 0.034 & NR & $\mathrm{UGL}$ \\
\hline FCO 06B-05 & SETOT & 450 & & -128 & NR & UGL \\
\hline FCO $06 \mathrm{~B}-12$ & SETOT & 1150 & & -134 & NR & UGL \\
\hline FCO 06B-04 & SR90 & 350 & & 298 & 31.1 & PCL \\
\hline FCO 06B-11 & SR90 & 1050 & $\bar{u}$ & -0.0356 & 3.1 & PCL \\
\hline FCO 06B-05 & TC99 & 450 & & 301 & 13.6 & $\overline{P C L}$ \\
\hline FCO 06B-12 & TC99 & 1150 & & 288 & 13.3 & PCL \\
\hline
\end{tabular}

Notes: $J=L T$ reporting limit $\quad N R=$ Not Reported $\mathrm{U}=\mathrm{LT}$ detection limit $\quad \mathrm{C}=$ lab control sample not met

$R=I C P$ interference check not met $V=$ lab blank contaminated

$E=$ value between sample specific $E Q L$ and detection limit

Accuracy Reported at $2 \delta$ 


\begin{tabular}{|c|c|c|c|c|c|c|}
\hline \multicolumn{7}{|c|}{ F-Area WTU Clearwell } \\
\hline \multirow{2}{*}{\multicolumn{7}{|c|}{\begin{tabular}{|l|l} 
Activated Carbon & \\
\end{tabular}}} \\
\hline & & & & & & \\
\hline Sample ID & Analyte & Avg Bedvo & Qualifier & Result & Accuracy & Units \\
\hline FCO 12.05 & AGTOT & 450 & & 0.043 & NR & $\mathbf{U G L}$ \\
\hline FCO 12.12 & AGTOT & 1150 & & 0.028 & NR & UGL \\
\hline FCO 12.01 & ALPHAG & 50 & & 261 & 84.6 & $P C L$ \\
\hline FCO 12.08 & ALPHAG & 750 & & 378 & 102 & $P C L$ \\
\hline $\mathrm{FCO} 12-15$ & ALPHAG & 1450 & & 281 & 64.8 & $\mathrm{PCL}$ \\
\hline FCO 12.05 & ASTOT & 450 & & -1.17 & NR & UGL \\
\hline FCO $12-12$ & ASTOT & 1150 & & -1.33 & NR & UGL \\
\hline FCO 12.05 & BATOT & 450 & & 76.8 & NR & $U G L$ \\
\hline $\mathrm{FCO} \mathrm{12-12}$ & BATOT & 1150 & & 74 & NR & UGL \\
\hline FCO 12.01 & BETAG & 50 & & 556 & 101 & $\overline{P C L}$ \\
\hline FCO 12.08 & BETAG & 750 & & 762 & 117 & $\mathrm{PCL}$ \\
\hline FCO $12-15$ & BETAG & 1450 & & 685 & 83.9 & $P C L$ \\
\hline FCO 12.02 & C14 & 150 & & 46.5 & 11 & $\mathrm{PCL}$ \\
\hline FCO 12.03 & $C_{14}$ & 250 & & 18.7 & 10.4 & $P C L$ \\
\hline FCO 12.09 & $\mathrm{C14}$ & 850 & & 64.4 & 5.3 & $\mathrm{PCL}$ \\
\hline FCO 12-10 & C14 & 950 & & 69.7 & 5.31 & $P C L$ \\
\hline $\mathrm{FCO} 12-16$ & C14 & 1550 & & 49.8 & 4.94 & PCL \\
\hline FCO 12-17 & C14 & 1650 & & 50.3 & 5.57 & $\overline{P C L}$ \\
\hline FCO 12.05 & CDTOT & 450 & & 0.089 & NR & UGL \\
\hline FCO $12-12$ & CDTOT & 1150 & & .081 & NR & $\overline{U G L}$ \\
\hline FCO 12.05 & CRTOT & 450 & & 0.739 & NR & UGL \\
\hline FCO $12-12$ & CRTOT & 1150 & & 0.73 & NR & UGL \\
\hline $\mathrm{FCO} 12-06$ & CS137 & 550 & & 15.4 & 5.3 & $\mathrm{PCL}$ \\
\hline FCO 12-07 & CS137 & 650 & & 13.7 & 4.9 & $P C L$ \\
\hline FCO $12-13$ & CS137 & 1250 & & 13.6 & 5.62 & $\mathrm{PCL}$ \\
\hline FCO 12-14 & CS137 & 1350 & & 14.5 & 5.35 & $\overline{P C L}$ \\
\hline FCO 12.05 & HGTOT & 450 & & -0.0954 & NR & $\overline{U G L}$ \\
\hline FCO $12-12$ & HGTOT & 1150 & & -0.0848 & NR & UGL \\
\hline FCO $12-02$ & 1129 & 150 & $J$ & 353 & 42.2 & $\mathrm{PCL}$ \\
\hline FCO 12.03 & 1129 & 250 & J & 333 & 39.6 & $P C L$ \\
\hline FCO 12.09 & 1129 & 850 & & 311 & 43 & $\mathrm{PCL}$ \\
\hline FCO 12.10 & 1129 & 950 & & 362 & 51.6 & $\mathrm{PCL}$ \\
\hline FCO 12-16 & 1129 & 1550 & & 362 & 48.7 & $\mathrm{PCL}$ \\
\hline FCO 12-17 & 1129 & 1650 & & 432 & 64.4 & PCL \\
\hline FCO 12-05 & PBTOT & 450 & & 0.062 & NR & UGL \\
\hline$F C O \quad 12-12$ & PBTOT & 1150 & & 0.03 & NR & UGL \\
\hline FCO $12-05$ & SETOT & 450 & & -112 & NR & $\overline{U G L}$ \\
\hline FCO 12.12 & SETOT & 1150 & $\mathrm{~J}$ & -123 & $\overline{N R}$ & UGL \\
\hline FCO 12.04 & SR90 & 350 & & 255 & 27.3 & $\mathrm{PCL}$ \\
\hline FCO 12.11 & SR90 & 1050 & & 276 & 29.1 & $\mathrm{PCL}$ \\
\hline FCO 12-05 & TC99 & 450 & & 77.4 & 7.78 & $\mathrm{PCL}$ \\
\hline FCO 12-12 & TC99 & 1150 & & 158 & 10.4 & $P C L$ \\
\hline
\end{tabular}

Notes: $\mathrm{J}=\mathrm{LT}$ reporting limit

NR $=$ Not Reported

$U=L T$ detection limit

$\mathrm{C}=$ lab control sample not met

$\mathrm{R}=\mathrm{ICP}$ interference check not met $\mathrm{V}=$ lab blank contaminated

$E=$ value between sample specific $E Q L$ and detection limit 


\begin{tabular}{|c|c|c|c|c|c|c|}
\hline \multicolumn{7}{|c|}{ F-Area WTU Clearwell } \\
\hline \multirow{2}{*}{$\begin{array}{l}\text { F-Area WTU Cle } \\
\mathrm{AG} 1 \times 2 \text { Resin } \\
\end{array}$} & & & & & & \\
\hline & & & & & & \\
\hline SAS Samplo ID & Analyte & Avg Bedvol & Anal Qual & Anal Result & Accuracy & Result Units \\
\hline FCO $08-04$ & AGTOT & 350 & & 0.039 & NR & UGL \\
\hline FCO 08.09 & AGTOT & 850 & & 0.031 & NR & UGL \\
\hline FCO $08-14$ & AGTOT & 1350 & & 0.021 & NR & UGL \\
\hline FCO 08.01 & ALPHAG & 50 & & 20.8 & 6.59 & PCL \\
\hline FCO 08-06 & ALPHAG & 550 & U & 2.15 & 6.00 & PCL \\
\hline FCO OB-11 & ALPHAG & 1050 & U & 4.85 & 6.07 & $P C L$ \\
\hline FCO 08.16 & ALPHAG & 1550 & U & 9.09 & 8.10 & PCL \\
\hline FCO 08-04 & ASTOT & 350 & & -1.23 & NR & UGL \\
\hline FCO $08-09$ & ASTOT & 850 & & -1.5 & NR & UGL \\
\hline FCO 08-14 & ASTOT & 1350 & & -2.05 & NR & UGL \\
\hline FCO 08.04 & BATOT & 350 & & 85.2 & NR & UGL \\
\hline FCO $08-09$ & BATOT & 850 & & 78.6 & NR & UGL \\
\hline FCO 08 - & BATOT & 1350 & & 85.1 & $N R$ & UGL \\
\hline FCO 08.01 & BETAG & 50 & & 376 & 14.2 & PCL \\
\hline FCO 08.06 & BETAG & 550 & & 443 & 15.2 & $P C L$ \\
\hline FCO 08.11 & BETAG & 1050 & & 489 & 15.8 & PCL \\
\hline FCO $08-16$ & BETAG & 1550 & & 514 & 16.8 & PCL \\
\hline FCO 08.02 & C14 & 150 & & 51.7 & 4.94 & $\mathrm{PCL}$ \\
\hline FCO 08-03 & $\mathrm{C}_{14}$ & 250 & & 42.8 & 4.75 & PCL \\
\hline FCOO 08.07 & C14 & 650 & & 73.2 & 5.4 & $P C L$ \\
\hline FCO $08-08$ & C14 & 750 & & 69.2 & 5.92 & $P C L$ \\
\hline FCO $08-12$ & C14 & 1150 & & 56.9 & 5.11 & PCL \\
\hline FCO 08-13 & C14 & 1250 & & 55.4 & 5.89 & PCL \\
\hline FCO 08.17 & C14 & 1650 & & 36.1 & 6.17 & $P C L$ \\
\hline FCO 08-18 & C14 & 1750 & & 54.2 & 4.95 & $P C L$ \\
\hline FCO 08.04 & CDTOT & 350 & & 0.137 & NR & UGL \\
\hline FCO 08-09 & CDTOT & 850 & & 0.105 & NR & UGL \\
\hline FCO 08-14 & CDTOT & 1350 & & 0.13 & NR & UGL \\
\hline FCO $08-04$ & CRTOT & 350 & & 0.842 & NR & UGL \\
\hline FCO 08.09 & CATOT & 850 & & 0.797 & NR & UGL \\
\hline FCO 08.14 & CATOT & 1350 & & 0.714 & NR & UGL \\
\hline FCO 08-04 & HGTOT & 350 & & -0.0405 & NA & UGL \\
\hline FCO 08-09 & HGTOT & 850 & & -0.0301 & NR & UGL \\
\hline FCO 08-14 & HGTOT & 1350 & & -0.03 & NR & UGL \\
\hline FCO 08-02 & 1129 & 150 & $J$ & 371 & 51.6 & $P C L$ \\
\hline$F C O \quad 08-03$ & 1129 & 250 & $J$ & 362 & 57.9 & $\overline{P C L}$ \\
\hline FCO $08-07$ & 1129 & 650 & $\mathrm{~J}$ & 365 & 52.9 & $\mathrm{PCL}$ \\
\hline FCO 08-08 & 1129 & 750 & $j$ & 377 & 52.5 & $\mathrm{PCL}$ \\
\hline FCO 08-12 & 1129 & 1150 & $\mathrm{~J}$ & 413 & 66.2 & $\mathrm{PCL}$ \\
\hline FCO $08-13$ & 1129 & 1250 & $\mathrm{~J}$ & 330 & 47.5 & PCL \\
\hline FCO 08-17 & 1129 & 1650 & $J$ & 395 & 59.6 & PCL \\
\hline FCO 08-18 & 1129 & 1750 & $J$ & 390 & 58.9 & PCL \\
\hline FCO $08-04$ & PBTOT & 350 & & 0.054 & NR & UGL \\
\hline FCO $08-09$ & PBTOT & 850 & & 0.019 & NR & UGL \\
\hline FCO $08-14$ & PBTOT & 1350 & & 0.043 & NR & UGL \\
\hline FCO 08.04 & SETOT & 350 & & -108 & NR & UGL \\
\hline FCO 08-09 & SETOT & 850 & & -158 & NR & UGL \\
\hline FCO 08-14 & SETOT & 1350 & & -162 & NR & UGL \\
\hline FCO $08-04$ & TC99 & 350 & R & 63.5 & 6.99 & PCL \\
\hline FCO 08.09 & TC99 & 850 & & 84.8 & 7.58 & $P C L$ \\
\hline FCO $08-14$ & TC99 & 1350 & & 301 & 13.4 & PCL \\
\hline
\end{tabular}

Notes: $J=L T$ reporting limit

NR $=$ Not Reported

$U=L T$ detection limit

$\mathrm{C}=$ lab control sample not met

$R=I C P$ interference check not met $V=$ lab blank contaminated

$E=$ value between sample specific EQL and detection limit

Accuracy Reported at $2 \delta$

Page A5 of A39

WSRC-TR-99-00020, Rev. 0 


\begin{tabular}{|c|c|c|c|c|c|c|}
\hline \\
\hline \multicolumn{7}{|c|}{\begin{tabular}{|l|l} 
AG $1 \times 8$ Resin \\
\end{tabular}} \\
\hline & & & & & & \\
\hline SRS Sample ID & Analyte & Avg Bedvol & AnalQual & Anal Result & Accuracy & Result Units \\
\hline FCO 09.04 & AGTOT & 350 & & \begin{tabular}{|r|}
0.084 \\
\end{tabular} & NR & UGL \\
\hline FCO 09.09 & AGTOT & 850 & & 0.049 & NR & UGL \\
\hline FCO 09-14 & AGTOT & 1350 & & 0.033 & NR & UGL \\
\hline FCO 09.01 & ALPHAG & 50 & $\mathrm{U}$ & 0.955 & 5.72 & $P C L$ \\
\hline FCO $09-06$ & ALPHAG & 550 & U & 5.65 & 6.73 & $\mathrm{PCL}$ \\
\hline FCO $09-11$ & $A L P H A G$ & 1050 & $\mathrm{U}$ & 8.79 & 6.18 & $\mathrm{PCL}$ \\
\hline FCO $09-16$ & ALPHAG & 1550 & $\mathrm{U}$ & 3.5 & 4.48 & $P C L$ \\
\hline FCO 09-04 & ASTOT & 350 & & -1.33 & NR & UGL \\
\hline FCO $09-09$ & ASTOT & 850 & & .1 .53 & NR & UGL \\
\hline FCO 09-14 & ASTOT & 1350 & & -1.76 & NR & UGL \\
\hline FCO 09.04 & BATOT & 350 & & 84.9 & NR & UGL \\
\hline FCO 09.09 & BATOT & 850 & & 77.9 & NR & UGL \\
\hline FCO $09-14$ & BATOT & 1350 & & 85.1 & NR & UGL \\
\hline$F C O \quad 09-01$ & BETAG & 50 & & 349 & 14.4 & $P G L$ \\
\hline$F C O 09-06$ & BETAG & 550 & & 472 & 14.8 & PCL \\
\hline$F C O 09.11$ & BETAG & 1050 & & 524 & 15.6 & $\mathrm{PCL}$ \\
\hline$F C O 09-16$ & BETAG & 1550 & & 393 & 13.8 & $\mathrm{PCL}$ \\
\hline FCO $09-02$ & C14 & 150 & & 50.6 & 4.86 & $P C L$ \\
\hline FCO $09-03$ & C.14 & 250 & & 42.1 & 4.54 & $P C L$ \\
\hline FCO $09-07$ & C14 & 650 & & 66.9 & 5.01 & PCL \\
\hline FCO 09.08 & C14 & 750 & & 68 & 5.22 & $P C L$ \\
\hline FCO $09-12$ & C 14 & 1150 & & 52.3 & 4.79 & $P C L$ \\
\hline FCO 09-13 & $\mathrm{C}_{14}$ & 1250 & & 55.7 & 5.25 & $P C L$ \\
\hline FCO $09-17$ & C14 & 1650 & & 62.4 & 5.92 & PCL \\
\hline FCO 09-18 & C14 & 1750 & & 63.2 & 6.71 & PCL \\
\hline $\mathrm{FCO} \quad 09-04$ & CDTOT & 350 & & 0.133 & NR & $\mathrm{UGL}$ \\
\hline FCO 09.09 & CDTOT & 850 & & 0.107 & NA & UGL \\
\hline FCO $09-14$ & CDTOT & 1350 & & 0.153 & NR & UGL \\
\hline FCO $09-04$ & CRTOT & 350 & & 0.494 & NR & UGL \\
\hline FCO 09-09 & CRTOT & 850 & & 0.647 & NR & $\mathrm{UGL}$ \\
\hline $\mathrm{FCO} 09.14$ & CRTOT & 1350 & & 0.719 & NR & $\mathrm{UGL}$ \\
\hline FCO 09-04 & HGTOT & 350 & & -0.0442 & NR & UGL \\
\hline FCO 09-09 & HGTOT & 850 & & -0.017 & NR & UGL \\
\hline FCO $09-14$ & HGTOT & 1350 & & -0.013 & NR & $\overline{U G L}$ \\
\hline FCO 09.02 & 1129 & 150 & $\mathrm{U}$ & 3.94 & 13.3 & PCL \\
\hline $\mathrm{FCO} 09.03$ & 1129 & 250 & & 40.6 & 22.3 & $P C L$ \\
\hline FCO 09.07 & 1129 & 650 & & 422 & 66.3 & $P C L$ \\
\hline FCO 09-08 & 1129 & 750 & & 352 & 50.3 & $\mathrm{PCL}$ \\
\hline FCO $09-12$ & 1129 & 1150 & & 386 & 56.6 & $\mathrm{PCL}$ \\
\hline FCO 09-13 & 1129 & 1250 & & 422 & 58.1 & $P C L$ \\
\hline FCO 09-17 & 1129 & 1650 & & 367 & 57.9 & PCL \\
\hline FCO $09-18$ & 1129 & 1750 & & 409 & 55.7 & PCL \\
\hline FCO $09-04$ & PBTOT & 350 & & 0.055 & NR & UGL \\
\hline FCO $09-09$ & PBTOT & 850 & & 0.041 & NR & $\mathrm{UGL}$ \\
\hline FCO 09-14 & PBTOT & 1350 & & 0.046 & NR & $\mathrm{UGL}$ \\
\hline FCO $09-04$ & SETOT & 350 & & -131 & NR & UGL \\
\hline FCO 09.09 & SETOT & 850 & & -155 & NR & UGL \\
\hline FCO 09.14 & SETOT & 1350 & & -146 & NB & UGL \\
\hline FCO 09.04 & TC99 & 350 & $\mathbf{R}$ & 47.2 & 6.19 & PCL \\
\hline FCO 09-09 & TC99 & 850 & $\mathrm{R}$ & 49.2 & 6.41 & PCL \\
\hline $\mathrm{FCO} \quad 09-14$ & TC99 & 1350 & $\mathbf{R}$ & 67.4 & 7.08 & $\mathrm{PCL}$ \\
\hline
\end{tabular}

Notes: $\mathrm{J}=\mathrm{LT}$ reporting limit

NR $=$ Not Reported

$U=L T$ detection limit

$\mathrm{C}=$ lab control sample not met

$\mathrm{R}=\mathrm{ICP}$ interference check not met $\mathrm{V}=$ lab blank contaminated

$\mathrm{E}=$ value between sample specific $E Q L$ and detection limit

Accuracy Reported at $2 \delta$

Page $A 6$ of $A 39$

WSRC-TR-99-00020, Rev. 0 


\begin{tabular}{|c|c|c|c|c|c|c|}
\hline \multicolumn{7}{|c|}{ F-Area WTU Clearwell } \\
\hline \multicolumn{7}{|c|}{ AG50W $\times 12$ Resin } \\
\hline SRS Samole ID & Analute & Ava Bedvol & AnalQual & Anal Result & Accuracy & Result Units \\
\hline FCO 15.03 & AGTOT & 250 & & 0.024 & $\frac{\text { Reculau }}{\text { NA }}$ & UGL \\
\hline FCO 15.04 & AGTOT & 350 & & 0.016 & NR & UGL \\
\hline FCO 15-07 & AGTOT & 650 & & 0.021 & NR & UGL \\
\hline FCO 15.08 & AGTOT & 750 & & 0.012 & NR & UGL \\
\hline FCO 15-11 & AGTOT & 1050 & & 0.053 & NR & UGL \\
\hline FCO 15-12 & AGTOT & 1150 & & 0.062 & NR & UGL \\
\hline FCO 15-15 & AGTOT & 1450 & & 0.045 & NR & UGL \\
\hline FCO 15-16 & AGTOT & 1550 & & 0.018 & $\mathrm{NR}$ & UGL \\
\hline FCO 15.01 & ALPHAG & 50 & & 56.1 & 10.1 & PCL \\
\hline FCO 15-05 & ALPHAG & 450 & & 392 & 102 & PCL \\
\hline FCO 15.09 & ALPHAG & 850 & & 362 & 105 & PCL \\
\hline FCO $15-13$ & ALPHAG & 1250 & & 281 & 89.1 & $P C L$ \\
\hline FCO 15-17 & $A L P H A G$ & 1650 & & 363 & 99.2 & $\overline{P C L}$ \\
\hline FCO 15.03 & ASTOT & 250 & & -1.69 & NR & UGL \\
\hline FCO 15.04 & ASTOT & 350 & & -2.24 & NR & UGL \\
\hline FCO 15.07 & ASTOT & 650 & & -1.53 & NR & UGL \\
\hline FCO 15.08 & ASTOT & 750 & & -1.47 & NR & UGL \\
\hline FCO $15-11$ & ASTOT & 1050 & & -2.11 & NR & UGL \\
\hline FCO $15-12$ & ASTOT & 1150 & & -1.25 & NR & UGL \\
\hline FCO 15-15 & ASTOT & 1450 & & -1.61 & NR & UGL \\
\hline FCO 15-16 & ASTOT & 1550 & & -1.52 & NR & UGL \\
\hline FCO 15.03 & BATOT & 250 & & 0.778 & NR & UGL \\
\hline FCO 15.04 & BATOT & 350 & & 0.506 & NR & UGL \\
\hline FCO 15.07 & BATOT & 650 & & 0.246 & NR & UGL \\
\hline FCO $15-08$ & BATOT & 750 & & 0.215 & NR & UGL \\
\hline FCO 15-11 & BATOT & 1050 & & 0.157 & NR & UGL \\
\hline FCO 15-12 & BATOT & 1150 & & 0.446 & NR & UGL \\
\hline FCO 15.15 & BATOT & 1450 & & 0.19 & NR & UGL \\
\hline FCO 15-16 & BATOT & 1550 & & 0.185 & NR & UGL \\
\hline FCO 15.01 & BETAG & 50 & & 52.4 & 6.93 & $P C L$ \\
\hline FCO 15.05 & BETAG & 450 & & 416 & 93 & PCL \\
\hline FCO 15.09 & BETAG & 850 & & 364 & 91.8 & PCL \\
\hline FCO 15-13 & BETAG & 1250 & & 289 & 88.3 & PCL \\
\hline FCO 15-17 & BETAG & 1650 & & 280 & 82.6 & $P C L$ \\
\hline
\end{tabular}

Notes: $J=L T$ reporting limit

NR $=$ Not Reported

$U=L T$ detection limit

$\mathrm{C}=$ lab control sample not met

$\mathrm{R}=\mathrm{ICP}$ interference check not met $\mathrm{V}=\mathrm{lab}$ blank contaminated

$E=$ value between sample specific $E Q L$ and detection limit

Accuracy Reported at $2 \delta$

Page A7 of A39

WSRC-TR-99-00020, Rev. 0 


\begin{tabular}{|c|c|c|c|c|c|c|}
\hline \multicolumn{7}{|c|}{ F-Area WTU Clearwell } \\
\hline AG50W $\times 12$ Res & Cont & & & & & \\
\hline & & & & & & \\
\hline SRS Sample ID & Analyte & Avg Bedvol & Anal Qual & Anal Result & Accuracy & Result Units \\
\hline FCO 15-03 & CDTOT & 250 & & 0.097 & NR & UGL \\
\hline FCO 15-04 & CDTOT & 350 & & 0.062 & NR & UGL \\
\hline FCO $15-07$ & CDTOT & 650 & & 0.071 & NR & UGL \\
\hline FCO 15.08 & CDTOT & 750 & & 0.063 & NR & UGL \\
\hline FCO 15-11 & ICDTOT & 1050 & & 0.067 & NR & UGL \\
\hline FCO 15-12 & CDTOT & 1150 & & 0.08 & NR & UGL \\
\hline FCO $15-15$ & CDTOT & 1450 & & 0.087 & NR & UGL \\
\hline FCO $15-16$ & CDTOT & 1550 & & 0.085 & NR & UGL \\
\hline FCO $15-03$ & CRTOT & 250 & & 0.724 & NA & UGL \\
\hline FCO $15-04$ & CRTOT & 350 & & 0.661 & NR & UGL \\
\hline FCO 15.07 & CRTOT & 650 & & 0.651 & NR & $\mathrm{UGL}$ \\
\hline FCO 15-08 & CRTOT & 750 & & 0.609 & NR & UGL \\
\hline FCO 15-11 & CRTOT & 1050 & & 0.932 & NR & UGL \\
\hline FCO 15-12 & CRTOT & 1150 & & 0.562 & NR & UGL \\
\hline FCO 15-15 & CRTOT & 1450 & & 0.601 & NR & UGL \\
\hline FCO $15-16$ & CRTOT & 1550 & & 0.604 & NR & UGL \\
\hline FCO 15-03 & CS137 & 250 & & 18.6 & 5.51 & $P C L$ \\
\hline FCO $15-04$ & CS137 & 350 & & 13.8 & 4.03 & $P C L$ \\
\hline FCO 15.07 & C\$137 & 650 & & 10.2 & 6.26 & PCL \\
\hline FCO $15-08$ & $\operatorname{cs} 137$ & 750 & & 24.4 & 8.49 & PCL \\
\hline FCO 15-11 & C\$137 & 1050 & & 20.2 & 7.64 & $\mathrm{PCL}$ \\
\hline FCO 15-12 & CS137 & 1150 & & 16.1 & 5.33 & $\mathrm{PCL}$ \\
\hline FCO 15-16 & CS137 & 1550 & & 20.6 & 5.82 & PCL \\
\hline FCO 15-03 & HGTOT & 250 & & -0.0858 & NR & UGL \\
\hline FCO 15-04 & HGTOT & 350 & & -0.0372 & NR & UGL \\
\hline FCO $15-07$ & HGTOT & 650 & & -0.017 & NR & UGL \\
\hline FCO 15-08 & HGTOT & 750 & & -0.0474 & NA & UGL \\
\hline FCO 15-11 & HGTOT & 1050 & & -0.0222 & NR & $\mathrm{UGL}$ \\
\hline FCO 15-12 & HGTOT & 1150 & & -0.0985 & NR & UGL \\
\hline FCO 15-15 & HGTOT & 1450 & & -0.0189 & NR & UGL \\
\hline FCO 15-16 & HGTOT & 1550 & & -0.0478 & NR & $U G L$ \\
\hline FCO 15-03 & PBTOT & 250 & & -0.017 & NR & UGL \\
\hline FCO 15.04 & PBTOT & 350 & & -0.004 & NR & UGL \\
\hline FCO 15-07 & PBTOT & 650 & & -0.025 & NA & UGL \\
\hline FCO 15-08 & PBTOT & 750 & & -0.034 & NR & UGL \\
\hline FCO 15-11 & PBTOT & 1050 & & -0.023 & NR & UGL \\
\hline FCO 15-12 & PBTOT & 1150 & & 0.02 & NR & UGL \\
\hline FCO $15-15$ & PBTOT & 1450 & & -0.021 & NR & UGL \\
\hline FCO 15-16 & PBTOT & 1550 & & -0.01 & NR & UGL \\
\hline FCO $15-03$ & SETOT & 250 & & -1.85 & NR & UGL \\
\hline FCO 15-04 & SETOT & 350 & & -5.5 & NA & UGL \\
\hline FCO 15-07 & SETOT & 650 & & -13.7 & NA & UGL \\
\hline FCO 15-08 & SETOT & 750 & & -6.33 & NA & UGL \\
\hline FCO 15-11 & SETOT & 1050 & & -287 & NR & UGL \\
\hline FCO 15-12 & SETOT & 1150 & & -1.19 & NR & UGL \\
\hline FCO 15-15 & SETOT & 1450 & & -7.09 & NR & UGL \\
\hline FCO 15-16 & SETOT & 1550 & & -6.8 & NR & UGL \\
\hline FCO 15.02 & SR90 & 150 & $\overline{\mathrm{U}}$ & 3.51 & 11 & $P C L$ \\
\hline FCO 15.06 & SR90 & 550 & $\mathrm{U}$ & -3.12 & 3.1 & $P C L$ \\
\hline FCO 15-10 & SR90 & 950 & $\mathbf{U}$ & 1.2 & 1.82 & PCL \\
\hline FCO 15-14 & SR90 & 1350 & U & -0.822 & 2.36 & $P C L$ \\
\hline
\end{tabular}

\author{
Notes: $J=L T$ reporting limit $\quad N R=$ Not Reported \\ $U=L T$ detection limit $\quad \mathrm{C}=$ lab control sample not met \\ $R=I C P$ interference check not met $V=$ lab blank contaminated
}

$\mathrm{E}=$ value between sample specific $E Q L$ and detection limit 


\begin{tabular}{|c|c|c|c|c|c|c|}
\hline \multicolumn{7}{|c|}{ F-Area WTU Clearwell } \\
\hline \multicolumn{7}{|c|}{ AG50W $\times 8$ Resin } \\
\hline & & & & & & \\
\hline SRS Sample ID & Analyte & Avg Bedvol & AnalQual & Anal Result & Accuracy & Result Units \\
\hline FCO 14.03 & AGTOT & 250 & & -0.067 & NR & $U G L$ \\
\hline FCO 14.04 & AGTOT & 350 & & 0.202 & NR & UGL \\
\hline FCO 14-07 & AGTOT & 650 & & 0.091 & NR & UGL \\
\hline FCO 14-08 & AGTOT & 750 & & 0.086 & NR & UGL \\
\hline FCO 14-11 & AGTOT & 1050 & & 0.029 & NR & UGL \\
\hline FCO 14.12 & AGTOT & 1150 & & 0.014 & NR & UGL \\
\hline FCO 14-15 & AGTOT & 1450 & & 0.083 & NR & UGL \\
\hline FCO 14-16 & AGTOT & 1550 & & 0.037 & NR & UGL \\
\hline FCO 14-01 & ALPHAG & 50 & & 107 & 18 & PCL \\
\hline FCO 14.05 & ALPHAG & 450 & & 344 & 28.6 & $P C L$ \\
\hline FCO 14.09 & ALPHAG & 850 & & 534 & 87.4 & $P C L$ \\
\hline FCO 14-13 & ALPHAG & 1250 & & 563 & 83 & $\mathrm{PCL}$ \\
\hline FCO 14-17 & ALPHAG & 1650 & & 339 & 67.9 & $\mathrm{PCL}$ \\
\hline FCO 14-03 & ASTOT & 250 & & -0.574 & NR & UGL \\
\hline FCO 14.04 & ASTOT & 350 & & -3.78 & NR & UGL \\
\hline FCO 14.07 & ASTOT & 650 & & -3.19 & NR & UGL \\
\hline FCO 14-08 & ASTOT & 750 & & -2.66 & NR & $\mathrm{UGL}$ \\
\hline FCO $14-11$ & ASTOT & 1050 & & -2.24 & NA & UGL \\
\hline FCO 14.12 & ASTOT & 1150 & & -2.19 & NR & UGL \\
\hline FCO 14.15 & ASTOT & 1450 & & -1.63 & NA & UGL \\
\hline FCO 14-16 & ASTOT & 1550 & & -1.58 & NA & UGL \\
\hline FCO 14-03 & BATOT & 250 & & 0.914 & NA & UGL \\
\hline FCO 14.04 & BATOT & 350 & & 0.843 & NR & UGL \\
\hline FCO 14-07 & BATOT & 650 & & 0.54 & NA & UGL \\
\hline FCO 14.08 & BATOT & 750 & & 0.513 & NA & UGL \\
\hline FCO 14-11 & BATOT & 1050 & & 0.407 & NA & UGL \\
\hline FCO 14-12 & BATOT & 1150 & & 0.405 & NR & UGL \\
\hline FCO 14-15 & BATOT & 1450 & & 0.618 & NR & UGL \\
\hline FCO 14.16 & BATOT & 1550 & & 0.543 & NA & UGL \\
\hline FCO 14-01 & BETAG & 50 & & 87.2 & 12.4 & PCL \\
\hline FCO $14-05$ & BETAG & 450 & & 233 & 13.1 & $P C L$ \\
\hline FCO 14-09 & BETAG & 850 & & 374 & 65.5 & PCL \\
\hline FCO 14-13 & BETAG & 1250 & & 338 & 61 & $\mathrm{PCL}$ \\
\hline FCO 14-17 & BETAG & 1650 & & 224 & 55.9 & PCL \\
\hline
\end{tabular}

Notes: $\mathrm{J}=\mathrm{LT}$ reporting limit

NR $=$ Not Reported

$U=L T$ detection limit

$\mathrm{C}=$ lab control sample not met

$R=I C P$ interference check not met $V=l a b$ blank contaminated

$E=$ value between sample specific $E Q L$ and detection limit

Accuracy Reported at $2 \delta$

Page A9 of A39

WSRC-TR-99-00020, Rev. 0 


\begin{tabular}{|c|c|c|c|c|c|c|}
\hline \multicolumn{7}{|c|}{ F-Area WTU Clearwell } \\
\hline \multicolumn{7}{|c|}{ AG50Wx8 Resir Cont } \\
\hline SRS Sample ID & Analyte & Avg Bedvol & Anal Qual & Anal Result & Accuracy & Result Units \\
\hline FCO 14-03 & CDTOT & 250 & & 0.084 & NR & UGL \\
\hline FCO 14-04 & CDTOT & 350 & & 0.114 & NR & UGL \\
\hline FCO 14-07 & CDTOT & 650 & & 0.067 & NR & UGL \\
\hline FCO 14-08 & CDTOT & 750 & & 0.074 & NR & UGL \\
\hline FCO 14-11 & CDTOT & 1050 & & 0.066 & NR & UGL \\
\hline FCO 14-12 & CDTOT & 1150 & & 0.112 & NR & UGL \\
\hline FCO 14-15 & CDTOT & 1450 & & 0.074 & NR & UGL \\
\hline FCO 14-16 & CDTOT & 1550 & & 0.096 & NA & UGL \\
\hline FCO 14-03 & CRTOT & 250 & & 0.451 & NR & UGL \\
\hline FCO 14-04 & CRTOT & 350 & & 0.69 & NR & UGL \\
\hline FCO 14-07 & CRTOT & 650 & & 0.62 & NR & $\mathrm{UGL}$ \\
\hline FCO 14-08 & CRTOT & 750 & & 0.672 & NR & UGL \\
\hline FCO 14-11 & CRTOT & 1050 & & 0.592 & NR & UGL \\
\hline FCO 14-12 & CRTOT & 1150 & & 0.571 & NR & UGL \\
\hline FCO 14-15 & CRTOT & 1450 & & 0.649 & NR & UGL \\
\hline FCO 14-16 & CRTOT & 1550 & & 0.623 & NR & UGL \\
\hline FCO 14-03 & CS137 & 250 & & 15 & 6.29 & $\mathrm{PCL}$ \\
\hline FCO 14-04 & CS137 & 350 & & 19.4 & 5.86 & $\mathrm{PCL}$ \\
\hline FCO 14-07 & CS137 & 650 & & 13.6 & 6.09 & $\overline{\mathrm{PCL}}$ \\
\hline FCO 14-08 & CS137 & 750 & & 18.9 & 6.47 & $\mathrm{PCL}$ \\
\hline FCO 14-11 & CS137 & 1050 & & 18.3 & 6.77 & $\mathrm{PCL}$ \\
\hline FCO 14-12 & CS137 & 1150 & & 14 & 4.65 & $\mathrm{PCL}$ \\
\hline FCO 14-15 & CS137 & 1450 & & 16.2 & 5.57 & $\mathrm{PCL}$ \\
\hline FCO 14-16 & CS137 & 1550 & & 16.4 & 4.43 & $\mathrm{PCL}$ \\
\hline FCO 14-03 & HGTOT & 250 & & -0.0637 & $\mathrm{NR}$ & UGL \\
\hline $\mathrm{FCO} 14-04$ & HGTOT & 350 & & 9.02 & NR & UGL \\
\hline FCO 14-07 & HGTOT & 650 & & 0.0656 & NR & UGL \\
\hline FCO 14-08 & HGTOT & 750 & & -0.0907 & NR & UGL \\
\hline FCO 14-11 & HGTOT & 1050 & & -0.0634 & NR & UGL \\
\hline FCO 14-12 & HGTOT & 1150 & & -0.0755 & NR & UGL \\
\hline FCO 14-15 & HGTOT & 1450 & & -0.109 & NR & UGL \\
\hline FCO 14-16 & HGTOT & 1550 & & -0.0783 & NR & UGL \\
\hline FCO 14-03 & PBTOT & 250 & & 0.127 & NR & UGL \\
\hline FCO 14-04 & PBTOT & 350 & & 0.018 & NR & UGL \\
\hline $\mathrm{FCO} 14-07$ & PBTOT & 650 & & -0.005 & NR & UGL \\
\hline FCO 14-08 & PBTOT & 750 & & -0.005 & NR & UGL \\
\hline FCO 14-11 & PBTOT & 1050 & & -0.036 & NR & UGL \\
\hline FCO 14-12 & PBTOT & 1150 & & 0.069 & NR & UGL \\
\hline FCO 14-15 & PBTOT & 1450 & & -0.006 & NR & UGL \\
\hline FCO 14-16 & PBTOT & 1550 & & 0.003 & NR & UGL \\
\hline $\mathrm{FCO} 14-03$ & SETOT & 250 & $\mathrm{~J}$ & -13.3 & NR & UGL \\
\hline FCO 14-04 & SETOT & 350 & & -2.07 & NR & UGL \\
\hline FCO 14-07 & SETOT & 650 & & -6.41 & NR & UGL \\
\hline FCO 14-08 & SETOT & 750 & & -0.04 & NR & UGL \\
\hline $\mathrm{FCO} 14-11$ & SETOT & 1050 & & -24 & NR & UGL \\
\hline FCO 14-12 & SETOT & 1150 & & -3.48 & NR & UGL \\
\hline FCO 14-15 & SETOT & 1450 & & -7.07 & NR & UGL \\
\hline $\mathrm{FCO} 14-16$ & SETOT & 1550 & & -0.91 & NR & UGL \\
\hline FCO 14-02 & SR90 & 150 & $\mathrm{U}$ & -0.725 & 3.63 & $\mathrm{PCL}$ \\
\hline FCO 14-06 & SR90 & 550 & $U$ & -0.971 & 2.56 & $\mathrm{PCL}$ \\
\hline FCO 14-10 & SR90 & 950 & $U$ & 2.37 & 3.48 & $P C L$ \\
\hline FCO 14-14 & SR90 & 1350 & & 6.77 & 3.18 & $\mathrm{PCL}$ \\
\hline
\end{tabular}

Notes: $\mathrm{J}=\mathrm{LT}$ reporting limit

$U=L T$ detection limit

NR $=$ Not Reported

$\mathrm{C}=$ lab control sample not met

$\mathrm{R}=\mathrm{ICP}$ interference check not met $\mathrm{V}=$ lab blank contaminated

$E=$ value between sample specific $E Q L$ and detection limit 


\begin{tabular}{|c|c|c|c|c|c|c|}
\hline \multicolumn{7}{|c|}{ F-Area WTU Clearwell } \\
\hline AGMP50 Resin & & & & & & \\
\hline & & & & & & \\
\hline SRS Sample ID & Analyte & Avg Bedvol & Anal Qual & Anal Result & Accuracy & Result Units \\
\hline FCO 05.03 & AGTOT & 250 & & 0.093 & NR & UGL \\
\hline FCO 05-04 & AGTOT & 350 & & 0.057 & NR & UGL \\
\hline FCO 05.07 & AGTOT & 650 & & 0.042 & NR & UGL \\
\hline FCO $05-08$ & AGTOT & 750 & & 0.031 & NR & UGL \\
\hline FCO $05-10$ & AGTOT & 950 & & 0.032 & NR & UGL \\
\hline FCO 05.11 & AGTOT & 1050 & & 0.024 & NR & UGL \\
\hline FCO $05-14$ & AGTOT & 1350 & & 0.021 & NR & UGL \\
\hline FCO 05.15 & AGTOT & 1450 & & 0.065 & NR & UGL \\
\hline FCO 05-01 & ALPHAG & 50 & & 313 & 92.2 & PCL \\
\hline FCO 05.06 & ALPHAG & 550 & & 480 & 115 & PCL \\
\hline FCO 05.12 & ALPHAG & 1150 & & 439 & 114 & PCL \\
\hline FCO 05.16 & ALPHAG & 1550 & & 463 & 110 & PCL \\
\hline FCO $05-18$ & ALPHAG & 1750 & & 550 & 125 & PCL \\
\hline FCO 05.03 & ASTOT & 250 & & -1.52 & NR & UGL \\
\hline FCO 05.04 & ASTOT & 350 & & -1.93 & NR & UGL \\
\hline FCO $05-07$ & ASTOT & 650 & & -2.49 & NR & UGL \\
\hline FCO $05-08$ & ASTOT & 750 & & -2.73 & NR & UGL \\
\hline FCO $05-10$ & ASTOT & 950 & & -2.3 & NR & $U G L$ \\
\hline FCO 05-11 & ASTOT & 1050 & & -2.75 & NR & UGL \\
\hline FCO 05-14 & ASTOT & 1350 & & -2.41 & NR & UGL \\
\hline FCO 05-15 & ASTOT & 1450 & & -2.5 & NR & UGL \\
\hline FCO $05-03$ & BATOT & 250 & & 2.02 & NR & $\mathrm{UGL}$ \\
\hline FCO $05-04$ & BATOT & 350 & & 1.87 & NR & UGL \\
\hline FCO 05-07 & BATOT & 650 & & 0.717 & NR & UGL \\
\hline FCO 05.08 & BATOT & 750 & & 1.8 & NR & UGL \\
\hline FCO 05.10 & BATOT & 950 & & 0.86 & NR & TUGL \\
\hline FCO 05-11 & BATOT & 1050 & & 0.821 & NA & UGL \\
\hline FCO $05-14$ & BATOT & 1350 & & 0.905 & NR & UGL \\
\hline FCO 05.15 & BATOT & 1450 & & 0.585 & NR & $\mathrm{UGL}$ \\
\hline FCO $05-01$ & BETAG & 50 & & 422 & 96.1 & PCL \\
\hline FCO 05.06 & BETAG & 550 & & 268 & 83.4 & $P C L$ \\
\hline FCO 05-12 & BETAG & 1150 & & 368 & 90 & PCL \\
\hline FCO $05-16$ & BETAG & 1550 & & 236 & 78.7 & PCL \\
\hline FCO 05.18 & BETAG & 1750 & & 337 & 88 & PCL \\
\hline
\end{tabular}

Notes: $J=L T$ reporting limit

NR $=$ Not Reported

$\mathrm{U}=\mathrm{LT}$ detection limit $\quad \mathrm{C}=$ lab control sample not met

$R=I C P$ interference check not met $V=$ lab blank contaminated

$E=$ value between sample specific $E Q L$ and detection limit

Accuracy Reported at $2 \delta$

Page A11 of A39

WSRC-TR-99-00020, Rev. 0 


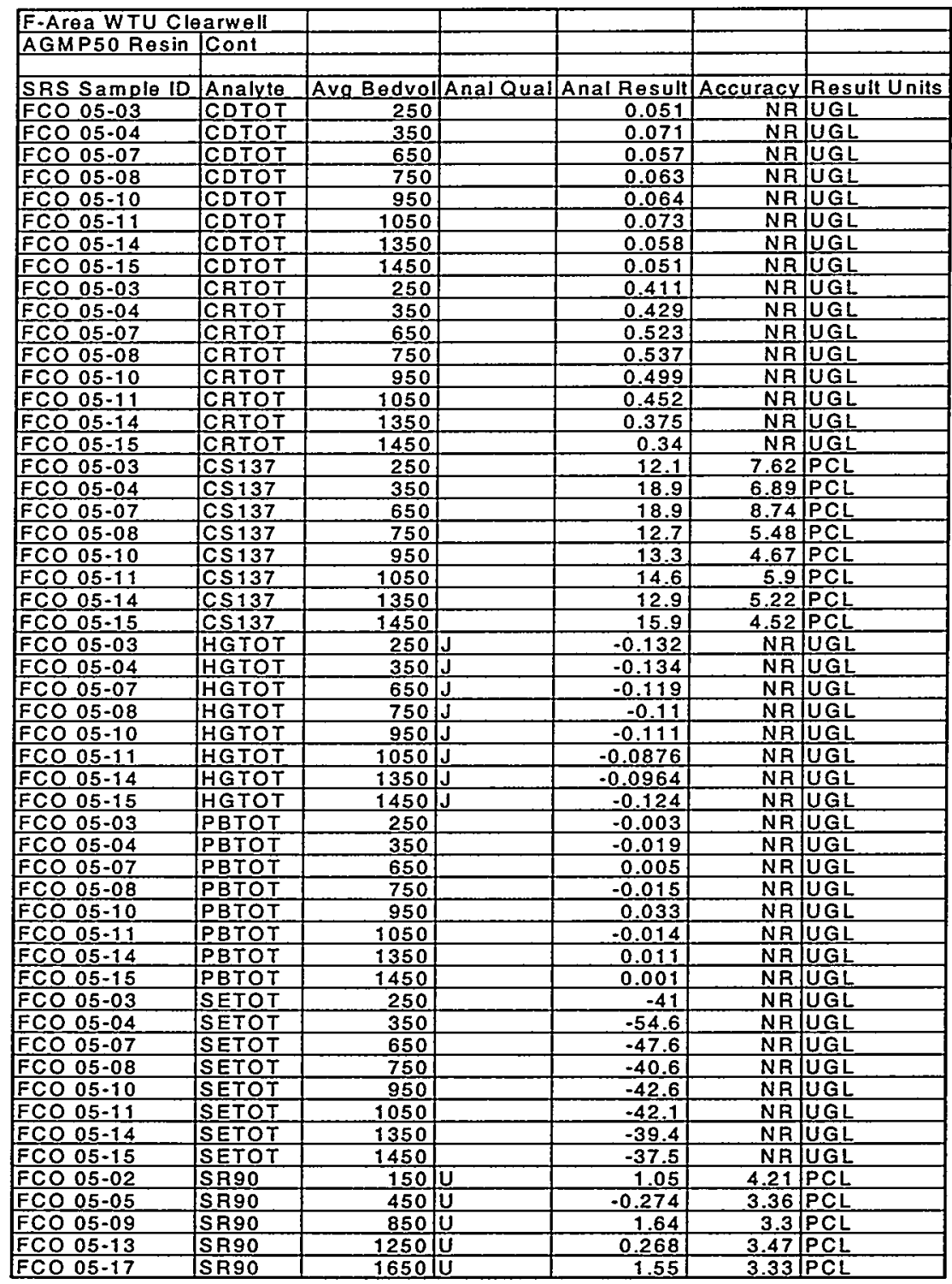

Notes: $\mathrm{J}=\mathrm{LT}$ reporting limit

$U=L T$ detection limit

$\mathrm{R}=\mathrm{ICP}$ interference $\mathrm{ch}$

$E=$ value between sample specific $E Q L$ and detection limit

Accuracy Reported at $2 \delta$
Page $A 12$ of $A 39$
NR $=$ Not Reported

$\mathrm{C}=$ lab control sample not met
WSRC-TR-99-00020, Rev. 0 


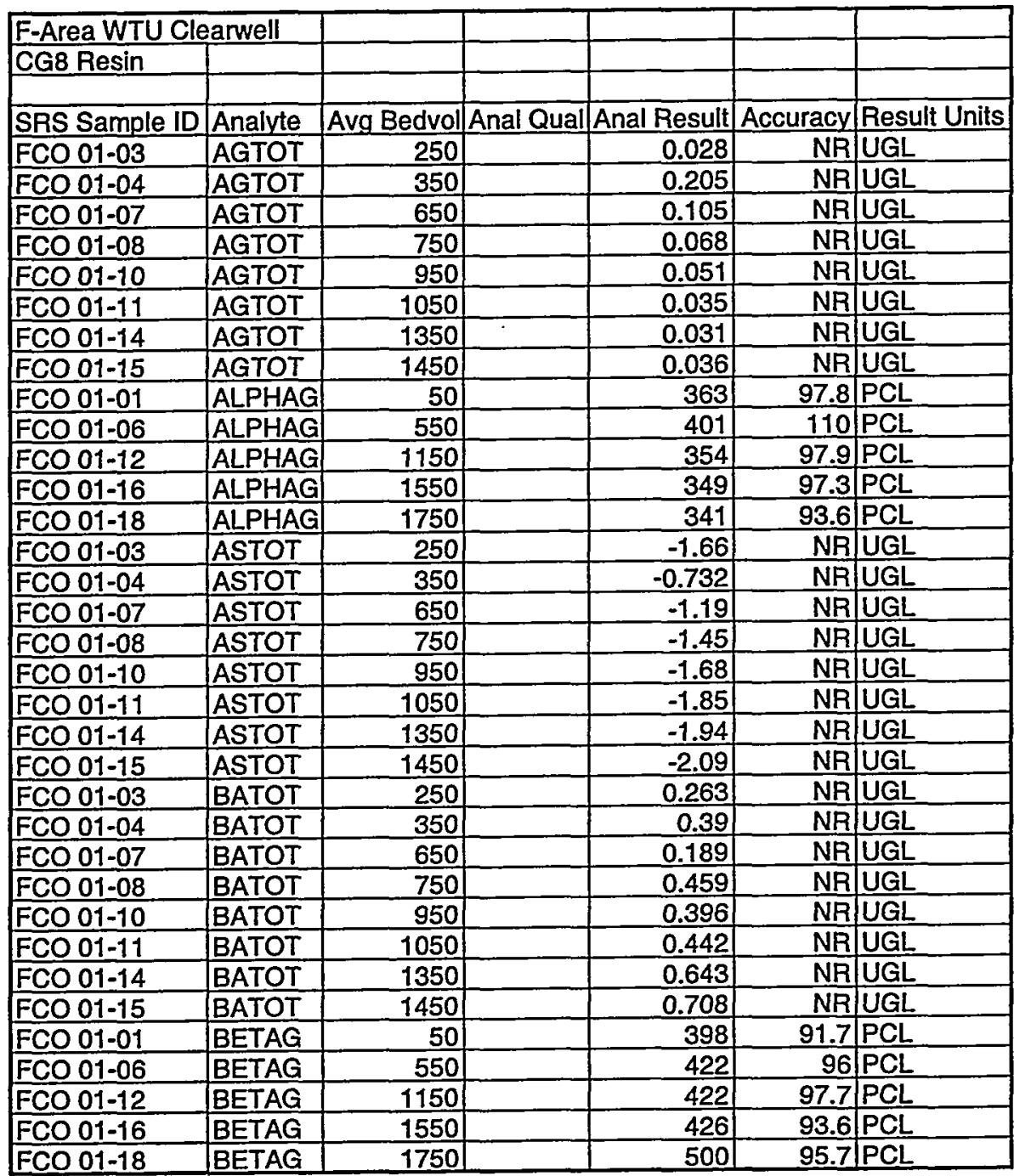

Notes: $J=L T$ reporting limit

$\mathrm{U}=\mathrm{LT}$ detection limit

$R=I C P$ interference check not met $V=$ lab blank contaminated

$E=$ value between sample specific $E Q L$ and detection limit

Accuracy Reported at $2 \delta$
NR $=$ Not Reported

$\mathrm{C}=$ lab control sample not met

Page $A 13$ of $A 39$
WSRC-TR-99-00020, Rev. 0 


\begin{tabular}{|c|c|c|c|c|c|c|}
\hline \multicolumn{7}{|c|}{ F-Area WTU Clearwell } \\
\hline CG8 Resin & Cont & & & & & \\
\hline SRS Sample ID & Analyte & Avg Bedvol & Anal Qual & Anal Result & Accuracy & Result Units \\
\hline FCO $01-03$ & CDTOT & 250 & & 0.116 & NR & UGL \\
\hline FCO $01-04$ & CDTOT & 350 & & 0.076 & NR & UGL \\
\hline FCO $01-07$ & CDTOT & 650 & & 0.048 & NR & UGL \\
\hline FCO $01-08$ & CDTOT & 750 & & 0.032 & NR & UGL \\
\hline FCO 01-10 & CDTOT & 950 & & 0.053 & NR & $U G L$ \\
\hline FCO 01-11 & CDTOT & 1050 & & 0.06 & NR & UGL \\
\hline FCO 01-14 & CDTOT & 1350 & & 0.053 & NR & UGL \\
\hline FCO 01-15 & CDTOT & 1450 & & 0.056 & NR & UGL \\
\hline $\mathrm{FCO} 01-03$ & CRTOT & 250 & & 0.777 & NR & UGL \\
\hline FCO 01-04 & CRTOT & 350 & & 0.28 & NR & UGL \\
\hline FCO 01-07 & CRTOT & 650 & & 0.369 & NR & UGL \\
\hline FCO 01-08 & CATOT & 750 & & 0.438 & NR & UGL \\
\hline FCO 01-10 & CRTOT & 950 & & 0.467 & NR & UGL \\
\hline FCO 01-11 & CRTOT & 1050 & & 0.475 & NR & UGL \\
\hline FCO 01-14 & CRTOT & 1350 & & 0.391 & NR & UGL \\
\hline FCO $01-15$ & CRTOT & 1450 & & 0.302 & NR & $\overline{U G L}$ \\
\hline FCO $01-03$ & CS137 & 250 & & 20.7 & 5.86 & $\mathrm{PCL}$ \\
\hline FCO 01-04 & CS137 & 350 & & 17.3 & 6.46 & $\mathrm{PCL}$ \\
\hline FCO 01-07 & CS137 & 650 & & 17.3 & 6.3 & $\mathrm{PCL}$ \\
\hline FCO 01-08 & CS137 & 750 & & 15.9 & 4.81 & $\mathrm{PCL}$ \\
\hline FCO 01-10 & CS137 & 950 & & 16.9 & 4.47 & $\mathrm{PCL}$ \\
\hline FCO 01-11 & CS137 & 1050 & & 15.4 & 5.86 & $\overline{P C L}$ \\
\hline FCO 01-14 & CS137 & 1350 & & 20 & 5.94 & $\mathrm{PCL}$ \\
\hline FCO $01-15$ & CS137 & 1450 & & 14.3 & 5.37 & $\mathrm{PCL}$ \\
\hline FCO $01-03$ & HGTOT & 250 & & -0.0997 & NR & UGL \\
\hline FCO $01-04$ & HGTOT & 350 & $\mathrm{~J}$ & -0.149 & NR & UGL \\
\hline FCO 01.07 & HGTOT & 650 & $\mathrm{~J}$ & -0.13 & NR & UGL \\
\hline FCO 01-08 & HGTOT & 750 & $\mathrm{~J}$ & -0.128 & NR & UGL \\
\hline FCO $01-10$ & HGTOT & 950 & $\mathrm{~J}$ & -0.138 & NR & UGL \\
\hline FCO 01-11 & HGTOT & 1050 & $\mathrm{~J}$ & -0.124 & NR & UGL \\
\hline FCO 01-14 & HGTOT & 1350 & $J$ & -0.137 & NR & UGL \\
\hline FCO 01-15 & HGTOT & 1450 & $\mathrm{~J}$ & -0.137 & NR & UGL \\
\hline FCO 01-03 & PBTOT & 250 & & 0.033 & NR & UGL \\
\hline FCO 01-04 & PBTOT & 350 & & -0.018 & NR & UGL \\
\hline FCO 01-07 & PBTOT & 650 & & -0.034 & NR & UGL \\
\hline FCO 01-08 & PBTOT & 750 & & -0.044 & NR & UGL \\
\hline FCO 01-10 & PBTOT & 950 & & 0.001 & NR & UGL \\
\hline FCO 01-11 & PBTOT & 1050 & & 0.02 & NR & UGL \\
\hline FCO $01-14$ & PBTOT & 1350 & & -0.006 & NR & UGL \\
\hline FCO 01-15 & PBTOT & 1450 & & -0.003 & NR & UGL \\
\hline FCO $01-03$ & SETOT & 250 & & -129 & NR & UGL \\
\hline FCO 01-04 & SETOT & 350 & & -79.5 & NR & UGL \\
\hline FCO $01-07$ & SETOT & 650 & & -59.9 & NR & UGL \\
\hline FCO 01-08 & SETOT & 750 & & -59.9 & NR & UGL \\
\hline FCO 01-10 & SETOT & 950 & & -60.1 & NR & UGL \\
\hline FCO 01-11 & SETOT & 1050 & & -52.9 & NR & UGL \\
\hline FCO 01-14 & SETOT & 1350 & & -61.2 & NR & UGL \\
\hline FCO 01-15 & SETOT & 1450 & & -59.6 & NR & UGL \\
\hline FCO $01-02$ & SR90 & 150 & $\underline{\mathrm{U}}$ & -1.58 & 2.49 & $\mathrm{PCL}$ \\
\hline FCO 01-05 & SR90 & 450 & $\mathrm{U}$ & 0.0703 & 2.99 & $P C L$ \\
\hline FCO 01-09 & SR90 & 850 & $\mathrm{U}$ & 1.81 & 2.11 & $\mathrm{PCL}$ \\
\hline FCO $01-13$ & SR90 & 1250 & & 22.4 & 3.48 & $\overline{P C L}$ \\
\hline FCO $01-17$ & SR90 & 1650 & & 108 & 21.7 & $\mathrm{PCL}$ \\
\hline
\end{tabular}

Notes: $J=L T$ reporting limit

NR $=$ Not Reported

$U=L T$ detection limit

$\mathrm{C}=$ lab control sample not met

$\mathrm{R}=\mathrm{ICP}$ interference check not met $\mathrm{V}=$ lab blank contaminated

$E=$ value between sample specific $E Q L$ and detection limit

Accuracy Reported at $2 \delta$ 


\begin{tabular}{|c|c|c|c|c|c|c|}
\hline \multicolumn{7}{|c|}{ F-Area WTU Clearwell } \\
\hline \multicolumn{7}{|c|}{ Chelex 20 Resin } \\
\hline & & & & & & \\
\hline SRS Sample ID & Analyte & Avg Bedvol & Anal Qual & Anal Result & Accuracy & Result Units \\
\hline FCO $04-03$ & AGTOT & 250 & & -0.024 & NR & UGL \\
\hline FCO 04-04 & AGTOT & 350 & & -0.052 & NR & UGL \\
\hline FCO 04.07 & AGTOT & 650 & & -0.056 & NR & UGL \\
\hline FCO 04.08 & AGTOT & 750 & & -0.066 & NR & UGL \\
\hline FCO 04-11 & AGTOT & 1050 & & -0.003 & NR & UGL \\
\hline FCO 04-12 & AGTOT & 1150 & & -0.039 & NR & UGL \\
\hline FCO 04-15 & AGTOT & 1450 & & -0.059 & NR & UGL \\
\hline FCO $04-16$ & AGTOT & 1550 & & -0.042 & NR & UGL \\
\hline FCO 04-01 & ALPHAG & 50 & $\mathbf{U}$ & 9.16 & 8.35 & $\mathrm{PCL}$ \\
\hline FCO 04-05 & ALPHAG & 450 & $\mathrm{U}$ & 27.4 & 19.3 & $\mathrm{PCL}$ \\
\hline FCO 04-09 & ALPHAG & 850 & $\mathrm{U}$ & 8.12 & 9.37 & $\mathrm{PCL}$ \\
\hline $\mathrm{FCO} \mathrm{04-13}$ & ALPHAG & 1250 & $\underline{U}$ & 3.58 & 8.63 & $\mathrm{PCL}$ \\
\hline $\mathrm{FCO} \mathrm{04-17}$ & ALPHAG & 1650 & $\bar{U}$ & 5.07 & 9.17 & $\mathrm{PCL}$ \\
\hline FCO 04-03 & ASTOT & 250 & & 0.014 & NR & UGL \\
\hline FCO 04-04 & ASTOT & 350 & & 0.014 & NR & UGL \\
\hline FCO 04-07 & ASTOT & 650 & & -0.009 & NR & UGL \\
\hline FCO 04.08 & ASTOT & 750 & & 0.14 & NR & UGL \\
\hline FCO 04-11 & ASTOT & 1050 & & -0.376 & NR & UGL \\
\hline $\mathrm{FCO} \mathrm{04-12}$ & ASTOT & 1150 & & -0.222 & NR & UGL \\
\hline FCO 04-15 & ASTOT & 1450 & & -0.027 & NR & UGL \\
\hline FCO 04-16 & ASTOT & 1550 & & -0.37 & NR & UGL \\
\hline FCO 04.03 & BATOT & 250 & & 3.66 & NR & UGL \\
\hline FCO 04-04 & BATOT & 350 & & 4.19 & NR & UGL \\
\hline FCO 04-07 & BATOT & 650 & & 43.4 & NR & UGL \\
\hline FCO 04.08 & BATOT & 750 & & 51.6 & NR & UGL \\
\hline FCO 04-11 & BATOT & 1050 & & 71.5 & NR & UGL \\
\hline FCO 04-12 & BATOT & 1150 & & 72.5 & NR & UGL \\
\hline FCO $04-15$ & BATOT & 1450 & & 76.8 & NR & UGL \\
\hline FCO 04-16 & BATOT & 1550 & & 94.4 & $\mathrm{NR}$ & $U G L$ \\
\hline FCO 04-01 & BETAG & 50 & & 84.5 & 10.5 & $\mathrm{PCL}$ \\
\hline FCO 04-05 & BETAG & 450 & & 224 & 30 & $\mathrm{PCL}$ \\
\hline FCO 04-09 & BETAG & 850 & & 535 & 19.8 & $\mathrm{PCL}$ \\
\hline FCO $04-13$ & BETAG & 1250 & & 548 & 20.5 & PCL \\
\hline FCO 04-17 & BETAG & 1650 & & 572 & 20.9 & $\mathrm{PCL}$ \\
\hline
\end{tabular}

Notes: $J=L T$ reporting limit

$\mathrm{U}=\mathrm{LT}$ detection limit $\mathrm{R}=\mathrm{ICP}$ interference check not met $\mathrm{V}=$ lab blank contaminated $\mathrm{E}=$ value between sample specific $E Q L$ and detection limit Accuracy Reported at $2 \delta$
Page A15 of A39 


\begin{tabular}{|c|c|c|c|c|c|c|}
\hline \\
\hline \multicolumn{7}{|c|}{ Chelex 20 Resin Cont } \\
\hline & & & & & & \\
\hline SRS Sample ID & Analyte & Avg Bedvol & Anal Qual & Anal Result & Accuracy & Result Units \\
\hline FCO $04-03$ & CDTOT & 250 & & 0.078 & NR & UGL \\
\hline FCO 04-04 & CDTOT & 350 & & 0.091 & NR & UGL \\
\hline FCO 04-07 & CDTOT & 650 & & 0.07 & NR & UGL \\
\hline FCO 04-08 & CDTOT & 750 & & 0.084 & NR & UGL \\
\hline FCO 04-11 & CDTOT & 1050 & & 0.073 & NR & UGL \\
\hline FCO 04-12 & CDTOT & 1150 & & 0.081 & NR & UGL \\
\hline FCO 04-15 & CDTOT & 1450 & & 0.074 & NR & UGL \\
\hline FCO 04-16 & CDTOT & 1550 & & 0.073 & NR & UGL \\
\hline FCO 04-03 & CRTOT & 250 & & 0.433 & NR & UGL \\
\hline FCO 04-04 & CRTOT & 350 & & 0.441 & NR & UGL \\
\hline FCO 04-07 & CRTOT & 650 & & 0.521 & NA & UGL \\
\hline FCO 04-08 & CRTOT & 750 & & 0.559 & NR & UGL \\
\hline FCO 04-11 & CRTOT & 1050 & & 0.446 & NR & UGL \\
\hline FCO 04-12 & CRTOT & 1150 & & 0.449 & NR & UGL \\
\hline FCO 04-15 & CRTOT & 1450 & & 0.389 & NR & UGL \\
\hline FCO 04-16 & CRTOT & 1550 & & 0.475 & NR & UGL \\
\hline FCO 04-03 & CS137 & 250 & & 11.3 & 5.12 & $\mathrm{PCL}$ \\
\hline FCO 04-04 & CS137 & 350 & & 21 & 5.6 & PCL \\
\hline FCO 04-07 & CS137 & 650 & & 18.3 & 7.61 & PCL \\
\hline FCO 04-08 & CS137 & 750 & & 18.2 & 5.75 & PCL \\
\hline FCO 04-11 & CS137 & 1050 & & 12.3 & 7.1 & $\overline{P C L}$ \\
\hline FCO 04-12 & CS137 & 1150 & & 14.8 & 6.52 & PCL \\
\hline FCO 04-15 & CS137 & 1450 & & 17.6 & 6.17 & PCL \\
\hline FCO 04-16 & CS137 & 1550 & & 17.4 & 5.83 & $\mathrm{PCL}$ \\
\hline FCO 04-03 & HGTOT & 250 & & -0.0241 & NR & UGL \\
\hline FCO 04-04 & HGTOT & 350 & & -0.0319 & NR & UGL \\
\hline FCO $04-07$ & HGTOT & 650 & & -0.0335 & NR & UGL \\
\hline FCO 04-08 & HGTOT & 750 & & -0.0255 & NR & UGL \\
\hline FCO 04-11 & HGTOT & 1050 & & -0.0125 & NR & UGL \\
\hline FCO 04-12 & HGTOT & 1150 & & 0.00441 & NR & UGL \\
\hline FCO 04-15 & HGTOT & 1450 & & -0.0536 & NR & UGL \\
\hline FCO 04-16 & HGTOT & 1550 & & -0.0646 & NR & UGL \\
\hline FCO 04-03 & PBTOT & 250 & & 0.104 & NR & UGL \\
\hline FCO 04-04 & PBTOT & 350 & & 0.169 & NR & UGL \\
\hline FCO 04-07 & PBTOT & 650 & & 0.072 & NR & UGL \\
\hline FCO 04-08 & PBTOT & 750 & & 0.147 & NR & IUGL \\
\hline FCO 04-11 & PBTOT & 1050 & & 0.079 & NR & UGL \\
\hline FCO 04-12 & PBTOT & 1150 & & 0.109 & $\mathrm{NR}$ & UGL \\
\hline FCO 04-15 & PBTOT & 1450 & & 0.062 & NR & UGL \\
\hline FCO 04-16 & PBTOT & 1550 & & 0.167 & NR & UGL \\
\hline FCO 04-03 & SETOT & 250 & & -16.7 & NR & UGL \\
\hline FCO 04-04 & SETOT & 350 & & -5.88 & NR & UGL \\
\hline FCO 04-07 & SETOT & 650 & & -5 & NR & UGL \\
\hline FCO 04-08 & SETOT & 750 & & -3.42 & NR & UGL \\
\hline FCO 04-11 & SETOT & 1050 & & -18.1 & NR & UGL \\
\hline FCO 04-12 & SETOT & 1150 & & -16.3 & NR & UGL \\
\hline FCO 04-15 & SETOT & 1450 & & -4.34 & NR & UGL \\
\hline FCO 04-16 & SETOT & 1550 & & -3.75 & NR & UGL \\
\hline FCO $04-02$ & SR90 & 150 & & 235 & 25.2 & $\mathrm{PCL}$ \\
\hline FCO $04-06$ & SR90 & 550 & & 183 & 9.95 & $\mathrm{PCL}$ \\
\hline FCO 04-10 & SR90 & 950 & & 283 & 13 & $\mathrm{PCL}$ \\
\hline
\end{tabular}

Notes: $\mathrm{J}=\mathrm{LT}$ reporting limit

$\mathrm{NR}=$ Not Reported

$U=L T$ detection limit $\quad \mathrm{C}=$ lab control sample not met

$R=I C P$ interference check not met $V=$ lab blank contaminated

$\mathrm{E}=$ value between sample specific $E Q L$ and detection limit

Accuracy Reported at $2 \delta$

Page $A 16$ of $A 39$

WSRC-TR-99-00020, Rev. 0 


\begin{tabular}{|c|c|c|c|c|c|c|}
\hline \multicolumn{7}{|c|}{ Resin F-Area WTU Clearwell } \\
\hline Dowex 21K & & & & & & \\
\hline & & & & & & \\
\hline SRS Sample ID & Analyte & Avg Bedvol & Anal Qual & Anal Result & Accuracy & Result Units \\
\hline FCO 03-05 & AGTOT & 450 & & 0.012 & NR & $\mathrm{UGL}$ \\
\hline $\mathrm{FCO} \quad 03-12$ & AGTOT & 1150 & & 0.013 & NR & UGL \\
\hline FCO 03-01 & ALPHAG & 50 & $\mathbf{U}$ & 6.43 & 7.47 & PCL \\
\hline FCO $03-08$ & ALPHAG & 750 & $\mathrm{U}$ & 11.8 & 9.79 & $\overline{P C L}$ \\
\hline FCO $03-15$ & ALPHAG & 1450 & U & 21.5 & 19.7 & PCL \\
\hline FCO 03.05 & ASTOT & 450 & & -1.2 & NR & UGL \\
\hline $\mathrm{FCO} \quad 03-12$ & ASTOT & 1150 & & -1.53 & NR & $\mathrm{UGL}$ \\
\hline FCO 03.05 & BATOT & 450 & & 72.8 & NR & UGL \\
\hline FCO $03-12$ & BATOT & 1150 & & 72.7 & NR & UGL \\
\hline FCO 03-01 & BETAG & 50 & & 390 & 17.3 & $\mathrm{PCL}$ \\
\hline FCO 03.08 & BETAG & 750 & & 544 & 19.6 & $\mathrm{PCL}$ \\
\hline FCO $03-15$ & BETAG & 1450 & & 520 & 43.2 & $P C L$ \\
\hline $\mathrm{FCO} 03-02$ & C14 & 150 & & 26.7 & 15.7 & $P C L$ \\
\hline FCO 03.03 & C14 & 250 & & 17.1 & 8.33 & PCL \\
\hline FCO 03-09 & C14 & 850 & & 16.8 & 8.93 & PCL \\
\hline FCO 03-10 & C14 & 950 & & 31.3 & 10.9 & $\mathrm{PCL}$ \\
\hline FCO $03-16$ & C14 & 1550 & & 14.7 & 7.6 & PCL \\
\hline FCO 03-17 & C14 & 1650 & $\mathrm{U}$ & 11.5 & 10.2 & $\mathrm{PCL}$ \\
\hline FCO 03.05 & CDTOT & 450 & & 0.122 & NR & UGL \\
\hline $\mathrm{FCO} 03-12$ & CDTOT & 1150 & & 0.098 & NR & UGL \\
\hline FCO 03.05 & CRTOT & 450 & & 0.674 & NR & UGL \\
\hline FCO 03-12 & CRTOT & 1150 & & 0.68 & NR & UGL \\
\hline FCO 03-06 & CS137 & 550 & & 14.7 & 6.61 & $\mathrm{PCL}$ \\
\hline FCO $03-07$ & CS137 & 650 & & 19 & 6.87 & $P C L$ \\
\hline FCO 03-13 & CS137 & 1250 & & 17.7 & 7.32 & $P C L$ \\
\hline FCO 03-14 & CS137 & 1350 & & 14.4 & 4.63 & $P C L$ \\
\hline FCO 03-05 & HGTOT & 450 & & -0.0201 & NR & UGL \\
\hline FCO $03-12$ & HGTOT & 1150 & & -0.0661 & NR & UGL \\
\hline FCO $03-02$ & 1129 & 150 & $\mathrm{~J}$ & 87.6 & 11.4 & PCL \\
\hline FCO $03-03$ & 1129 & 250 & $\mathrm{~J}$ & 166 & 20 & PCL \\
\hline FCO 03-09 & 1129 & 850 & J & 368 & 44 & PCL \\
\hline FCO $03-10$ & 1129 & 950 & $\mathrm{~J}$ & 371 & 43.5 & $\mathrm{PCL}$ \\
\hline FCO $03-16$ & 1129 & 1550 & $J$ & 369 & 44.2 & $P C L$ \\
\hline $\mathrm{FCO} 03-17$ & 1129 & 1650 & J & 350 & 41.2 & $\mathrm{PCL}$ \\
\hline FCO 03-05 & PBTOT & 450 & & 0.047 & NA & UGL \\
\hline FCO $03-12$ & PBTOT & 1150 & & 0.055 & NA & UGL \\
\hline FCO 03.05 & SETOT & 450 & & -136 & NR & UGL \\
\hline FCO 03.12 & SETOT & 1150 & & -142 & NR & UGL \\
\hline $\mathrm{FCO} \mathrm{03-04}$ & SR90 & 350 & & 211 & 27.9 & $P C L$ \\
\hline FCO 03-11 & SA90 & 1050 & & 246 & 11 & $\mathrm{PCL}$ \\
\hline FCO 03-05 & TC99 & 450 & $\bar{R}$ & 30.3 & 5.68 & PCL \\
\hline FCO 03-12 & TC99 & 1150 & & 111 & 8.67 & PCL \\
\hline
\end{tabular}

Notes: $J=L T$ reporting limit

NR $=$ Not Reported

$\mathrm{U}=\mathrm{LT}$ detection limit

$\mathrm{C}=$ lab control sample not met

$R=I C P$ interference check not met $V=$ lab blank contaminated

$E=$ value between sample specific EQL and detection limit

Accuracy Reported at $2 \delta$

Page A17 of A39

WSRC-TR-99-00020, Rev. 0 


\begin{tabular}{|c|c|c|c|c|c|c|}
\hline \multicolumn{7}{|c|}{ F-Area WTU Clearwell } \\
\hline \multicolumn{7}{|c|}{ Monosodium Titanate } \\
\hline SRS Sample ID & Analyte & Avg Bedvol & Anal Qual & Anal Result & Accuracy & Result Units \\
\hline FCO 13-03 & AGTOT & 250 & & -0.054 & $\begin{array}{l}\mathrm{NR} \\
\end{array}$ & UGL \\
\hline FCO 13-04 & AGTOT & 350 & & -0.058 & NR & UGL \\
\hline FCO 13-07 & AGTOT & 650 & & -0.075 & $\mathrm{NR}$ & UGL \\
\hline FCO 13-08 & AGTOT & 750 & & -0.076 & $\mathrm{NR}$ & UGL \\
\hline FCO 13-11 & AGTOT & 1050 & & -0.075 & NR & UGL \\
\hline FCO 13-12 & AGTOT & 1150 & & -0.003 & NR & UGL \\
\hline FCO 13-15 & AGTOT & 1450 & & -0.047 & NR & UGL \\
\hline FCO 13-16 & AGTOT & 1550 & & -0.051 & $\mathrm{NR}$ & $\overline{U G L}$ \\
\hline FCO 13-01 & ALPHAG & 50 & $\mathrm{U}$ & 6.22 & 11.4 & PCL \\
\hline FCO 13-05 & ALPHAG & 450 & & 128 & 45.8 & $\mathrm{PCL}$ \\
\hline FCO 13-09 & ALPHAG & 850 & & 291 & 65.4 & $\mathrm{PCL}$ \\
\hline FCO 13-13 & ALPHAG & 1250 & & 168 & 50.9 & $P C L$ \\
\hline FCO 13-17 & ALPHAG & 1650 & & 175 & 51.9 & $\mathrm{PCL}$ \\
\hline FCO 13-03 & ASTOT & 250 & & -0.024 & NR & UGL \\
\hline FCO 13-04 & ASTOT & 350 & & -0.577 & NR & $\underline{U G L}$ \\
\hline FCO 13-07 & ASTOT & 650 & & -0.197 & NR & UGL \\
\hline FCO 13-08 & ASTOT & 750 & & -0.332 & NR & UGL \\
\hline FCO 13-11 & ASTOT & 1050 & & -0.116 & $\mathrm{NR}$ & UGL \\
\hline FCO 13-12 & ASTOT & 1150 & & -0.619 & NR & UGL \\
\hline FCO 13-15 & ASTOT & 1450 & & -0.617 & NR & UGL \\
\hline FCO 13-16 & ASTOT & 1550 & & -0.582 & NR & UGL \\
\hline FCO 13-03 & BATOT & 250 & & 28.5 & NR & UGL \\
\hline FCO 13-04 & BATOT & 350 & & 35.7 & NR & UGL \\
\hline FCO 13-07 & BATOT & 650 & & 47.6 & NR & UGL \\
\hline FCO 13-08 & BATOT & 750 & & 49.4 & NR & UGL \\
\hline FCO 13-11 & BATOT & 1050 & & 51.4 & NA & UGL \\
\hline FCO 13-12 & BATOT & 1150 & & 49.1 & NR & UGL \\
\hline FCO 13-15 & BATOT & 1450 & & 50 & NR & UGL \\
\hline FCO 13-16 & BATOT & 1550 & & 49.1 & $\mathrm{NR}$ & $\overline{U G L}$ \\
\hline FCO 13-01 & BETAG & 50 & & 374 & 34.9 & PCL \\
\hline FCO 13-05 & BETAG & 450 & & 571 & 75.1 & $P C L$ \\
\hline FCO 13-09 & BETAG & 850 & & 683 & 81 & $\mathrm{PCL}$ \\
\hline FCO 13-13 & BETAG & 1250 & & 657 & 77.3 & PCL \\
\hline FCO 13-17 & BETAG & 1650 & & 729 & 80.6 & $\mathrm{PCL}$ \\
\hline
\end{tabular}

Notes: $\mathrm{J}=\mathrm{LT}$ reporting limit

NR $=$ Not Reported

$U=L T$ detection limit

$\mathrm{C}=$ lab control sample not met

$\mathrm{R}=\mathrm{ICP}$ interference check not met $\mathrm{V}=$ lab blank contaminated

$E=$ value between sample specific $E Q L$ and detection limit

Accuracy Reported at $2 \delta$

Page $A 18$ of $A 39$

WSRC-TR-99-00020, Rev. 0 


\begin{tabular}{|c|c|c|c|c|c|c|}
\hline \multicolumn{7}{|c|}{ F-Area WTU Clearwell } \\
\hline \multicolumn{2}{|c|}{ Monosodium Titanate } & Cont & & & & \\
\hline & & & & & & \\
\hline SRS Sample ID & Analyte & Avg Bedvol & Anal Qual & Anal Result & Accuracy & Result Units \\
\hline FCO 13-03 & CDTOT & 250 & & 0.066 & NR & UGL \\
\hline FCO 13-04 & CDTOT & 350 & & 0.102 & NR & UGL \\
\hline FCO 13-07 & CDTOT & 650 & & 0.08 & NA & UGL \\
\hline FCO 13.08 & CDTOT & 750 & & 0.071 & NA & UGL \\
\hline FCO 13-11 & CDTOT & 1050 & & 0.096 & NR & UGL \\
\hline FCO 13-12 & CDTOT & 1150 & & 0.049 & NR & UGL \\
\hline FCO 13-15 & CDTOT & 1450 & & 0.084 & NR & UGL \\
\hline FCO 13-16 & CDTOT & 1550 & & 0.06 & NA & UGL \\
\hline FCO 13-03 & CRTOT & 250 & & 0.432 & NR & UGL \\
\hline FCO 13-04 & CRTOT & 350 & & 0.456 & NR & UGL \\
\hline FCO 13-07 & CATOT & 650 & & 0.299 & NA & UGL \\
\hline FCO 13-08 & CATOT & 750 & & 0.397 & NR & UGL \\
\hline FCO 13-11 & CRTOT & 1050 & & 0.33 & NR & UGL \\
\hline FCO 13-12 & CRTOT & 1150 & & 0.373 & NR & UGL \\
\hline FCO 13-15 & CRTOT & 1450 & & 0.318 & NR & UGL \\
\hline FCO 13-16 & CRTOT & 1550 & & 0.387 & NR & UGL \\
\hline $\mathrm{FCO} \mathrm{13-03}$ & CS137 & 250 & & 15.8 & 5.1 & $\mathrm{PCL}$ \\
\hline FCO 13-04 & CS137 & 350 & & 15 & 8.07 & PCL \\
\hline FCO 13-07 & CS137 & 650 & & 13.8 & 7.71 & $\mathrm{PCL}$ \\
\hline FCO 13-08 & CS137 & 750 & & 13.9 & 6.09 & $\mathrm{PCL}$ \\
\hline FCO 13-11 & CS137 & 1050 & & 15.3 & 6.79 & $\mathrm{PCL}$ \\
\hline FCO 13-12 & CS137 & 1150 & & 15 & 6.24 & PCL \\
\hline FCO 13.15 & C\$137 & 1450 & & 16.8 & 5.33 & $P C L$ \\
\hline FCO 13-16 & CS137 & 1550 & & 21.2 & 6.17 & PCL \\
\hline FCO 13.03 & HGTOT & 250 & & -0.0423 & NR & UGL \\
\hline FCO 13-04 & HGTOT & 350 & & -0.0452 & NR & UGL \\
\hline FCO 13.07 & HGTOT & 650 & & -0.0517 & NR & UGL \\
\hline FCO 13-08 & HGTOT & 750 & & -0.056 & NR & UGL \\
\hline FCO 13-11 & HGTOT & 1050 & & -0.048 & NR & UGL \\
\hline FCO 13-12 & HGTOT & 1150 & & -0.0635 & NR & UGL \\
\hline FCO 13-15 & HGTOT & 1450 & & 0.00336 & NA & UGL \\
\hline FCO 13-16 & HGTOT & 1550 & & -0.0627 & NR & UGL \\
\hline FCO 13.03 & PBTOT & 250 & & 0.055 & NA & $U G L$ \\
\hline FCO 13-04 & PBTOT & 350 & & 0.073 & NA & UGL \\
\hline FCO 13.07 & PBTOT & 650 & & 0.063 & NR & UGL \\
\hline FCO 13-08 & PBTOT & 750 & & 0.062 & NR & UGL \\
\hline FCO 13-11 & PBTOT & 1050 & & 0.065 & NR & UGL \\
\hline FCO 13-12 & PBTOT & 1150 & & 0.093 & NR & UGL \\
\hline FCO 13-15 & PBTOT & 1450 & & 0.113 & NR & UGL \\
\hline FCO 13-16 & PBTOT & 1550 & & 0.095 & NR & UGL \\
\hline FCO 13-03 & SETOT & 250 & & -5.85 & NR & UGL \\
\hline FCO 13-04 & SETOT & 350 & & -14.6 & NR & UGL \\
\hline $\mathrm{FCO} \mathrm{13.07}$ & SETOT & 650 & & -15.2 & NA & UGL \\
\hline FCO 13-08 & SETOT & 750 & & -15.3 & NR & UGL \\
\hline FCO 13.11 & SETOT & 1050 & & -15.8 & NA & UGL \\
\hline FCO 13-12 & SETOT & 1150 & & -16.4 & NR & UGL \\
\hline FCO 13-15 & SETOT & 1450 & & -18.6 & NR & UGL \\
\hline FCO 13.16 & SETOT & 1550 & & -15.7 & NR & UGL \\
\hline FCO 13-02 & SR90 & 150 & & 292 & 31 & PCL \\
\hline FCO 13.06 & SR90 & 550 & & 233 & 27.1 & PCL \\
\hline FCO 13-10 & SR90 & 950 & & 190 & 9.63 & PCL \\
\hline FCO 13-14 & SR90 & 1350 & & 221 & 11.2 & $\mathrm{PCL}$ \\
\hline
\end{tabular}

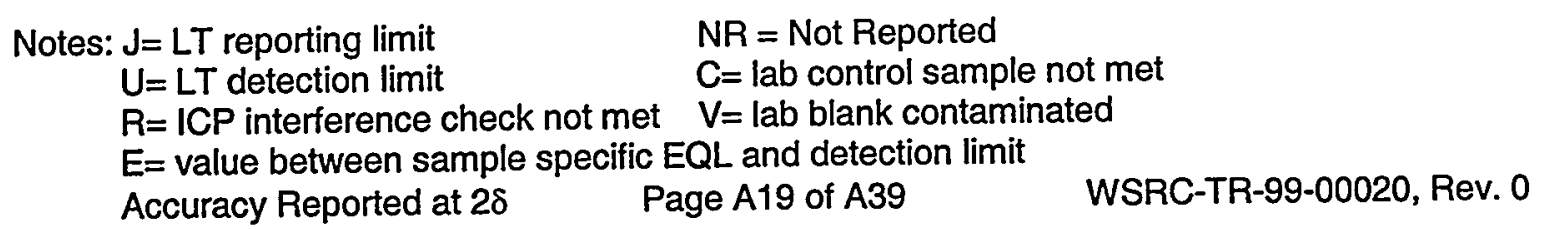


$\dot{\mathrm{B}}$

\begin{tabular}{|c|c|c|c|c|c|c|}
\hline \multirow{2}{*}{\multicolumn{7}{|c|}{$\begin{array}{l}\text { F-Area WTU Clearwell } \\
\text { Reillex HQL Resin }\end{array}$}} \\
\hline & & & & & & \\
\hline & & & & & & \\
\hline SRS sample ID & Analyte & Avg Bedvol & Anal Qual & Anal Result & Accuracy & Result Units \\
\hline FCO $10-04$ & AGTOT & 350 & & 0.024 & NR & $U G L$ \\
\hline FCO 10-09 & AGTOT & 850 & & 0.024 & NR & UGL \\
\hline FCO 10-14 & AGTOT & 1350 & & 0.045 & NR & UGL \\
\hline$F C O \quad 10-0.1$ & ALPHAG & 50 & $\mathrm{u}$ & 0.879 & 5.9 & PCL \\
\hline FCO 10-06 & ALPHAG & 550 & & 10.8 & 7.07 & $\mathrm{PCL}$ \\
\hline FCO 10-11 & ALPHAG & 1050 & & 123 & 62.7 & PCL \\
\hline FCO 10-16 & ALPHAG & 1550 & & 218 & 80.2 & $P C L$ \\
\hline FCO 10-04 & ASTOT & 350 & & .1 .76 & NR & UGL \\
\hline FCO 10-09 & ASTOT & 850 & & -1.86 & NR & UGL \\
\hline FCO $10-14$ & ASTOT & 1350 & & -1.55 & NR & UGL \\
\hline FCO 10-04 & BATOT & 350 & & 81.6 & NR & UGL \\
\hline FCO 10-09 & BATOT & 850 & & 74.9 & $\mathrm{NA}$ & UGL \\
\hline FCO 10-14 & BATOT & 1350 & & 78.9 & NR & UGL \\
\hline FCO 10-01 & BETAG & 50 & & 376 & 14 & $P C L$ \\
\hline$F C O \quad 10-06$ & BETAG & 550 & & 418 & 15 & $\mathrm{PCL}$ \\
\hline FCO 10-11 & BETAG & 1050 & & 718 & 119 & PCL \\
\hline $\mathrm{FCO} 10-16$ & BETAG & 1550 & & 698 & 113 & $\mathrm{PCL}$ \\
\hline$F C O \quad 10-02$ & C14 & 150 & & 52.6 & 6.32 & $P C L$ \\
\hline FCO 10-03 & C14 & 250 & & 43.5 & 5.95 & PCL \\
\hline FCO 10-07 & C14 & 650 & & 65.8 & 7.42 & $\overline{P C L}$ \\
\hline FCO $10-08$ & $\mathrm{C}_{14}$ & 750 & & 64 & 6.65 & PCL \\
\hline FCO 10-12 & C14 & 1150 & & 44.4 & 6.11 & $\mathrm{PCL}$ \\
\hline$F C O \quad 10-13$ & C14 & 1250 & & 45.1 & 6.22 & $\mathrm{PCL}$ \\
\hline$F \operatorname{CO} 10-17$ & $c 14$ & 1650 & & 37.8 & 5.96 & PCL \\
\hline FCO $10-18$ & $\mathrm{C}_{14}$ & 1750 & & 45.6 & 6.3 & $P C L$ \\
\hline FCO 10-04 & CDTOT & 350 & & 0.119 & NA & UGL \\
\hline FCO $10-09$ & CDTOT & 850 & & 0.12 & NR & UGL \\
\hline FCO 10-14 & CDTOT & 1350 & & 0.114 & NA & UGL \\
\hline$F C O \quad 10-04$ & CRTOT & 350 & & 0.773 & NA & UGL \\
\hline FCO $10-09$ & CRTOT & 850 & & 0.595 & NR & UGL \\
\hline FCO 10-14 & CRTOT & 1350 & & 0.605 & NR & UGL \\
\hline FCO 10-04 & HGTOT & 350 & & -0.0101 & $\mathrm{NR}$ & $U G L$ \\
\hline FCO $10-09$ & HGTOT & 850 & & -0.044 & NR & $U G L$ \\
\hline FCO 10-14 & HGTOT & 1350 & & 0.019 & NR & $U G L$ \\
\hline$F C O \quad 10-02$ & 1129 & 150 & & 27.4 & 16.3 & $P C L$ \\
\hline$F C O \quad 10.03$ & 1129 & 250 & & 116 & 22.9 & PCL \\
\hline FCO 10-07 & 1129 & 650 & & 363 & 57.9 & $\mathrm{PCL}$ \\
\hline$F C O \quad 10-08$ & 1129 & 750 & & 325 & 47 & PCL \\
\hline$F C 0 \quad 10-12$ & 1129 & 1150 & & 361 & 53.9 & $\mathrm{PCL}$ \\
\hline FCO $10-13$ & 1129 & 1250 & & 346 & 49.1 & $\mathrm{PCL}$ \\
\hline FCO 10-17 & 1129 & 1650 & & 343 & 52.9 & PCL \\
\hline$F C O \quad 10-18$ & 1129 & 1750 & & 368 & 51.6 & $\mathrm{PCL}$ \\
\hline FCO 10-04 & PBTOT & 350 & & 0.042 & NR & UGL \\
\hline FCO $10-09$ & PBTOT & 850 & & 0.051 & NR & UGL \\
\hline$F C O \quad 10.14$ & PBTOT & 1350 & & 0.038 & NR & UGL \\
\hline $\mathrm{FCO} 10-04$ & SETOT & 350 & & -146 & NR & UGL \\
\hline FCO $10-09$ & SETOT & 850 & & -147 & NR & UGL \\
\hline $\mathrm{FCO} 10-14$ & SETOT & 1350 & & -134 & NR & UGL \\
\hline FCO $10-04$ & TC99 & 350 & R & 59.3 & 6.58 & $P C L$ \\
\hline$F C O \quad 10-09$ & TC99 & 850 & $\mathbf{R}$ & 62.6 & 7.06 & $\mathrm{PCL}$ \\
\hline FCO $10-14$ & TC99 & 1350 & $\mathrm{R}$ & 76.6 & 7.68 & $P C L$ \\
\hline
\end{tabular}

Notes: $J=L T$ reporting limit

$\mathrm{NR}=$ Not Reported

$U=L T$ detection limit

$\mathrm{C}=$ lab control sample not met

$R=I C P$ interference check not met $V=$ lab blank contaminated

$E=$ value between sample specific $E Q L$ and detection limit

Accuracy Reported at $2 \delta$

Page A20 of A39

WSRC-TR-99-00020, Rev. 0 


\begin{tabular}{|c|c|c|c|c|c|c|}
\hline \multicolumn{7}{|c|}{ F-Area WTU Clearwell } \\
\hline \multicolumn{7}{|c|}{ SIR600 Zeolite } \\
\hline & & & & & & \\
\hline SRS Sample ID & Analyte & Avg Bedvol & Anal Qual & Anal Result & Accuracy & Result Units \\
\hline FCO 07-05 & AGTOT & 450 & & 0.063 & $\begin{array}{r}\text { NR } \\
\end{array}$ & UGL \\
\hline FCO $07-12$ & AGTOT & 1150 & & 0.058 & NA & UGL \\
\hline FCO 07.01 & ALPHAG & 50 & & 453 & 112 & $P C L$ \\
\hline FCO 07-08 & ALPHAG & 750 & & 322 & 94.7 & $P C L$ \\
\hline FCO 07-11 & ALPHAG & 1050 & & 388 & 99.1 & $\mathrm{PCL}$ \\
\hline FCO $07-18$ & ALPHAG & 1750 & & 462 & 112 & $\mathrm{PCL}$ \\
\hline FCO 07-0. & ASTOT & 450 & & -1.3 & NA & UGL \\
\hline $\mathrm{FCO} \mathrm{07-12}$ & ASTOT & 1150 & & -1.09 & NR & UGL \\
\hline FCO 07.05 & BATOT & 450 & & 22.4 & NR & UGL \\
\hline $\mathrm{FCO} \mathrm{07-12}$ & BATOT & 1150 & & 17.2 & NR & UGL \\
\hline FCO 07.01 & BETAG & 50 & & 351 & 90.2 & $\mathrm{PCL}$ \\
\hline $\mathrm{FCO} 07.08$ & BETAG & 750 & & 349 & 86.1 & PCL \\
\hline FCO 07-11 & BETAG & 1050 & & 516 & 96.8 & PCL \\
\hline FCO 07-18 & BETAG & 1750 & & 542 & 104 & PCL \\
\hline FCO 07.02 & C14 & 150 & & 57.6 & 5.05 & PCL \\
\hline FCO 07.03 & C14 & 250 & & 45.5 & 4.89 & PCL \\
\hline FCO $07-06$ & $\mathrm{C14}_{4}$ & 550 & & 35.2 & 4.79 & PCL \\
\hline FCO 07.07 & C14 & 650 & & 66.4 & 5.33 & $\mathrm{PCL}$ \\
\hline FCO $07-16$ & C14 & 1550 & & 60.4 & 6.19 & PCL \\
\hline FCO 07-17 & $\mathrm{C14}$ & 1650 & & 54.7 & 5.11 & $\mathrm{PCL}$ \\
\hline FCO 07-0.5 & CDTOT & 450 & & 0.113 & NR & UGL \\
\hline FCO $07-12$ & CDTOT & 1150 & & 0.121 & NR & UGL \\
\hline FCO 07-05 & CATOT & 450 & & 0.724 & NR & UGL \\
\hline FCO 07-12 & CATOT & 1150 & & 0.571 & NR & UGL \\
\hline FCO $07-09$ & CS137 & 850 & $\mathrm{U}$ & -0.656 & 2.53 & $P C L$ \\
\hline FCO $07-10$ & CS137 & 950 & $\mathrm{U}$ & 1.52 & 2.75 & $\overline{P C L}$ \\
\hline FCO $07-13$ & CS137 & 1250 & $\mathrm{U}$ & 0.251 & 7.38 & PCL \\
\hline$F C O 07-14$ & CS137 & 1350 & $\mathrm{U}$ & 3.78 & 4.28 & $P C L$ \\
\hline FCO $07-05$ & HGTOT & 450 & & -0.0264 & NR & UGL \\
\hline FCO $07-12$ & HGTOT & 1150 & & -0.0255 & NR & UGL \\
\hline FCO 07-02 & 1129 & 150 & $\mathbf{J}$ & 396 & 54.2 & $\mathbf{P C L}$ \\
\hline FCO $07-03$ & 1129 & 250 & $\mathrm{~J}$ & 406 & 63.5 & PCL \\
\hline FCO $07-06$ & 1129 & 550 & $J$ & 385 & 60.3 & $\mathrm{PCL}$ \\
\hline FCO $07-07$ & 1129 & 650 & J & 410 & 58.5 & $P C L$ \\
\hline FCO $07-16$ & 1129 & 1550 & $\mathrm{~J}$ & 424 & 62.6 & $P C L$ \\
\hline FCO 07-17 & 1129 & 1650 & $J$ & 338 & 56.4 & $\mathrm{PCL}$ \\
\hline FCO $07-05$ & PBTOT & 450 & & 0.046 & NR & UGL \\
\hline FCO $07-12$ & PBTOT & 1150 & & 0.063 & NR & UGL \\
\hline FCO $07-05$ & SETOT & 450 & & -119 & NR & UGL \\
\hline FCO $07-12$ & SETOT & 1150 & & -117 & NR & UGL \\
\hline FCO $07-04$ & SR90 & 350 & & 41.3 & 4.15 & $P C L$ \\
\hline FCO $07-15$ & SR90 & 1450 & & 92.4 & 4.97 & $\mathrm{PCL}$ \\
\hline FCO $07-05$ & TC99 & 450 & & 317 & 14.1 & $\mathrm{PCL}$ \\
\hline FCO $07-12$ & TिC99 & 1150 & & 316 & 13.8 & PCL \\
\hline
\end{tabular}

Notes: $J=L T$ reporting limit NR $=$ Not Reported $U=L T$ detection limit $\quad \mathrm{C}=$ lab control sample not met $\mathrm{R}=\mathrm{ICP}$ interference check not met $\mathrm{V}=$ lab blank contaminated $E=$ value between sample specific $E Q L$ and detection limit 


\begin{tabular}{|c|c|c|c|c|c|c|}
\hline \multirow{2}{*}{\multicolumn{7}{|c|}{$\begin{array}{l}\text { F-Area WTU Clearwell } \\
\text { SR Treat Resin }\end{array}$}} \\
\hline & & & & & & \\
\hline SRS Sample ID & Analyte & Avg Bedvol & Anal Qual & Anal Result & Accuracy & Result Units \\
\hline FCO $02-03$ & AGTOT & 250 & & 0.016 & $\mathrm{NR}$ & UGL \\
\hline $\mathrm{FCO} 02-04$ & AGTOT & 350 & & 0.072 & NR & UGL \\
\hline FCO $02-07$ & AGTOT & 650 & & 0.04 & NR & UGL \\
\hline FCO 02-08 & AGTOT & 750 & & 0.03 & $\mathrm{NR}$ & UGL \\
\hline FCO 02-11 & AGTOT & 1050 & & 0.025 & NR & UGL \\
\hline FCO 02-12 & AGTOT & 1150 & & 0.143 & NR & UGL \\
\hline FCO 02-15 & AGTOT & 1450 & & 0.061 & NR & UGL \\
\hline FCO 02-16 & AGTOT & 1550 & & 0.003 & NR & UGL \\
\hline FCO $02-01$ & ALPHAG & 50 & & 616 & 131 & PCL \\
\hline FCO $02-05$ & ALPHAG & 450 & & 681 & 140 & $\mathrm{PCL}$ \\
\hline FCO 02-09 & ALPHAG & 850 & & 133 & 61.8 & $\mathrm{PCL}$ \\
\hline FCO 02-13 & ALPHAG & 1250 & $\underline{\mathrm{U}}$ & 8.85 & 6.58 & $\mathrm{PCL}$ \\
\hline FCO 02-17 & ALPHAG & 1650 & $\underline{\mathrm{U}}$ & 4.96 & 6.73 & PCL \\
\hline FCO $02-03$ & ASTOT & 250 & & -2.76 & $\mathrm{NR}$ & UGL \\
\hline FCO 02-04 & ASTOT & 350 & & -1.67 & $\mathrm{NR}$ & UGL \\
\hline FCO $02-07$ & ASTOT & 650 & & -2.37 & NR & UGL \\
\hline FCO 02-08 & ASTOT & 750 & & -2.52 & NR & UGL \\
\hline FCO 02-11 & ASTOT & 1050 & & -2.6 & NR & UGL \\
\hline FCO $02-12$ & ASTOT & 1150 & & -0.135 & NR & UGL \\
\hline FCO 02-15 & ASTOT & 1450 & & -0.216 & NR & UGL \\
\hline FCO 02-16 & ASTOT & 1550 & & -0.016 & $\mathrm{NR}$ & UGL \\
\hline FCO 02-03 & BATOT & 250 & & 4.68 & NR & UGL \\
\hline FCO $02-04$ & BATOT & 350 & & 4.42 & NR & UGL \\
\hline FCO $02-07$ & BATOT & 650 & & 7.19 & NR & UGL \\
\hline FCO 02-08 & BATOT & 750 & & 1.54 & $\mathrm{NR}$ & UGL \\
\hline FCO 02-11 & BATOT & 1050 & & 2.57 & $\mathrm{NR}$ & UGL \\
\hline FCO 02-12 & BATOT & 1150 & & 1.99 & $\mathrm{NR}$ & UGL \\
\hline FCO 02-15 & BATOT & 1450 & & 0.566 & $\mathrm{NR}$ & UGL \\
\hline FCO 02-16 & BATOT & 1550 & & 1.29 & $\mathrm{NR}$ & UGL \\
\hline $\mathrm{FCO} 02-01$ & BETAG & 50 & & 712 & 115 & $\mathrm{PCL}$ \\
\hline FCO $02-05$ & BETAG & 450 & & 952 & 126 & $P C L$ \\
\hline FCO $02-09$ & BETAG & 850 & & 269 & 77.9 & $\mathrm{PCL}$ \\
\hline FCO 02-13 & BETAG & 1250 & & 79.6 & 9.81 & $\mathrm{PCL}$ \\
\hline FCO 02-17 & BETAG & 1650 & & 109 & 11.2 & $\mathrm{PCL}$ \\
\hline
\end{tabular}

Notes: $J=L T$ reporting limit NR $=$ Not Reported

$\mathrm{U}=\mathrm{LT}$ detection limit $\quad \mathrm{C}=$ lab control sample not met

$\mathrm{R}=\mathrm{ICP}$ interference check not met $\mathrm{V}=$ lab blank contaminated

$E=$ value between sample specific $E Q L$ and detection limit Accuracy Reported at $2 \delta$ 


\begin{tabular}{|c|c|c|c|c|c|c|}
\hline \multicolumn{7}{|c|}{ F-Area WTU Clearwell } \\
\hline SR Treat Resin & Cont & & & & & \\
\hline & & & & & & \\
\hline SRS Sample ID & Analyte & Avg Bedvol & Anal Qual & Anal Result & Accuracy & Result Units \\
\hline $\mathrm{FCO} 02-03$ & CDTOT & 250 & & 0.065 & NR & UGL \\
\hline FCO $02-04$ & CDTOT & 350 & & 0.046 & NR & UGL \\
\hline $\mathrm{FCO} 02-07$ & CDTOT & 650 & & 0.032 & NR & UGL \\
\hline $\mathrm{FCO} \quad 02.08$ & CDTOT & 750 & & 0.068 & NR & UGL \\
\hline$F C Q 02-11$ & CDTOT & 1050 & & 0.044 & NR & UGL \\
\hline $\mathrm{FCO} \mathrm{02-12}$ & CDTOT & 1150 & & 0.08 & NR & UGL \\
\hline FCO 02-15 & CDTOT & 1450 & & 0.088 & NR & UGL \\
\hline FCO $02-16$ & CDTOT & 1550 & & 0.07 & NR & UGL \\
\hline $\mathrm{FCO} 02-03$ & CRTQT & 250 & & 0.602 & NA & UGL \\
\hline FCO $02-04$ & CRTOT & 350 & & 0.493 & NR & UGL \\
\hline FCO $02-07$ & CATOT & 650 & & 0.527 & NR & UGL \\
\hline FCO 02-08 & CRTOT & 750 & & 0.466 & NA & UGL \\
\hline $\mathrm{FCO} 02-11$ & CRTOT & 1050 & & 0.475 & $\mathrm{NR}$ & UGL \\
\hline FCO $02-12$ & CATOT & 1150 & & 0.213 & NB & UGL \\
\hline $\mathrm{FCO} 02-15$ & CRTOT & 1450 & & 0.277 & NR & UGL \\
\hline $\mathrm{FCO} \quad 02-16$ & CRTOT & 1550 & & 0.446 & NR & UGL \\
\hline$F C O \quad 02-03$ & CS137 & 250 & & 5.97 & 5.7 & $P C L$ \\
\hline FCO $02-04$ & C\$137 & 350 & & 7.29 & 6.6 & $\mathrm{PCL}$ \\
\hline$F C O 02-07$ & CS137 & 650 & & 9.02 & 6.68 & $P C L$ \\
\hline $\mathrm{FCO} 02.08$ & CS 137 & 750 & & 16.5 & 6.15 & $P C L$ \\
\hline FCO $02-11$ & CS137 & 1050 & & 11 & 6.43 & PCL \\
\hline FCO $02-12$ & CS137 & 1150 & & 16.3 & 6.76 & $P C L$ \\
\hline FCO 02-15 & CS137 & 1450 & & 16.4 & 5.96 & $P C L$ \\
\hline FCO 02-16 & CS137 & 1550 & & 19.4 & 5.46 & $\mathrm{PCL}$ \\
\hline FCO $02-03$ & HGTOT & 250 & $J$ & -0.0773 & NR & UGL \\
\hline FCO $02-04$ & HGTOT & 350 & $J$ & -0.131 & NA & UGL \\
\hline FGO $02-07$ & HGTQT & 650 & $J$ & -0.127 & NR & UGL \\
\hline FCO $02-08$ & HGTOT & 750 & $j$ & -0.115 & NR & UGL \\
\hline $\mathrm{FCO} 02-11$ & HGTOT & 1050 & $\mathrm{~J}$ & $-0,133$ & NR & UGL \\
\hline FCO 02-12 & HGTQT & 1150 & & -0.00853 & NR & UGL \\
\hline $\mathrm{FCO} \quad 02-15$ & HGIOT & 1450 & & $-0,0277$ & NR & UGL \\
\hline FCO $02-16$ & HGTOT & 1550 & & -0.0257 & NA & UGL \\
\hline$F C O 02-03$ & PBTOT & 250 & & 0.361 & NR & UGL \\
\hline FCO $02-04$ & PBTOT & 350 & & 0.351 & NR & UGL \\
\hline $\mathrm{FCO} 02-07$ & PBTQT & 650 & & 0.208 & NR & UGL \\
\hline FCO $02-08$ & PBTOT & 750 & & 0.094 & NR & UGL \\
\hline FCO $02-11$ & PBTQT & 1050 & & 0.458 & NR & UGL \\
\hline FCO $02-12$ & PBTOT & 1150 & & 0.187 & NR & UGL \\
\hline FCO $02-15$ & PBTQT & 1450 & & 0.14 & NR & UGL \\
\hline$F C O Q 2-16$ & PBTOT & 1550 & & 0.553 & NR & UGL \\
\hline $\mathrm{FCO} 02-03$ & SETQT & 250 & & -41 & NR & UGL \\
\hline $\mathrm{FCO} \quad 02-04$ & SETOT & 350 & & -33.7 & NR & UGL \\
\hline FCO $02-07$ & SETQT & 650 & & -43.6 & NR & UGL \\
\hline FCO $02-08$ & SETOT & 750 & & -42 & NR & UGL \\
\hline FCO $02-11$ & SETOT & 1050 & $J$ & -35.7 & NA & UGL \\
\hline $\mathrm{FCO} 02-12$ & SETOT & 1150 & & -13.2 & NR & UGL \\
\hline $\mathrm{FCO} 02-15$ & SETOT & 1450 & & -14.7 & NR & UGL \\
\hline $\mathrm{FCO} \mathrm{02.16}$ & SETOT & 1550 & & -16.6 & NR & UGL \\
\hline $\mathrm{FCO} 02-02$ & SR90 & 150 & U & 3.06 & 3,36 & $P C L$ \\
\hline FCO 02-06 & SR90 & 550 & $\mathrm{U}$ & 4.33 & 3.56 & $\mathrm{PCL}$ \\
\hline$F C Q \quad 02.10$ & SR9O & 950 & $U$ & 3.6 & 4.14 & $\mathrm{PCL}$ \\
\hline $\mathrm{FCO} \mathrm{02-14}$ & SR90 & 1350 & $U$ & -0.649 & 3.21 & $\mathrm{PCl}$ \\
\hline
\end{tabular}

Notes: $J=L T$ reporting limit $U=L T$ detection limit NR $=$ Not Reported $R=I C P$ interference check not met $V=$ lab blank contaminated $E=$ value between sample specific $E Q L$ and detection limit Accuracy Reported at $2 \delta$ 


\begin{tabular}{|c|c|c|c|c|c|c|}
\hline \multicolumn{7}{|c|}{$\begin{array}{l}\text { H-Area WTU Clearwell } \\
\text { Blank_A }\end{array}$} \\
\hline & & & & & & \\
\hline$\frac{\text { SRS Sample ID }}{\mathrm{HCO} 6 \mathrm{~A}-1}$ & Analyte & Avg Bedvol & Anal Qual & Anal Result & Accuracy & Result Units \\
\hline HCO $6 A-6$ & ALPHAG & $\begin{array}{r}50 \\
550 \\
\end{array}$ & & $\begin{array}{r}7.62 \\
5.25 \\
\end{array}$ & $\begin{array}{r}2.76 \\
1.76 \\
\end{array}$ & $\frac{P C L}{P C L}$ \\
\hline HCO $6 \mathrm{~A}-11$ & ALPHAG & 1050 & & 7.45 & 2.29 & PCL \\
\hline HCO 6A-16 & ALPHAG & 1550 & & -1.11 & 1.53 & PCL \\
\hline HCO $6 A-5$ & ALTOT & 450 & & 50 & NA & UGL \\
\hline HCO $6 \mathrm{~A}-10$ & ALTOT & 950 & $E$ & 30.2 & NR & UGL \\
\hline HCO $6 A-15$ & ALTOT & 1450 & & 50 & NA & UGL \\
\hline HCO $6 \overline{A-1}$ & BETAG & 50 & & 843 & 14.1 & PCL \\
\hline HCO $6 A-6$ & BETAG & 550 & & 380 & 9.36 & PCL \\
\hline HCO 6A-11 & BETAG & 1050 & & 501 & 11 & $\mathrm{PCL}$ \\
\hline HCO $6 A-16$ & BETAG & 1550 & & 371 & 5.7 & $\overline{P C L}$ \\
\hline HCO $6 A-3$ & C14 & 250 & C & 50.8 & 14.9 & $\overline{P C L}$ \\
\hline HCO $6 A-4$ & $C 14$ & 350 & & 52.9 & 15 & $\mathrm{PCL}$ \\
\hline $\mathrm{HCO} 6 \mathrm{~A}-7$ & C14 & 650 & & 38.3 & 15.6 & $\mathrm{PCL}$ \\
\hline HCO $6 A-8$ & C14 & 750 & & 94.3 & 16.6 & $\mathrm{PCL}$ \\
\hline $\mathrm{HCO} 6 \mathrm{~A}-12$ & C14 & 1150 & & 71.4 & 16.3 & $\overrightarrow{P C L}$ \\
\hline HCO $6 A-13$ & $\mathrm{C} 14$ & 1250 & & 71.2 & 15.5 & $\mathrm{PCL}$ \\
\hline HCO $6 A-17$ & C14 & 1650 & & 52.3 & 15.7 & $\overline{P C L}$ \\
\hline HCO 6A-18 & C14 & 1750 & & 57.3 & 15.9 & $\overline{P C L}$ \\
\hline HCO 6A-5 & FETOT & 450 & & 114 & $\mathrm{NR}$ & UGL \\
\hline HCO $6 \mathrm{~A}-10$ & FETOT & 950 & & 50 & NR & UGL \\
\hline HCO $6 A-15$ & FETOT & 1450 & & 50 & NR & $U G L$ \\
\hline HCO $6 A-3$ & 1129 & 250 & & 41.5 & 7.51 & PCL \\
\hline $\mathrm{HCO} \quad 6 \mathrm{~A}-4$ & 1129 & 350 & & 38.6 & 5.89 & $\overline{P C L}$ \\
\hline $\mathrm{HCO} 6 \mathrm{~A}-7$ & 1129 & 650 & & 38.7 & 6.8 & $\overline{P C L}$ \\
\hline HCO 6A-8 & 1129 & 750 & C & 41.1 & 7.17 & PCL \\
\hline HCO $6 \bar{A}-12$ & 1129 & 1150 & & 40.5 & 7.77 & $\overline{P C L}$ \\
\hline HCO $6 A-13$ & 1129 & 1250 & C & 31.9 & 6.05 & $\overline{P C L}$ \\
\hline HCO 6A-17 & 1129 & 1650 & & 38.3 & 6.65 & $\mathrm{PCL}$ \\
\hline HCO $6 A-18$ & 1129 & 1750 & & 32.4 & 5.05 & PCL \\
\hline HCO $6 A-2$ & SR90 & 150 & & 642 & 11.5 & $\mathrm{PCL}$ \\
\hline HCO $6 A-9$ & SR90 & 850 & & 631 & 11.8 & $\mathrm{PCL}$ \\
\hline HCO $6 A-14$ & SR90 & 1350 & & 660 & 12.3 & $\overline{P C L}$ \\
\hline HCO $6 A-19$ & SR90 & 1850 & C & 491 & 13 & $\overline{\mathrm{PCL}}$ \\
\hline HCO $6 A-5$ & TC99 & 450 & & 121 & 14.7 & $\overline{\mathrm{PCL}}$ \\
\hline HCO $6 A-10$ & TC99 & 950 & & 121 & 17.9 & PCL \\
\hline HCO $6 A-15$ & TC99 & 1450 & & 122 & 14.3 & $\overline{P C L}$ \\
\hline
\end{tabular}

Notes: $J=L T$ reporting limit NR $=$ Not Reported $U=L T$ detection limit $\mathrm{R}=\mathrm{ICP}$ interference check not met $\mathrm{C}=$ lab control sample not met $E=$ value between sample specific $E Q L$ and detection limit 


\begin{tabular}{|c|c|c|c|c|c|c|}
\hline \multirow{2}{*}{\multicolumn{7}{|c|}{$\begin{array}{l}\text { H-Area WTU Clearwell } \\
\text { Blank_B }\end{array}$}} \\
\hline & & & & & & \\
\hline & & & & & & \\
\hline SRS Sample ID & Analyte & Avg Bedvol & Anal Qual & Anal Result & Accuracy & Result Units \\
\hline $\mathrm{HCO} 6 \mathrm{~B}-1$ & ALPHAG & 50 & $1 \mathrm{C}$ & 1.52 & 0.959 & $\mathrm{PCL}$ \\
\hline $\mathrm{HCO} 6 \mathrm{~B}-6$ & ALPHAG & 550 & C & 9.4 & 2.02 & $\mathrm{PCL}$ \\
\hline $\mathrm{HCO} 6 \mathrm{~B}-11$ & ALPHAG & 1050 & & 7.03 & 1.89 & $\mathrm{PCL}$ \\
\hline $\mathrm{HCO} 6 \mathrm{~B}-16$ & ALPHAG & 1550 & C & 0.766 & 1.95 & $\mathrm{PCL}$ \\
\hline $\mathrm{HCO} 6 \mathrm{~B}-5$ & ALTOT & 450 & & 50 & NR & UGL \\
\hline $\mathrm{HCO} 6 \mathrm{~B}-10$ & ALTOT & 950 & & 50 & NA & UGL \\
\hline HCQ 6B-15 & ALTQT & 1450 & & 50 & NR & UGL. \\
\hline $\mathrm{HCO} 6 \mathrm{~B}-20$ & ALTOT & 1950 & & 50 & NR & UGL \\
\hline HCQ 6B-1 & BETAG & 50 & $\mathrm{~V}$ & 273 & 4.03 & $\mathrm{PCL}$ \\
\hline HCO 6B-6 & BETAG & 550 & V & 487 & 6.71 & $\mathrm{PCL}$ \\
\hline $\mathrm{HCO} 6 \mathrm{~B}-11$ & BETAG & 1050 & & 420 & 6.17 & $\mathrm{PCL}$ \\
\hline HCO 6B-16 & BETAG & 1550 & $\mathrm{~V}$ & 880 & 9.03 & $P C L$ \\
\hline $\mathrm{HCO} 6 \mathrm{~B}-3$ & $\mathrm{C} 14$ & 250 & & 59.3 & 15.2 & $P C L$ \\
\hline $\mathrm{HCO} 6 \mathrm{~B}-4$ & C14 & 350 & & 49.8 & 15.2 & $P G L$ \\
\hline HCO 6B-7 & $\mathrm{C14}$ & 650 & & 61.6 & 16 & $\mathrm{PCL}$ \\
\hline HCO $6 B-8$ & C14 & 750 & & 63.9 & 7.91 & $P C L$ \\
\hline $\mathrm{HCO} 6 \mathrm{~B}-12$ & C14 & 1150 & & 46.9 & 23 & $\mathrm{PCL}$ \\
\hline $\mathrm{HCO} 6 \mathrm{~B}-13$ & C14 & 1250 & & 62.9 & 16.7 & $P C L$ \\
\hline $\mathrm{HCO} 6 \mathrm{~B}-17$ & C14 & 1650 & & 71,5 & 15.4 & $P C L$ \\
\hline $\mathrm{HCO} 6 \mathrm{~B}-18$ & C14 & 1750 & & 74 & 15.6 & $P C L$ \\
\hline HCO 6B-5 & FETQT & 450 & & 53.8 & NR & UGL \\
\hline $\mathrm{HCO} 6 \mathrm{~B}-10$ & FETOT & 950 & & 56.5 & NR & UGL \\
\hline $\mathrm{HCO} 6 \mathrm{~B}-15$ & FETOT & 1450 & & 50 & NR & UGL \\
\hline $\mathrm{HCO} 6 \mathrm{~B}-20$ & FETOT & 1950 & & 50 & NR & UGL \\
\hline $\mathrm{HCO} 6 \mathrm{~B}-3$ & 1129 & 250 & & 35.5 & 6.63 & $P C L$ \\
\hline $\mathrm{HCO} 6 \mathrm{~B}-4$ & 1129 & 350 & & 36 & 5.38 & $P C L$ \\
\hline $\mathrm{HCO} 6 \mathrm{~B}-7$ & 1129 & 650 & & 35.6 & 6.67 & $\mathrm{PCL}$ \\
\hline $\mathrm{HCO} 6 \mathrm{~B}-8$ & 1129 & 750 & & 35.2 & 5.61 & $\mathrm{PCL}$ \\
\hline $\mathrm{HCO} 6 \mathrm{~B}-12$ & 1129 & 1150 & & 30.8 & 6.62 & PCL \\
\hline $\mathrm{HCO} 6 \mathrm{~B}-13$ & 1129 & 1250 & & 35.7 & 6.04 & $\mathrm{PCL}$ \\
\hline $\mathrm{HCO} 6 \mathrm{~B}-17$ & 1129 & 1650 & C & 38.9 & 7.15 & $\mathrm{PCL}$ \\
\hline $\mathrm{HCO} 6 \mathrm{~B}-18$ & 1129 & 1750 & $\mathrm{C}$ & 39.7 & 7.46 & $\mathrm{PCL}$ \\
\hline $\mathrm{HCO} 6 \mathrm{~B}-2$ & SR90 & 150 & & 428 & 20.3 & $\mathrm{PCL}$ \\
\hline $\mathrm{HCO} 6 \mathrm{~B}-9$ & SR90 & 850 & $C$ & 365 & 8.28 & $P C L$ \\
\hline $\mathrm{HCO} 6 \mathrm{~B}-14$ & SR9Q & 1350 & & 590 & 11.3 & $\mathrm{PCL}$ \\
\hline $\mathrm{HCO} 6 \mathrm{~B}-19$ & SR90 & 1850 & C & 563 & 14.1 & PCL \\
\hline HCO $6 B-5$ & TCQ9 & 450 & & 98 & 16 & $\mathrm{PCL}$ \\
\hline HCO $6 B-10$ & TC99 & 950 & & 98.7 & 16.1 & $P C L$ \\
\hline $\mathrm{HCO} 6 \mathrm{~B}-15$ & TC99 & 1450 & & 99 & 16.5 & $\mathrm{PCL}$ \\
\hline $\mathrm{HCO} 6 \mathrm{~B}-20$ & TC99 & 1950 & & 99.4 & 16.1 & $\mathrm{PCL}$ \\
\hline
\end{tabular}

Notes: $J=L T$ reporting limit

NR $=$ Not Reported

$U=L T$ detection limit

$\mathrm{C}=$ lab control sample not met

$R=I C P$ interference check not met $V=$ lab blank contaminated

$E=$ value between sample specific $E Q L$ and detection limit

Accuracy Reported at $2 \delta$

Page A25 of A39

WSRC-TR-99-00020, Rev. 0 


\begin{tabular}{|c|c|c|c|c|c|c|}
\hline H-Area WTU Cle & earwell & & & & & \\
\hline Activated Carb & bon & & & & & \\
\hline & & & & & & \\
\hline SRS Sample ID & Analyte & Avg Bedvol & Anal Qual & Anal Result & Accuracy & Result Units \\
\hline HCO 12-1 & ALPHAG & 50 & C & 1.78 & $\begin{array}{r}1.72 \\
\end{array}$ & PCL \\
\hline $\mathrm{HCO} 12-6$ & ALPHAG & 550 & $\mathrm{C}$ & 11 & 2.36 & PCL \\
\hline $\mathrm{HCO} 12-11$ & ALPHAG & 1050 & & 7.2 & 2.86 & $P C L$ \\
\hline HCO 12-16 & ALPHAG & 1550 & C & 2.77 & 0.894 & PCL \\
\hline $\mathrm{HCO} 12-5$ & ALTOT & 450 & & 50 & NR & UGL \\
\hline HCO 12-10 & ALTOT & 950 & & 50 & NA & UGL \\
\hline $\mathrm{HCO} 12.15$ & ALTOT & 1450 & & 50 & NR & UGL \\
\hline $\mathrm{HCO} 12-20$ & ALTOT & 1950 & & 50 & NA & UGL \\
\hline $\mathrm{HCO} 12-1$ & BETAG & 50 & $V$ & 314 & 5.27 & PCL \\
\hline $\mathrm{HCO} 12-6$ & BETAG & 550 & $\mathrm{~V}$ & 920 & 9.21 & PCL \\
\hline HCO 12-11 & BETAG & 1050 & & 603 & 11.7 & PCL \\
\hline $\mathrm{HCO} 12-16$ & BETAG & 1550 & V & 272 & 4.73 & PCL \\
\hline $\mathrm{HCO} 12-3$ & $\mathrm{C} 14$ & 250 & & 71.2 & 15.9 & $\mathrm{PCL}$ \\
\hline HCO $12-4$ & C14 & 350 & & 50.1 & 14.8 & PCL \\
\hline HCO 12-7 & C14 & 650 & & 37.5 & 15.4 & $P C L$ \\
\hline $\mathrm{HCO} 12-8$ & C14 & 750 & & 68.2 & 7.26 & $\mathrm{PCL}$ \\
\hline $\mathrm{HCO} 12-12$ & C14 & 1150 & & 50.4 & 16.7 & $P C L$ \\
\hline HCO 12-13 & C14 & 1250 & & 44.8 & 16.9 & PCL \\
\hline HCO 12-17 & C14 & 1650 & & 76.3 & 15.4 & PCL \\
\hline $\mathrm{HCO} 12-18$ & C14 & 1750 & & 48.5 & 14.9 & $P C L$ \\
\hline $\mathrm{HCO} 12-5$ & FETOT & 450 & & 55.6 & NR & $\mathrm{UGL}$ \\
\hline $\mathrm{HCO} 12-10$ & FETOT & 950 & $\div$ & 90.6 & NR & UGL \\
\hline $\mathrm{HCO} 12-15$ & FETOT & 1450 & & 50 & NA & UGL \\
\hline HCO 12-20 & FETOT & 1950 & & 50 & NA & UGL \\
\hline $\mathrm{HCO} 12-3$ & 1129 & 250 & & 29.6 & 5.78 & PCL \\
\hline $\mathrm{HCO} 12-4$ & 1129 & 350 & & 32.5 & 5.3 & PCL \\
\hline $\mathrm{HCO} 12-7$ & 1129 & 650 & & 33.6 & 6.6 & $P C L$ \\
\hline $\mathrm{HCO} 12.8$ & 1129 & 750 & & 32 & 5.47 & PCL \\
\hline $\mathrm{HCO} 12-12$ & 1129 & 1150 & & 36.4 & 5.68 & $\mathrm{PCL}$ \\
\hline HCO 12-13 & 1129 & 1250 & & 34.7 & 5.32 & $\mathrm{PCL}$ \\
\hline $\mathrm{HCO} 12-17$ & 1129 & 1650 & C & 26.2 & 5.73 & $\mathrm{PCL}$ \\
\hline HCO 12-18 & 1129 & 17.50 & $\mathrm{C}$ & 29.6 & 6.01 & $\mathrm{PCL}$ \\
\hline $\mathrm{HCO} 12-2$ & SR90 & 150 & $\mathrm{C}$ & 489 & 11.8 & PCL \\
\hline $\mathrm{HCO} 12.9$ & SR90 & 850 & C & 440 & 13.4 & $P C L$ \\
\hline HCO 12-14 & SR90 & 1350 & & 582 & 10.6 & $P C L$ \\
\hline HCO 12.19 & SR90 & 1850 & C & 551 & 13.5 & $\mathrm{PCL}$ \\
\hline $\mathrm{HCO} 12-5$ & TC99 & 450 & & 2.58 & 8.92 & $P C L$ \\
\hline $\mathrm{HCO} 12-10$ & TC99 & 950 & & 4.24 & 9.39 & $\mathrm{PCL}$ \\
\hline $\mathrm{HCO} 12-15$ & TC99 & 1450 & & 15.7 & 9.58 & PCL \\
\hline HCO 12-20 & TC99 & 1950 & & 27.8 & 11.2 & $\mathrm{PCL}$ \\
\hline
\end{tabular}

Notes: $J=L T$ reporting limit $\quad N R=$ Not Reported

$\mathrm{U}=\mathrm{LT}$ detection limit $\quad \mathrm{C}=$ lab control sample not met

$R=I C P$ interference check not met $V=$ lab blank contaminated

$E=$ value between sample specific $E Q L$ and detection limit

Accuracy Reported at $2 \delta \quad$ Page A26 of A39 WSRC-TR-99-00020, Rev. 0 


\begin{tabular}{|c|c|c|c|c|c|c|}
\hline \multicolumn{3}{|c|}{ H-Area WTU Clearwell } & & & & \\
\hline \multicolumn{2}{|c|}{ AG1 X2 Resin } & & & & & \\
\hline & & & & & & Result Units \\
\hline Lab ID & Analyte & Avg Beavol & Anal Qual & Anal hesuli & Accuracy & PCl \\
\hline $\mathrm{HCO} 8-1$ & ALPHAG & 50 & & 4.05 & 1.65 & $P C L$ \\
\hline $\mathrm{HCO} 8-6$ & ALPHAG & 550 & & 0.717 & 1.55 & $P C L$ \\
\hline $\mathrm{HCO} 8-11$ & ALPHAG & 1050 & & 20 & 10.2 & $P C L$ \\
\hline $\mathrm{HCO} 8-16$ & ALPHAG & 1550 & & 3.71 & 1.29 & $\mathrm{PCL}$ \\
\hline $\mathrm{HCO} 8-5$ & ALTOT & 450 & & 50 & NR & UGL \\
\hline HCO 8-10 & ALTOT & 950 & & 50 & NR & UGL \\
\hline $\mathrm{HCO} 8-15$ & ALTOT & 1450 & & 50 & NR & UGL \\
\hline $\mathrm{HCO} 8-20$ & ALTOT & 1950 & & 50 & NR & UGL \\
\hline $\mathrm{HCO} 8-1$ & BETAG & 50 & & 415 & 9.77 & $\mathrm{PCL}$ \\
\hline $\mathrm{HCO} 8-6$ & BETAG & 550 & & 328 & 5.33 & $\mathrm{PCL}$ \\
\hline $\mathrm{HCO} 8-11$ & BETAG & 1050 & & 962 & 36.4 & $\mathrm{PCL}$ \\
\hline $\mathrm{HCO} 8-16$ & BETAG & 1550 & & 332 & 5.45 & $\mathrm{PCL}$ \\
\hline $\mathrm{HCO} 8-3$ & C14 & 250 & C & 47.1 & 14.8 & $P C L$ \\
\hline $\mathrm{HCO} 8-4$ & C14 & 350 & & 52.6 & 17.4 & $\mathrm{PCL}$ \\
\hline $\mathrm{HCO} 8-7$ & C14 & 650 & & 39.3 & 15.6 & $\mathrm{PCL}$ \\
\hline $\mathrm{HCO} 8-8$ & C14 & 750 & C & 42.2 & 14.6 & $\mathrm{PCL}$ \\
\hline $\mathrm{HCO} 8-12$ & C14 & 1150 & & 55.5 & 15.8 & $\mathrm{PCL}$ \\
\hline $\mathrm{HCO} 8-13$ & C14 & 1250 & & 21.6 & 13.8 & $\mathrm{PCL}$ \\
\hline $\mathrm{HCO} 8-17$ & C14 & 1650 & & 77.4 & 16.5 & $P C L$ \\
\hline $\mathrm{HCO} 8-18$ & C14 & 17.50 & & 66.8 & 15.8 & $\mathrm{PCL}$ \\
\hline $\mathrm{HCO} 8-5$ & FETOT & 450 & & 50 & NR & UGL \\
\hline HCO 8-10 & FETOT & 950 & & 50 & NR & UGL \\
\hline HCO 8-15 & FETOT & 1450 & & 50 & NR & UGL \\
\hline HCO 8-20 & FETOT & 1950 & & 50 & NR & UGL \\
\hline $\mathrm{HCO} 8-3$ & 1129 & 250 & & 10.2 & 3.7 & $\mathrm{PCL}$ \\
\hline $\mathrm{HCO} 8-4$ & 1129 & 350 & & 12.1 & 2.67 & $P C L$ \\
\hline $\mathrm{HCO} 8-7$ & 1129 & 650 & & 40.2 & 7.46 & $P C L$ \\
\hline $\mathrm{HCO} 8.8$ & 1129 & 750 & & 36.7 & 7.15 & $\mathrm{PCL}$ \\
\hline $\mathrm{HCO} 8-12$ & 1129 & 1150 & & 32.1 & 6.23 & $\mathrm{PCL}$ \\
\hline $\mathrm{HCO} 8-13$ & 1129 & 1250 & C & 29.3 & 5.87 & $\mathrm{PCL}$ \\
\hline $\mathrm{HCO} 8-17$ & 1129 & 1650 & & 37.7 & 5.47 & $\mathrm{PCL}$ \\
\hline $\mathrm{HCO} 8-18$ & 1129 & 1750 & & 41.5 & 6.25 & $\mathrm{PCL}$ \\
\hline $\mathrm{HCO} 8-2$ & SR90 & 150 & & 655 & 7.79 & $\mathrm{PCL}$ \\
\hline $\mathrm{HCO} 8-9$ & SR90 & 850 & & 699 & 14.4 & $\mathrm{PCL}$ \\
\hline $\mathrm{HCO} 8-14$ & SR90 & 1350 & & 612 & 16.3 & $P C L$ \\
\hline $\mathrm{HCO} 8-19$ & SR9O & 1850 & & 469 & 24.6 & $\mathrm{PCL}$ \\
\hline $\mathrm{HCO} 8-5$ & TC99 & 450 & & 4.54 & 7.49 & $\mathrm{PCL}$ \\
\hline HCO 8-10 & TC99 & 950 & & 7.31 & 10.1 & $\mathrm{PCL}$ \\
\hline HCO 8-15 & TC99. & 1450 & & 5.26 & 7.21 & $\mathrm{PCL}$ \\
\hline $\mathrm{HCO} 8-20$ & TC99 & 1950 & & 9.79 & 7.63 & $P C L$ \\
\hline
\end{tabular}

Notes: $\mathrm{J}=\mathrm{LT}$ reporting limit

$\mathrm{NR}=$ Not Reported

$\mathrm{U}=\mathrm{LT}$ detection limit

$\mathrm{C}=$ lab control sample not met

$R=I C P$ interference check not met $V=$ lab blank contaminated

$E=$ value between sample specific $E Q L$ and detection limit

Accuracy Reported at $2 \delta$

Page A27 of A39

WSRC-TR-99-00020, Rev. 0 


\begin{tabular}{|c|c|c|c|c|c|c|}
\hline \multicolumn{3}{|c|}{ H-Area WTU Clearwell } & & & & \\
\hline \multicolumn{2}{|c|}{ AG1 $\times 8$ Resin } & & & & & . \\
\hline Lab ID & lanalute & IAvg Bedvol & Anal Oual & Anal Result & Accuracy & Result Units \\
\hline $\mathrm{HCO} 9-1$ & ALPHAG & 50 & & 8.2 & 2.88 & $\mathrm{PCL}$ \\
\hline HCO 9-6 & ALPHAG & 550 & & 2.34 & 1.67 & PCL \\
\hline HCO 9-11 & ALPHAG & 1050 & & 1.39 & 1.39 & $\mathrm{PCL}$ \\
\hline HCO 9.16 & ALPHAG & 1550 & & 9.92 & 2.08 & $\mathrm{PCL}$ \\
\hline HCO 9-5 & ALTOT & 450 & & 50 & NR & UGL \\
\hline HCO 9-10 & ALTOT & 950 & & 50 & NR & UGL \\
\hline $\mathrm{HCO} 9-15$ & ALTOT & 1450 & & 50 & $\mathrm{NR}$ & UGL \\
\hline $\mathrm{HCO} 9-20$ & ALTOT & 1950 & & 50 & NR & UGL \\
\hline $\mathrm{HCO} 9-1$ & BETAG & 50 & & 460 & 10.5 & $\mathrm{PCL}$ \\
\hline $\mathrm{HCO} 9-6$ & BETAG & 550 & & 391 & 5.85 & $\mathrm{PCL}$ \\
\hline HCO 9-11 & BETAG & 1050 & & 503 & 6.78 & $P C L$ \\
\hline $\mathrm{HCO} 9-16$ & BETAG & 1550 & & 392 & 5.81 & $\mathrm{PCL}$ \\
\hline $\mathrm{HCO} 9-3$ & C14 & 250 & & 64.8 & 16.1 & $\mathrm{PCL}$ \\
\hline $\mathrm{HCO} 9.4$ & C14 & 350 & & 71.3 & 15.6 & $\mathrm{PCL}$ \\
\hline $\mathrm{HCO} 9-7$ & C14 & 650 & & 65.8 & 15.3 & $\mathrm{PCL}$ \\
\hline HCO 9-8 & C14 & 750 & C & 35.2 & 15.8 & $\mathrm{PCL}$ \\
\hline $\mathrm{HCO} 9-12$ & $\mathrm{C}_{14}$ & 1150 & C & 46.4 & 14.8 & $\mathrm{PCL}$ \\
\hline $\mathrm{HCO} 9-13$ & C14 & 1250 & C & 47 & 14.8 & $P C L$ \\
\hline $\mathrm{HCO} 9-17$ & C14 & 1650 & & 49.3 & 17 & $\mathrm{PCL}$ \\
\hline $\mathrm{HCO} 9-18$ & C14 & 1750 & & 53.7 & 16 & $\mathrm{PCL}$ \\
\hline $\mathrm{HCO} 9-5$ & FETOT & 450 & & 50 & NR & UGL \\
\hline $\mathrm{HCO} 9-10$ & FETOT & 950 & & 50 & $\mathrm{NR}$ & UGL \\
\hline $\mathrm{HCO} 9-15$ & FETOT & 1450 & & 50 & NR & UGL \\
\hline $\mathrm{HCO} 9-20$ & FETOT & 1950 & & 50 & NR & UGL \\
\hline $\mathrm{HCO} 9-3$ & 1129 & 250 & & 12.3 & 3.51 & $\mathrm{PCL}$ \\
\hline $\mathrm{HCO}$ 9-4 & 1129 & 350 & & 10.3 & 3.14 & PCL \\
\hline $\mathrm{HCO} 9-7$ & 1129 & 650 & C & 11.1 & 3.62 & $\mathrm{PCL}$ \\
\hline $\mathrm{HCO} 9-8$ & 1129 & 750 & & 8.37 & 4.14 & $\mathrm{PCL}$ \\
\hline $\mathrm{HCO} 9-12$ & 1129 & 1150 & & 12.4 & 4.15 & $\mathrm{PCL}$ \\
\hline $\mathrm{HCO} 9-13$ & 1129 & 1250 & & 10.9 & 3.24 & $\mathrm{PCL}$ \\
\hline $\mathrm{HCO} 9-17$ & 1129 & 1650 & & 10.8 & 2.43 & $P C L$ \\
\hline $\mathrm{HCO} 9-18$ & 1129 & 1750 & & 10.7 & 2.69 & $P C L$ \\
\hline HCO 9-2 & SR90 & 150 & & 637 & 11.4 & PCL \\
\hline $\mathrm{HCO} 9-9$ & SR90 & 850 & & 649 & 11.4 & PCL \\
\hline $\mathrm{HCO} 9-14$ & SR90 & 1350 & & 600 & 11.1 & $\mathrm{PCL}$ \\
\hline HCO 9-19 & SR90 & 1850 & & 520 & 20.5 & PGL \\
\hline HCO 9.5 & TC99 & 450 & & -1.9 & 8.47 & $\mathrm{PCL}$ \\
\hline $\mathrm{HCO} 9-10$ & TC99 & 950 & & -3.44 & 8.75 & PCL \\
\hline $\mathrm{HCO} 9-15$ & TC99 & 1450 & & 0.156 & 7.31 & PCL \\
\hline $\mathrm{HCO} 9-20$ & TC99 & 1950 & & 2.9 & 7.04 & PCL \\
\hline
\end{tabular}

Notes: $J=L T$ reporting limit $\quad N R=$ Not Reported $U=L T$ detection limit $\quad \mathrm{C}=$ lab control sample not met $R=I C P$ interference check not met $V=$ lab blank contaminated $E=$ value between sample specific $E Q L$ and detection limit Accuracy Reported at $2 \delta$ 


\begin{tabular}{|c|c|c|c|c|c|c|}
\hline \multicolumn{7}{|c|}{ H-Area WTU Clearwell } \\
\hline \multicolumn{7}{|c|}{$\begin{array}{ll}\text { AG50W } \times 12 \text { Resin } \\
\end{array}$} \\
\hline & & & & & & \\
\hline Lab ID & Analyte & Avg Bedvol & Anal Qua & Anal Result & Accuracy & Result Units \\
\hline $\mathrm{HCO} 15-1$ & ALPHAG & 50 & C & 1.35 & 0.44 & $\mathrm{PCL}$ \\
\hline $\mathrm{HCO} 15-6$ & ALPHAG & 550 & C & 1.72 & 0.881 & $\mathrm{PCL}$ \\
\hline HCO 15-11 & ALPHAG & 1050 & & 2.21 & 1.46 & $\mathrm{PCL}$ \\
\hline $\mathrm{HCO} 15-16$ & ALPHAG & 1550 & C & 1.79 & 0.866 & $\mathrm{PCL}$ \\
\hline HCO $15-5$ & ALTOT & 450 & & 50 & NR & UGL \\
\hline HCO 15-10 & ALTOT & 950 & & 50 & NR & UGL \\
\hline $\mathrm{HCO} 15-15$ & ALTOT & 1450 & & 50 & NR & UGL. \\
\hline HCO 15-20 & ALTOT & 1950 & & 50 & NR & UGL \\
\hline HCO 15-1 & BETAG & 50 & V & 15.5 & 1.05 & $\mathrm{PCL}$ \\
\hline HCO 15-6 & BETAG & 550 & $\mathrm{~V}$ & 9.75 & 1.11 & $\mathrm{PCL}$ \\
\hline $\mathrm{HCO} 15-11$ & BETAG & 1050 & & 10.1 & 2.3 & PCL \\
\hline $\mathrm{HCO} 15-16$ & BETAG & 1550 & V & 11.8 & 1.09 & $\mathrm{PCL}$ \\
\hline $\mathrm{HCO} 15-3$ & $\mathrm{C}_{14}$ & 250 & & 5.22 & 13.5 & PCL \\
\hline $\mathrm{HCO} 15-4$ & $\mathrm{C14}$ & 350 & & 7.52 & 13.6 & $\mathrm{PCL}$ \\
\hline $\mathrm{HCO} 15-7$ & C14 & 650 & & 31.9 & 15.2 & PCL \\
\hline $\mathrm{HCO} 15-8$ & C14 & 750 & & 45.8 & 9.16 & $\mathrm{PCL}$ \\
\hline $\mathrm{HCO} 15-12$ & $\mathrm{C} 14$ & 1150 & & 66.3 & 17.4 & $\mathrm{PCL}$ \\
\hline $\mathrm{HCO} 15-13$ & $\mathrm{C} 14$ & 1250 & & 65.1 & 14.9 & $\mathrm{PCL}$ \\
\hline $\mathrm{HCO} 15-17$ & $\mathrm{C} 14$ & 1650 & C & 54.4 & 15.1 & $\mathrm{PCL}$ \\
\hline $\mathrm{HCO} 15-18$ & $\mathrm{C}_{14}$ & 1750 & C & 43 & 15.7 & $\mathrm{PCL}$ \\
\hline HCO 15-5 & FETOT & 450 & & 50 & $\mathrm{NR}$ & UGL \\
\hline $\mathrm{HCO} 15-10$ & FETOT & 950 & & 50 & NR & UGL \\
\hline $\mathrm{HCO} 15-15$ & FETOT & 1450 & & 50 & NR & UGL \\
\hline $\mathrm{HCO} 15-20$ & FETOT & 1950 & & 50 & NR & UGL \\
\hline $\mathrm{HCO} 15-3$ & 1129 & 250 & & 24.7 & 4.41 & $\mathrm{PCL}$ \\
\hline $\mathrm{HCO} 15-4$ & 1129 & 350 & & 34 & 5.99 & $\mathrm{PCL}$ \\
\hline $\mathrm{HCO} 15-7$ & 1129 & 650 & & 43.6 & 7.43 & $\mathrm{PCL}$ \\
\hline HCO 15-8 & 1129 & 750 & & 38.9 & 6.3 & $\mathrm{PCL}$ \\
\hline $\mathrm{HCO} 15-12$ & 1129 & 1150 & & 37.9 & 6.29 & $\mathrm{PCL}$ \\
\hline $\mathrm{HCO} 15-13$ & 1129 & 1250 & & 40.6 & 6.04 & $\mathrm{PCL}$ \\
\hline $\mathrm{HCO} 15-17$ & 1129 & 1650 & & 34.7 & 8.28 & $\mathrm{PCL}$ \\
\hline $\mathrm{HCO} 15-18$ & 1129 & 1750 & & 34.9 & 6.94 & PCL \\
\hline $\mathrm{HCO} 15-2$ & SR90 & 150 & & 0.033 & 0.944 & PCL \\
\hline HCO 15-9 & SR90 & 850 & C & -0.43 & 1.02 & $\mathrm{PCL}$ \\
\hline $\mathrm{HCO} 15-14$ & SR90 & 1350 & & 0.748 & 0.723 & $\mathrm{PCL}$ \\
\hline HCO 15-19 & SR90 & 1850 & C & 0.605 & 0.741 & $\mathrm{PCL}$ \\
\hline $\mathrm{HCO} 15-5$ & TC99 & 450 & & 113 & 17 & $\mathrm{PCL}$ \\
\hline HCO 15-10 & TC99 & 950 & & 102 & 16.2 & $\mathrm{PCL}$ \\
\hline $\mathrm{HCO} 15-15$ & TC99 & 1450 & & 117 & 17.3 & $\mathrm{PCL}$ \\
\hline $\mathrm{HCO} 15-20$ & TC99 & 1950 & & 96 & 15.1 & $\mathrm{PCL}$ \\
\hline
\end{tabular}

Notes: $J=L T$ reporting limit

NR $=$ Not Reported

$U=L T$ detection limit

$\mathrm{C}=$ lab control sample not met

$\mathrm{R}=\mathrm{ICP}$ interference check not met $\mathrm{V}=$ lab blank contaminated

$E=$ value between sample specific $E Q L$ and detection limit

Accuracy Reported at $2 \delta$

Page A29 of $\mathrm{A} 39$

WSRC-TR-99-00020, Rev. 0 


\begin{tabular}{|c|c|c|c|c|c|c|}
\hline \multicolumn{7}{|c|}{ H-Area WTU Clearwell } \\
\hline \\
\hline Lab ID & Analvte & Ava Bedvol & Anal Oual & Anal Result & Accuracy & Pooult Inito \\
\hline $\mathrm{HCO} 14-1$ & ALPHAG & 50 & & 0.851 & 0.449 & $\mathrm{PCL}$ \\
\hline $\mathrm{HCO} 14-6$ & ALPHAG & 550 & C & 1.65 & 0.801 & PCL \\
\hline $\mathrm{HCO} 14-11$ & ALPHAG & 1050 & & 1.13 & 1.58 & PCL \\
\hline HCO 14-16 & ALPHAG & 1550 & C & 0.839 & 0.63 & $\mathrm{PCL}$ \\
\hline $\mathrm{HCO} 14-5$ & ALTOT & 450 & & 50 & NR & UGL \\
\hline HCO 14-10 & ALTOT & 950 & & 50 & NR & UGL \\
\hline $\mathrm{HCO} 14-15$ & ALTOT & 1450 & & 50 & NR & UGL \\
\hline $\mathrm{HCO} 14-20$ & ALTOT & 1950 & & 50 & NR & UGL \\
\hline $\mathrm{HCO}$ 14-1 & BETAG & 50 & & 16.4 & 1.31 & PCL \\
\hline $\mathrm{HCO} 14-6$ & BETAG & 550 & $\mathrm{~V}$ & 8.12 & 1.02 & $\mathrm{PCL}$ \\
\hline $\mathrm{HCO} 14-11$ & BETAG & 1050 & & 10.7 & 2.41 & $\mathrm{PCL}$ \\
\hline $\mathrm{HCO} 14-16$ & BETAG & 1550 & $\underline{V}$ & 14.9 & 1.28 & $\mathrm{PCL}$ \\
\hline $\mathrm{HCO} 14-3$ & C14 & 250 & & -2.85 & 13.4 & $\mathrm{PCL}$ \\
\hline $\mathrm{HCO} 14-4$ & $\mathrm{C} 14$ & 350 & & 5.77 & 14.4 & $\mathrm{PCL}$ \\
\hline $\mathrm{HCO} 14-7$ & $\mathrm{C} 14$ & 650 & & 80.7 & 16.2 & $\mathrm{PCL}$ \\
\hline $\mathrm{HCO} 14-8$ & C14 & 750 & & 67.8 & 7.51 & $\mathrm{PCL}$ \\
\hline $\mathrm{HCO} 14-12$ & $\mathrm{C} 14$ & 1150 & & 66.7 & 15.6 & $\mathrm{PCL}$ \\
\hline $\mathrm{HCO} 14-13$ & $\mathrm{C}_{14}$ & 1250 & & 67.6 & 7.22 & $P C L$ \\
\hline $\mathrm{HCO} 14-17$ & $\mathrm{C}_{14}$ & 1650 & & 50.6 & 15 & $\mathrm{PCL}$ \\
\hline $\mathrm{HCO} 14-18$ & C14 & 1750 & & 72.6 & 18.6 & $\mathrm{PCL}$ \\
\hline $\mathrm{HCO} 14-5$ & FETOT & 450 & & 50 & NR & UGL \\
\hline $\mathrm{HCO} 14-10$ & FETOT & 950 & & 68.3 & NR & UGL \\
\hline $\mathrm{HCO} 14-15$ & FETOT & 1450 & & 50 & NR & UGL \\
\hline $\mathrm{HCO} 14-20$ & FETOT & 1950 & & 50 & NR & UGL \\
\hline $\mathrm{HCO} 14-3$ & 1129 & 250 & & 16.8 & 3.78 & $\mathrm{PCL}$ \\
\hline $\mathrm{HCO} 14-4$ & 1129 & 350 & & 31.4 & 5.31 & $\mathrm{PCL}$ \\
\hline HCO 14-7 & 1129 & 650 & $C$ & 37.3 & 7.76 & $\mathrm{PCL}$ \\
\hline $\mathrm{HCO} 14-8$ & 1129 & 750 & & 40 & 6.44 & PCL \\
\hline $\mathrm{HCO} 14-12$ & 1129 & 1150 & & 38 & 6.08 & PCL \\
\hline HCO 14-13 & 1129 & 1250 & & 35.5 & 5.38 & $\mathrm{PCL}$ \\
\hline $\mathrm{HCO} 14-17$ & 1129 & 1650 & & 36.8 & 6.37 & $\mathrm{PCL}$ \\
\hline HCO 14-18 & 1129 & 1750 & C & 38.7 & 7.79 & $\mathrm{PCL}$ \\
\hline $\mathrm{HCO} 14-2$ & SR90 & 150 & $\mathrm{C}$ & 1.78 & 0.928 & $\mathrm{PCL}$ \\
\hline $\mathrm{HCO} 14-9$ & SR90 & 850 & C & -0.398 & 0.657 & PCL \\
\hline HCO 14-14 & SR90 & 1350 & & 0.981 & 0.801 & $\mathrm{PCL}$ \\
\hline $\mathrm{HCO} 14-19$ & SR90 & 1850 & C & 333 & 8.28 & PCL \\
\hline $\mathrm{HCO} 14-5$ & TC99 & 450 & & 100 & 16.1 & $\mathrm{PCL}$ \\
\hline HCO 14-10 & TC99 & 950 & & 118 & 17.5 & $\mathrm{PCL}$ \\
\hline $\mathrm{HCO} 14-15$ & TC99 & 1450 & & 111 & 16.8 & $\mathrm{PCL}$ \\
\hline HCO 14-20 & TC99 & 1950 & & 90.9 & 15.2 & $\mathrm{PCL}$ \\
\hline
\end{tabular}

Notes: $J=L T$ reporting limit $\quad N R=$ Not Reported $\mathrm{U}=\mathrm{LT}$ detection limit $\quad \mathrm{C}=$ lab control sample not met

$R=I C P$ interference check not met $V=$ lab blank contaminated $E=$ value between sample specific $E Q L$ and detection limit Accuracy Reported at $2 \delta$ 


\begin{tabular}{|c|c|c|c|c|c|c|}
\hline \multicolumn{7}{|c|}{ H-Area WTU Clearwell } \\
\hline \multicolumn{7}{|c|}{\begin{tabular}{l|l} 
AGMP50 Resin \\
\end{tabular}} \\
\hline & & & & & & \\
\hline Lab ID & Analyte & Avg Bedvo & Anal Qual & Anal Result & Accuracy & Result Units \\
\hline HCO 5-1 & ALPHAG & 50 & & $\begin{array}{r}2.4 \\
\end{array}$ & 1.15 & $\mathrm{PCL}$ \\
\hline $\mathrm{HCO} 5-6$ & ALPHAG & 550 & & 1.08 & 0.657 & $\mathrm{PCL}$ \\
\hline $\mathrm{HCO} 5-11$ & ALPHAG & 1050 & & 2.4 & 1.47 & PCL \\
\hline $\mathrm{HCO} 5-16$ & ALPHAG & 1550 & & 1.2 & 0.799 & $\mathrm{PCL}$ \\
\hline $\mathrm{HCO} 5-5$ & ALTOT & 450 & & 50 & NR & UGL \\
\hline $\mathrm{HCO} 5-10$ & ALTOT & 950 & & 50 & NR & UGL \\
\hline $\mathrm{HCO}$ 5-15 & ALTOT & 1450 & & 50 & NR & UGL \\
\hline $\mathrm{HCO} 5-20$ & ALTOT & 1950 & & 50 & NR & UGL \\
\hline $\mathrm{HCO} 5-1$ & BETAG & 50 & & 19.4 & 2.74 & $\mathrm{PCL}$ \\
\hline $\mathrm{HCO} 5-6$ & BETAG & 550 & & 5.55 & 0.868 & PCL \\
\hline $\mathrm{HCO} 5-11$ & BETAG & 1050 & & 17.3 & 2.7 & PCL \\
\hline $\mathrm{HCO} 5-16$ & BETAG & 1550 & & 6.33 & 0.911 & $P C L$ \\
\hline $\mathrm{HCO} 5-3$ & C14 & 250 & & 57.8 & 15.1 & PCL \\
\hline $\mathrm{HCO} 5-4$ & C14 & 350 & & 55.6 & 15.2 & PCL \\
\hline $\mathrm{HCO} 5-7$ & $\mathrm{C14}$ & 650 & & 27.8 & 15 & $\mathrm{PCL}$ \\
\hline $\mathrm{HCO} 5-8$ & $\mathrm{C}_{14}$ & 750 & & 84.5 & 16.1 & $\mathrm{PCL}$ \\
\hline $\mathrm{HCO} 5-12$ & $\mathrm{C14}$ & 1150 & & 30.2 & 15.4 & $\mathrm{PCL}$ \\
\hline $\mathrm{HCO} 5-13$ & $\mathrm{C} 14$ & 1250 & & 72.5 & 17.5 & $\mathrm{PCL}$ \\
\hline $\mathrm{HCO} 5-17$ & $\mathrm{C} 14$ & 1650 & & 74.3 & 15.9 & $\mathrm{PCL}$ \\
\hline $\mathrm{HCO} 5-18$ & C14 & 1750 & C & 48.1 & 16.4 & $P C L$ \\
\hline HCO 5-5 & FETOT & 450 & $\mathbf{E}$ & 47.1 & NR & UGL \\
\hline $\mathrm{HCO} 5-10$ & FETOT & 950 & & 50 & NR & UGL \\
\hline $\mathrm{HCO} 5-15$ & FETOT & 1450 & & 50 & NR & UGL \\
\hline $\mathrm{HCO} 5-20$ & FETOT & 1950 & & 50 & NR & UGL \\
\hline $\mathrm{HCO} 5-3$ & 1129 & 250 & C & 33 & 7.11 & $\mathrm{PCL}$ \\
\hline $\mathrm{HCO} 5-4$ & 1129 & 350 & & 36.2 & 6.26 & $\mathrm{PCL}$ \\
\hline $\mathrm{HCO} 5-7$ & 1129 & 650 & & 36.4 & 6.81 & $\mathrm{PCL}$ \\
\hline $\mathrm{HCO} 5-8$ & 1129 & 750 & C & 39.9 & 7.44 & $\mathrm{PCL}$ \\
\hline $\mathrm{HCO} 5-12$ & 1129 & 1150 & & 31.8 & 6.6 & $\mathrm{PCL}$ \\
\hline $\mathrm{HCO} 5-13$ & 1129 & 1250 & & 35.1 & 5.51 & PCL \\
\hline $\mathrm{HCO} 5-17$ & 1129 & 1650 & & 39 & 5.84 & $\mathrm{PCL}$ \\
\hline $\mathrm{HCO} 5-18$ & 1129 & 1750 & & 34.2 & 7.29 & PCL \\
\hline $\mathrm{HCO} 5-2$ & SR90 & 150 & & 0.933 & 0.882 & $\mathrm{PCL}$ \\
\hline $\mathrm{HCO} 5-9$ & SR90 & 850 & & -0.122 & 1 & PCL \\
\hline $\mathrm{HCO} 5-14$ & SR90 & 1350 & & 0.33 & 0.742 & $\mathrm{PCL}$ \\
\hline $\mathrm{HCO} 5-19$ & SR90 & 1850 & & -0.00944 & 0.85 & PCL \\
\hline HCO 5-5 & TC99 & 450 & & 119 & 14.2 & $P C L$ \\
\hline $\mathrm{HCO} 5-10$ & TC99 & 950 & & 116 & 17.3 & PCL \\
\hline $\mathrm{HCO} 5-15$ & TC99 & 1450 & & 122 & 14.2 & $P C L$ \\
\hline HCO 5-20 & TC99 & 1950 & & 122 & 14.1 & $\mathrm{PCL}$ \\
\hline
\end{tabular}

Notes: $J=L T$ reporting limit NR $=$ Not Reported $U=L T$ detection limit $\mathrm{C}=$ lab control sample not met $R=I C P$ interference check not met $V=$ lab blank contaminated $E=$ value between sample specific $E Q L$ and detection limit Accuracy Reported at $2 \delta$ 


\begin{tabular}{|c|c|c|c|c|c|c|}
\hline \multicolumn{3}{|c|}{ H-Area WTU Clearwell } & & & & \\
\hline \multicolumn{2}{|c|}{ CG8 Resin } & & & & & \\
\hline & & & & & & \\
\hline Lab ID & Analyte & Avg Bedvol & Anal Qual & Anal Result & Accuracy & Result Units \\
\hline $\mathrm{HCO} 1-1$ & ALPHAG & $\begin{array}{r}50 \\
\end{array}$ & & -0.0117 & 1.23 & PCL \\
\hline $\mathrm{HCO} 1-6$ & ALPHAG & 550 & & 1.26 & 0.785 & $\mathrm{PCL}$ \\
\hline $\mathrm{HCO} 1-11$ & ALPHAG & 1050 & & 2.16 & 1.63 & PCL \\
\hline $\mathrm{HCO} 1-16$ & ALPHAG & 1550 & & 1.95 & 0.959 & $\mathrm{PCL}$ \\
\hline $\mathrm{HCO} 1-5$ & ALTOT & 450 & & 50 & NA & UGL \\
\hline $\mathrm{HCO} 1-10$ & ALTOT & 950 & & 50 & NR & UGL \\
\hline HCO 1-15 & ALTOT & 1450 & & 50 & NR & UGL \\
\hline $\mathrm{HCO} 1-20$ & ALTOT & 1950 & & 50 & NR & UGL \\
\hline $\mathrm{HCO} 1-1$ & BETAG & 50 & & 10.6 & 2.34 & PCL \\
\hline $\mathrm{HCO} 1-6$ & BETAG & 550 & & 14.7 & 1.27 & $\mathrm{PCL}$ \\
\hline $\mathrm{HCO} 1-11$ & BETAG & 1050 & & 11.6 & 2.38 & PCL \\
\hline $\mathrm{HCO} 1-16$ & BETAG & 1550 & & 13.1 & 1.2 & PCL \\
\hline $\mathrm{HCO} 1-3$ & C14 & 250 & C & 29.9 & 18.4 & PCL \\
\hline $\mathrm{HCO} 1-4$ & C14 & 350 & & 43.5 & 15.7 & PCL \\
\hline $\mathrm{HCO} 1-7$ & $\mathrm{C} 14$ & 650 & & 32.1 & 15.2 & $\mathrm{PCL}$ \\
\hline $\mathrm{HCO} 1-8$ & C14 & 750 & & 75.7 & 16.5 & $\mathrm{PCL}$ \\
\hline $\mathrm{HCO} 1-12$ & C14 & 1150 & & 59.7 & 16.6 & $\mathrm{PCL}$ \\
\hline $\mathrm{HCO} 1-13$ & C14 & 1250 & & 66.3 & 14.9 & PCL \\
\hline $\mathrm{HCO} 1-17$ & C14 & 1650 & & 61.3 & 16 & $\mathrm{PCL}$ \\
\hline $\mathrm{HCO} 1-18$ & C14 & 1750 & & 53.6 & 15.8 & $\mathrm{PCL}$ \\
\hline HCO 1-5 & FETOT & 450 & & 393 & NR & UGL \\
\hline $\mathrm{HCO} 1-10$ & FETOT & 950 & & 50 & NR & UGL \\
\hline $\mathrm{HCO} 1-15$ & FETOT & 1450 & & 50 & NR & UGL \\
\hline $\mathrm{HCO} 1-20$ & FETOT & 1950 & & 50 & $\mathrm{NR}$ & UGL \\
\hline $\mathrm{HCO} 1-3$ & 1129 & 250 & & 38.2 & 8.36 & $\mathrm{PCL}$ \\
\hline $\mathrm{HCO} 1-4$ & 1129 & 350 & & 39.5 & 6.38 & $\mathrm{PCL}$ \\
\hline $\mathrm{HCO} 1-7$ & 1129 & 650 & & 32.3 & 6.44 & PCL \\
\hline $\mathrm{HCO} 1-8$ & 1129 & 750 & C & 35.9 & 7.7 & $\mathrm{PCL}$ \\
\hline HCO 1-12 & 1129 & 1150 & & 35.4 & 6.61 & $\mathrm{PCL}$ \\
\hline $\mathrm{HCO} 1-13$ & 1129 & 1250 & C & 33.8 & 7.33 & $\mathrm{PCL}$ \\
\hline $\mathrm{HCO} 1-17$ & 1129 & 1650 & & 39.2 & 5.93 & $\mathrm{PCL}$ \\
\hline $\mathrm{HCO} 1-18$ & 1129 & 1750 & & 36.8 & 5.79 & PCL \\
\hline $\mathrm{HCO}$ 1-2 & SR90 & 150 & & 1.44 & 0.778 & $\mathrm{PCL}$ \\
\hline $\mathrm{HCO} 1-9$ & SR90 & 850 & & 0.383 & 0.928 & $P C L$ \\
\hline $\mathrm{HCO} 1-14$ & SR90 & 1350 & & 1.69 & 0.845 & $\mathrm{PCL}$ \\
\hline HCO 1-19 & SR90 & 1850 & & 0.0618 & 0.972 & $\mathrm{PCL}$ \\
\hline $\mathrm{HCO} 1-5$ & TC99 & 450 & & 119 & 14.3 & $P C L$ \\
\hline HCO 1-10 & TC99 & 950 & & 98 & 15.8 & $\mathrm{PCL}$ \\
\hline $\mathrm{HCO} 1-15$ & TC99 & 1450 & & 122 & 14 & $\mathrm{PCL}$ \\
\hline $\mathrm{HCO} 1-20$ & TC99 & 1950 & & 122 & 14.3 & $P C L$ \\
\hline
\end{tabular}

Notes: $\mathrm{J}=\mathrm{LT}$ reporting limit $U=L T$ detection limit $\mathrm{R}=\mathrm{ICP}$ interference $E=$ value between sample specific $E Q L$ and detection limit Accuracy Reported at $2 \delta$
NR $=$ Not Reported

$\mathrm{C}=$ lab control sample not met

$\mathrm{V}=$ lab blank contaminated

Page A32 of A39 


\begin{tabular}{|c|c|c|c|c|c|c|}
\hline \multicolumn{7}{|c|}{ H-Area WTU Clearwell } \\
\hline \multicolumn{7}{|c|}{ Chelex 20 Resin } \\
\hline & & & & & & \\
\hline Lab ID & Analyte & & Anal Qua & Anal Result & Accuracy & Result Units \\
\hline $\mathrm{HCO} 4-1$ & ALPHAG & 50 & C & -0.102 & 0.467 & $\mathrm{PCL}$ \\
\hline $\mathrm{HCO} 4-6$ & ALPHAG & 550 & c & 0.781 & 0.556 & $\mathrm{PCL}$ \\
\hline $\mathrm{HCO} 4-11$ & ALPHAG & 1050 & & 0.747 & 2.22 & $\mathrm{PCL}$ \\
\hline $\mathrm{HCO} 4-16$ & ALPHAG & 1550 & C. & 0.92 & 0.673 & $\mathrm{PCL}$ \\
\hline $\mathrm{HCO} 4-5$ & ALTOT & 450 & & 50 & NR & UGL \\
\hline $\mathrm{HCO} 4-10$ & ALTOT & 950 & & 50 & NR & UGL \\
\hline $\mathrm{HCO} 4-15$ & ALTOT & 1450 & & 50 & NR & UGL \\
\hline $\mathrm{HCO} 4-20$ & ALTOT & 1950 & & 50 & NR & UGL \\
\hline $\mathrm{HCO} 4-1$ & BETAG & 50 & $\mathrm{~V}$ & 11.6 & 0.953 & $\mathrm{PCL}$ \\
\hline $\mathrm{HCO} 4-6$ & BETAG & 550 & $\mathrm{~V}$ & 9.69 & 0.872 & PCL \\
\hline $\mathrm{HCO} 4-11$ & BETAG & 1050 & & 356 & 9.15 & $\mathrm{PCL}$ \\
\hline $\mathrm{HCO} 4-16$ & BETAG & 1550 & $\mathrm{~V}$ & 665 & 7.51 & $\mathrm{PCL}$ \\
\hline $\mathrm{HCO} 4-3$ & C14 & 250 & & 67.8 & 17.7 & $\mathrm{PCL}$ \\
\hline $\mathrm{HCO} 4-4$ & C14 & 350 & & 67.4 & 15.5 & $\mathrm{PCL}$ \\
\hline $\mathrm{HCO} 4-7$ & C14 & 650 & & 43.9 & 15.3 & $\mathrm{PCL}$ \\
\hline HCO 4-8 & C14 & 750 & & 53 & 8.83 & $\mathrm{PCL}$ \\
\hline $\mathrm{HCO} 4-12$ & $\mathrm{C14}$ & 1150 & & 54.9 & 15.2 & $\mathrm{PCL}$ \\
\hline $\mathrm{HCO} 4-13$ & C14 & 1250 & & 57.2 & 7.13 & $\mathrm{PCL}$ \\
\hline $\mathrm{HCO} 4-17$ & C14 & 1650 & & 56.8 & 17.2 & PCL \\
\hline $\mathrm{HCO} 4-18$ & C14 & 1750 & c & 46.9 & 14.8 & $\mathrm{PCL}$ \\
\hline $\mathrm{HCO} 4-5$ & FETOT & 450 & & 50 & NA & UGL \\
\hline $\mathrm{HCO} 4-10$ & FETOT & 950 & & 61.7 & NR & UGL \\
\hline $\mathrm{HCO} 4-15$ & FETOT & 1450 & & 50 & NR & UGL \\
\hline $\mathrm{HCO} 4-20$ & FETOT & 1950 & & 50 & NR & UGL \\
\hline $\mathrm{HCO} 4-3$ & 1129 & 250 & & 36.9 & 6.23 & $\mathrm{PCL}$ \\
\hline $\mathrm{HCO} 4-4$ & 1129 & 350 & & 35.5 & 5.42 & $\mathrm{PCL}$ \\
\hline $\mathrm{HCO} 4-7$ & 1129 & 650 & & 38.9 & 6.36 & $\mathrm{PCL}$ \\
\hline $\mathrm{HCO} 4-8$ & 1129 & 750 & & 32.2 & 6.01 & $\mathrm{PCL}$ \\
\hline $\mathrm{HCO}_{4-12}$ & 1129 & 1150 & & 34.4 & 5.22 & $\mathrm{PCL}$ \\
\hline $\mathrm{HCO} 4-13$ & 1129 & 1250 & & 36.7 & 6.07 & $\mathrm{PCL}$ \\
\hline $\mathrm{HCO}_{4-17}$ & 1129 & 1650 & & 30.9 & 5.26 & $\mathrm{PCL}$ \\
\hline $\mathrm{HCO}_{4-18}$ & 1129 & 1750 & & 37.1 & 6.93 & $\mathrm{PCL}$ \\
\hline $\mathrm{HCO} 4-2$ & SR90 & 150 & C & 400 & 11.6 & $\mathrm{PCL}$ \\
\hline $\mathrm{HCO} 4-9$ & SR90 & 850 & c & 55.1 & 4.18 & $P C L$ \\
\hline $\mathrm{HCO} 4-14$ & SR90 & 1350 & & 556 & 10.4 & $\mathrm{PCL}$ \\
\hline $\mathrm{HCO} 4-19$ & SR90 & 1850 & C & 589 & 12.2 & $\mathrm{PCL}$ \\
\hline $\mathrm{HCO} 4-5$ & TC99 & 450 & & 95.3 & 15.1 & $\mathrm{PCL}$ \\
\hline $\mathrm{HCO} 4-10$ & TC99 & 950 & & 95.6 & 15.9 & $\mathrm{PCL}$ \\
\hline $\mathrm{HCO} 4-15$ & TC99 & 1450 & & 101 & 16.2 & $\mathrm{PCL}$ \\
\hline $\mathrm{HCO} 4-2 \mathrm{O}$ & TC99 & 1950 & & 95.1 & 15.7 & $\mathrm{PCL}$ \\
\hline
\end{tabular}

Notes: $\mathrm{J}=\mathrm{LT}$ reporting limit

$U=L T$ detection limit

$R=I C P$ interference check not met $V=$ lab blank contaminated

$E=$ value between sample specific EQL and detection limit 


\begin{tabular}{|c|c|c|c|c|c|c|}
\hline \multicolumn{7}{|c|}{ H-Area WTU Clearwell } \\
\hline \multicolumn{7}{|c|}{ Dowex 21K Resin } \\
\hline Lab ID & Analyte & Avg Bedvol & Anal Qual & Anal Result & Accuracy & Result Units \\
\hline $\mathrm{HCO} 3-1$ & ALPHAG & 50 & & 6.59 & 1.7 & PCL \\
\hline $\mathrm{HCO} 3-6$ & ALPHAG & 550 & C & 0.914 & 1.79 & $P C L$ \\
\hline $\mathrm{HCO} 3-11$ & ALPHAG & 1050 & & 2.89 & 1.72 & $\mathrm{PCL}$ \\
\hline $\mathrm{HCO} 3-16$ & ALPHAG & 1550 & C & 2.76 & 1.04 & $\mathrm{PCL}$ \\
\hline $\mathrm{HCO} 3-5$ & ALTOT & 450 & & 50 & NR & UGL \\
\hline $\mathrm{HCO} 3-15$ & ALTOT & 1450 & & 50 & NR & UGL \\
\hline $\mathrm{HCO} 3-20$ & ALTOT & 1950 & & 50 & NR & UGL \\
\hline $\mathrm{HCO} 3-1$ & BETAG & 50 & & 386 & 5.97 & $\mathrm{PCL}$ \\
\hline $\mathrm{HCO} 3-6$ & BETAG & 550 & V & 725 & 8.18 & $\mathrm{PCL}$ \\
\hline $\mathrm{HCO} 3-11$ & BETAG & 1050 & & 348 & 5.51 & $\mathrm{PCL}$ \\
\hline $\mathrm{HCO} 3-16$ & BETAG & 1550 & $\mathrm{~V}$ & 953 & 8.99 & $\mathrm{PCL}$ \\
\hline $\mathrm{HCO} 3-3$ & C14 & 250 & & 56.3 & 16.6 & $\mathrm{PCL}$ \\
\hline $\mathrm{HCO} 3-4$ & C14 & 350 & & 56.4 & 17.1 & $P C L$ \\
\hline $\mathrm{HCO} 3-7$ & C14 & 650 & C & 48 & 16.2 & $\mathrm{PCL}$ \\
\hline $\mathrm{HCO} 3-8$ & C14 & 750 & & 66.2 & 7.16 & $\mathrm{PCL}$ \\
\hline $\mathrm{HCO} 3.12$ & $\mathrm{C}_{14}$ & 1150 & & 6.57 & 13.2 & $P C L$ \\
\hline $\mathrm{HCO} 3-13$ & C14 & 1250 & & 60.6 & 7.16 & $P C L$ \\
\hline $\mathrm{HCO} 3-17$ & C14 & 1650 & C & 45.4 & 16.6 & $\mathrm{PCL}$ \\
\hline $\mathrm{HCO} 3-18$ & C14 & 1750 & & 58.5 & 15.6 & $P C L$ \\
\hline $\mathrm{HCO} 3-5$ & FETOT & 450 & & 50 & $\mathrm{NR}$ & UGL \\
\hline $\mathrm{HCO} 3-15$ & FETOT & 1450 & & 50 & $N R$ & UGL \\
\hline $\mathrm{HCO} 3-20$ & FETOT & 1950 & $E$ & 48.9 & NR & UGL \\
\hline $\mathrm{HCO} 3-3$ & 1129 & 250 & & 11.2 & 2.69 & $\mathrm{PCL}$ \\
\hline $\mathrm{HCO} 3-4$ & 1129 & 350 & & 11.6 & 3.28 & $\mathrm{PCL}$ \\
\hline $\mathrm{HCO} 3-7$ & 1129 & 650 & & 12.4 & 4.22 & $\mathrm{PCL}$ \\
\hline $\mathrm{HCO} 3-8$ & 1129 & 750 & & 13 & 2.89 & $\mathrm{PCL}$ \\
\hline $\mathrm{HCO} 3-12$ & 1129 & 1150 & & 15.3 & 3.72 & $\mathrm{PCL}$ \\
\hline $\mathrm{HCO} 3-13$ & 1129 & 1250 & & 26.1 & 4.43 & $\mathrm{PCL}$ \\
\hline $\mathrm{HCO} 3-17$ & 1129 & 1650 & & 36.2 & 7.08 & $\mathrm{PCL}$ \\
\hline $\mathrm{HCO} 3-18$ & 1129 & 1750 & & 27.1 & 5.02 & $P C L$ \\
\hline $\mathrm{HCO} 3-2$ & SR90 & 150 & C & -1.25 & 1.36 & PCL \\
\hline $\mathrm{HCO} 3-9$ & SR90 & 850 & C & 554 & 13.3 & $\mathrm{PCL}$ \\
\hline $\mathrm{HCO} 3-14$ & SR90 & 1350 & & 608 & 11.7 & $\mathrm{PCL}$ \\
\hline $\mathrm{HCO} 3-19$ & SR90 & 1850 & C & 0.149 & 0.583 & $\mathrm{PCL}$ \\
\hline $\mathrm{HCO} 3-5$ & TC99 & 450 & & -5.19 & 8.35 & $\mathrm{PCL}$ \\
\hline $\mathrm{HCO} 3-15$ & TC99 & 1450 & & -6.15 & 8.33 & $P C L$ \\
\hline $\mathrm{HCO} 3-20$ & TC99 & 1950 & & 0.422 & 8.98 & $\mathrm{PCL}$ \\
\hline
\end{tabular}

Notes: $J=L T$ reporting limit $U=L T$ detection limit $\mathrm{R}=\mathrm{ICP}$ interference $E=$ value between sample specific $E Q L$ and detection limit Accuracy Reported at $2 \delta$ 


\begin{tabular}{|c|c|c|c|c|c|c|}
\hline \multicolumn{7}{|c|}{ H-Area WTU Clearwell } \\
\hline \multicolumn{7}{|c|}{\begin{tabular}{|l|l} 
Iron Powder & \\
\end{tabular}} \\
\hline Lab ID & Analyte & Avg Bedvol & Anal Qual & Anal Result & Accuracy & Result Units \\
\hline HCO 11-1 & ALPHAG & \begin{tabular}{|r|}
50 \\
\end{tabular} & & 2.13 & 1.98 & $\mathrm{PCL}$ \\
\hline HCO 11-4 & ALTOT & 350 & & 50 & $\mathrm{NR}$ & UGL \\
\hline $\mathrm{HCO} 11-1$ & BETAG & 50 & & 565 & 10.1 & PCL \\
\hline HCO 11-4 & FETOT & 350 & & 50 & $\mathrm{NR}$ & UGL \\
\hline HCO 11-3 & SR90 & 250 & & 622 & 11.1 & PCL \\
\hline $\mathrm{HCO} 11-4$ & TC99 & 350 & & 13.1 & 8.17 & $\mathrm{PCL}$ \\
\hline
\end{tabular}

Notes: $\mathrm{J}=\mathrm{LT}$ reporting limit $U=L T$ detection limit $R=I C P$ interference check not met $E=$ value between sample specific $E Q L$ and detection limit Accuracy Reported at $2 \delta$
NR $=$ Not Reported

$\mathrm{C}=$ lab control sample not met

$\mathrm{V}=$ lab blank contaminated

Page A35 of A39 


\begin{tabular}{|c|c|c|c|c|c|c|}
\hline \multicolumn{7}{|c|}{ H-Area WTU Clearwell } \\
\hline \multicolumn{7}{|c|}{ Monosodium Titanate } \\
\hline Lab ID & Analyte & Avg Bedvol & Anal Qual & Anal Result & Accuracy & Result Units \\
\hline $\mathrm{HCO} 13-1$ & ALPHAG & 50 & C & -0.00304 & 0.469 & $\mathrm{PCL}$ \\
\hline $\mathrm{HCO} 13-6$ & ALPHAG & 550 & C & 2.43 & 0.85 & $\mathrm{PCL}$ \\
\hline $\mathrm{HCO} 13-11$ & ALPHAG & 1050 & & 1.24 & 1.71 & PCL \\
\hline HCO 13-16 & ALPHAG & 1550 & C & 2.53 & 1.13 & $\mathrm{PCL}$ \\
\hline $\mathrm{HCO} 13-5$ & ALTOT & 450 & & 50 & $\mathrm{NR}$ & UGL \\
\hline $\mathrm{HCO} 13-10$ & ALTOT & 950 & & 50 & NR & UGL \\
\hline $\mathrm{HCO} 13-15$ & ALTOT & 1450 & & 50 & NR & UGL \\
\hline $\mathrm{HCO} 13-20$ & ALTOT & 1950 & & 50 & $\mathrm{NR}$ & UGL \\
\hline $\mathrm{HCO} 13-1$ & BETAG & 50 & $\mathrm{v}$ & 10.1 & 0.938 & $\mathrm{PCL}$ \\
\hline $\mathrm{HCO} 13-6$ & BETAG & 550 & $\underline{v}$ & 567 & 5.74 & $P C L$ \\
\hline $\mathrm{HCO} 13-11$ & BETAG & 1050 & & 474 & 10.5 & $\mathrm{PCL}$ \\
\hline $\mathrm{HCO} 13-16$ & BETAG & 1550 & v & 302 & 5.1 & $\mathrm{PCL}$ \\
\hline HCO 13-3 & C14 & 250 & & 62.2 & 15.7 & $\mathrm{PCL}$ \\
\hline $\mathrm{HCO} 13-4$ & C14 & 350 & & 57.6 & 15.4 & PCL \\
\hline $\mathrm{HCO} 13-7$ & $\mathrm{C} 14$ & 650 & & 26 & 16.5 & $\mathrm{PCL}$ \\
\hline $\mathrm{HCO} 13-8$ & C14 & 750 & & 68 & 15.6 & $\mathrm{PCL}$ \\
\hline $\mathrm{HCO} 13-12$ & C14 & 1150 & & 51.9 & 17.2 & PCL \\
\hline $\mathrm{HCO} 13-13$ & $\mathrm{C}_{14}$ & 1250 & & 52 & 18 & PCL \\
\hline $\mathrm{HCO} 13-17$ & $\mathrm{C}_{14}$ & 1650 & & 48.4 & 15.2 & $\mathrm{PCL}$ \\
\hline $\mathrm{HCO} 13-18$ & C14 & 1750 & & 65.5 & 15.7 & $\mathrm{PCL}$ \\
\hline $\mathrm{HCO} 13-5$ & FETOT & 450 & & 50 & NR & UGL \\
\hline $\mathrm{HCO} 13-10$ & FETOT & 950 & & 50 & NR & UGL \\
\hline $\mathrm{HCO} 13-15$ & FETOT & 1450 & & 50 & NR & UGL \\
\hline $\mathrm{HCO} 13-20$ & FETOT & 1950 & & 94.9 & NR & UGL \\
\hline $\mathrm{HCO} 13-3$ & 1129 & 250 & & 35.7 & 5.72 & PCL \\
\hline $\mathrm{HCO} 13-4$ & 1129 & 350 & & 26.4 & 5.05 & $\mathrm{PCL}$ \\
\hline $\mathrm{HCO} 13-7$ & 1129 & 650 & & 36.5 & 6.83 & $\mathrm{PCL}$ \\
\hline HCO 13-8 & 1129 & 750 & & 32.3 & 5.41 & $\mathrm{PCL}$ \\
\hline $\mathrm{HCO} 13-12$ & 1129 & 1150 & & 34.6 & 5.81 & $P C L$ \\
\hline $\mathrm{HCO} 13-13$ & 1129 & 1250 & & 32.7 & 6.16 & PCL \\
\hline $\mathrm{HCO} 13-17$ & 1129 & 1650 & & 31.3 & 5.21 & $\mathrm{PCL}$ \\
\hline $\mathrm{HCO} 13-18$ & 1129 & 1750 & C & 37.3 & 7.39 & $\mathrm{PCL}$ \\
\hline $\mathrm{HCO} 13-2$ & SR90 & 150 & C & 1.78 & 1.02 & $\mathrm{PCL}$ \\
\hline $\mathrm{HCO} 13-9$ & SR90 & 850 & & 470 & 10.3 & $\mathrm{PCL}$ \\
\hline $\mathrm{HCO} 13-14$ & SR90 & 1350 & & 426 & 9.74 & $\mathrm{PCL}$ \\
\hline HCO 13-19 & SR90 & 1850 & C & 536 & 12.1 & PCL \\
\hline $\mathrm{HCO} 13-5$ & TC99 & 450 & & 95.3 & 15.6 & $\mathrm{PCL}$ \\
\hline $\mathrm{HCO} 13-10$ & TC99 & 950 & & 122 & 16.7 & $\mathrm{PCL}$ \\
\hline $\mathrm{HCO} 13-15$ & TC99 & 1450 & & 102 & 16.1 & $P C L$ \\
\hline $\mathrm{HCO} 13-20$ & TC99 & 1950 & & 113 & 16.6 & PCL \\
\hline
\end{tabular}

Notes: $J=L T$ reporting limit $U=L T$ detection limit NR $=$ Not Reported $R=I C P$ interference check not met $V=$ lab blank contaminated $E=$ value between sample specific $E Q L$ and detection limit Accuracy Reported at $2 \delta$ 


\begin{tabular}{|c|c|c|c|c|c|c|}
\hline \multicolumn{7}{|c|}{ H-Area WTU Clearwell } \\
\hline \multicolumn{7}{|c|}{ Reillex HQL Resin } \\
\hline Lab ID & Analyte & Avg Bedvol & Anal Qual & Anal Result & Accuracy & Result Units \\
\hline $\mathrm{HCO} 10-1$ & ALPHAG & 50 & & \begin{tabular}{|r|}
5.15 \\
\end{tabular} & 3 & $\mathrm{PCL}$ \\
\hline $\mathrm{HCO} 10-6$ & ALPHAG & 550 & & 1.07 & 1.51 & $\mathrm{PCL}$ \\
\hline HCO 10-11 & ALPHAG & 1050 & & 4.4 & 2.33 & $\mathrm{PCL}$ \\
\hline $\mathrm{HCO} 10-16$ & ALPHAG & 1550 & & 2.35 & 0.904 & $\mathrm{PCL}$ \\
\hline HCO 10-10 & ALTOT & 950 & & 50 & NR & UGL \\
\hline $\mathrm{HCO} 10-15$ & ALTOT & 1450 & & 50 & NR & UGL \\
\hline $\mathrm{HCO}$ 10-20 & ALTOT & 1950 & & 50 & NR & UGL \\
\hline $\mathrm{HCO} 10-1$ & BETAG & 50 & & 577 & 11.6 & $P C L$ \\
\hline HCO 10-6 & BETAG & 550 & & 385 & 5.88 & $\mathrm{PCL}$ \\
\hline HCO 10-11 & BETAG & 1050 & & 497 & 10.8 & $\mathrm{PCL}$ \\
\hline $\mathrm{HCO} 10-16$ & BETAG & 1550 & & 305 & 5.11 & $\mathrm{PCL}$ \\
\hline $\mathrm{HCO} 10-3$ & C14 & 250 & $\underline{\mathrm{C}}$ & 45.3 & 16 & $\mathrm{PCL}$ \\
\hline $\mathrm{HCO} 10.4$ & C14 & 350 & & 61.8 & 15.5 & $\mathrm{PCL}$ \\
\hline HCO 10-7 & C14 & 650 & C & 61.5 & 15.5 & $\mathrm{PCL}$ \\
\hline $\mathrm{HCO} 10-8$ & C14 & 750 & & 87.2 & 16.3 & $\mathrm{PCL}$ \\
\hline $\mathrm{HCO} 10-12$ & C14 & 1150 & & 76.2 & 15.8 & $\mathrm{PCL}$ \\
\hline HCO 10-13 & C14 & 1250 & C & 41.7 & 15.5 & $\mathrm{PCL}$ \\
\hline $\mathrm{HCO} 10-17$ & C14 & 1650 & & 53 & 15.8 & $\mathrm{PCL}$ \\
\hline $\mathrm{HCO} 10-18$ & C14 & 1750 & & 38.8 & 14.8 & $\mathrm{PCL}$ \\
\hline $\mathrm{HCO} 10-10$ & FETOT & 950 & & 50 & $\mathrm{NR}$ & UGL \\
\hline HCO 10-15 & FETOT & 1450 & & 50 & NR & UGL \\
\hline $\mathrm{HCO} 10-20$ & FETOT & 1950 & & 50 & $\mathrm{NR}$ & UGL \\
\hline $\mathrm{HCO} 10-3$ & 1129 & 250 & & 11.5 & 2.91 & $\mathrm{PCL}$ \\
\hline HCO 10-4 & 1129 & 350 & & 13.1 & 2.89 & $\mathrm{PCL}$ \\
\hline $\mathrm{HCO} 10-7$ & 1129 & 650 & & 9.3 & 3.5 & $\mathrm{PCL}$ \\
\hline $\mathrm{HCO} 10-8$ & 1129 & 750 & C & 10.9 & 3.88 & $\mathrm{PCL}$ \\
\hline $\mathrm{HCO} 10-12$ & 1129 & 1150 & C & 10.4 & 2.94 & $\mathrm{PCL}$ \\
\hline $\mathrm{HCO} 10-13$ & 1129 & 1250 & & 12.4 & 3.98 & $\mathrm{PCL}$ \\
\hline $\mathrm{HCO} 10-17$ & 1129 & 1650 & & 16.7 & 3.27 & $\mathrm{PCL}$ \\
\hline HCO 10-18 & 1129 & 1750 & & 19 & 4.99 & $\mathrm{PCL}$ \\
\hline $\mathrm{HCO} 10-2$ & SR90 & 150 & & 522 & 11.4 & $\mathrm{PCL}$ \\
\hline $\mathrm{HCO} 10-9$ & SR90 & 850 & & 605 & 12.5 & $\mathrm{PCL}$ \\
\hline $\mathrm{HCO} 10-14$ & SR90 & 1350 & & 457 & 9.58 & $\mathrm{PCL}$ \\
\hline HCO 10-19 & SR90 & 1850 & & 687 & 14.1 & $\mathrm{PCL}$ \\
\hline $\mathrm{HCO} 10-10$ & TC99 & 950 & & -5.46 & 8.73 & $\mathrm{PCL}$ \\
\hline $\mathrm{HCO} 10-15$ & TC99 & 1450 & & -3.07 & 6.41 & $\mathrm{PCL}$ \\
\hline HCO 10-20 & TC99 & 1950 & & 4.63 & 7.64 & $\mathrm{PCL}$ \\
\hline
\end{tabular}

Notes: $J=L T$ reporting limit $\quad N R=$ Not Reported $U=L T$ detection limit $\quad \mathrm{C}=$ lab control sample not met $R=I C P$ interference check not met $V=$ lab blank contaminated $E=$ value between sample specific EQL and detection limit Accuracy Reported at $2 \delta$ 


\begin{tabular}{|c|c|c|c|c|c|c|}
\hline \multicolumn{7}{|c|}{ H-Area WTU Clearwell } \\
\hline \multicolumn{7}{|c|}{ SIR600 Zeolite } \\
\hline & & & & & & \\
\hline Lab ID & Analyte & Avg Bedvol & Anal Qual & Anal Result & Accuracy & Result Units \\
\hline $\mathrm{HCO} 7-1$ & ALPHAG & 50 & & 1.42 & 1.24 & $\mathrm{PCL}$ \\
\hline $\mathrm{HCO} 7-6$ & ALPHAG & 550 & & 0.694 & 1.18 & $P C L$ \\
\hline $\mathrm{HCO} 7-11$ & ALPHAG & 1050 & & 1.62 & 2.26 & $\mathrm{PCL}$ \\
\hline $\mathrm{HCO} 7-16$ & ALPHAG & 1550 & & 1.46 & 0.763 & $\mathrm{PCL}$ \\
\hline $\mathrm{HCO} 7-5$ & ALTOT & 450 & & 50 & NR & UGL \\
\hline $\mathrm{HCO} 7-10$ & ALTOT & 950 & & 50 & NR & UGL \\
\hline $\mathrm{HCO} 7-15$ & ALTOT & 1450 & & 50 & NR & UGL \\
\hline $\mathrm{HCO} 7-20$ & ALTOT & 1950 & & 50 & NR & UGL \\
\hline $\mathrm{HCO} 7-1$ & BETAG & 50 & & 13.4 & 2.52 & $\mathrm{PCL}$ \\
\hline $\mathrm{HCO} 7-6$ & BETAG & 550 & & 13.5 & 2.74 & $\mathrm{PCL}$ \\
\hline $\mathrm{HCO} 7-11$ & BETAG & 1050 & & 33.9 & 3.42 & $\mathrm{PCL}$ \\
\hline $\mathrm{HCO} 7-16$ & BETAG & 1550 & & 41.3 & 1.94 & $\mathrm{PCL}$ \\
\hline $\mathrm{HCO} 7-3$ & C14 & 250 & & 78.6 & 15.8 & PCL \\
\hline $\mathrm{HCO} 7.4$ & C14 & 350 & & 53.5 & 15.7 & $\mathrm{PCL}$ \\
\hline $\mathrm{HCO} 7-7$ & $\mathrm{C} 14$ & 650 & & 80 & 15.6 & $\mathrm{PCL}$ \\
\hline $\mathrm{HCO} 7-8$ & $\mathrm{C} 14$ & 750 & C & 47.3 & 15 & $P C L$ \\
\hline $\mathrm{HCO} 7-12$ & $\mathrm{C} 14$ & 1150 & C & 46.8 & 15.6 & $\mathrm{PCL}$ \\
\hline $\mathrm{HCO} 7-13$ & C14 & 1250 & & 77 & 15.9 & $\mathrm{PCL}$ \\
\hline $\mathrm{HCO} 7-17$ & C14 & 1650 & $C$ & 34.7 & 14.4 & PCL \\
\hline $\mathrm{HCO} 7-18$ & $\mathrm{C} 14$ & 1750 & & 21.1 & 14.7 & $\mathrm{PCL}$ \\
\hline $\mathrm{HCO} 7-5$ & FETOT & 450 & & 130 & $\mathrm{NR}$ & UGL \\
\hline $\mathrm{HCO} 7-10$ & FETOT & 950 & & 50 & NR & UGL \\
\hline $\mathrm{HCO} 7-15$ & FETOT & 1450 & & 50 & NR & UGL \\
\hline $\mathrm{HCO} 7-20$ & FETOT & 1950 & & 50 & NR & UGL \\
\hline $\mathrm{HCO} 7.3$ & 1129 & 250 & C & 33.6 & 7.55 & $P C L$ \\
\hline $\mathrm{HCO} 7-4$ & 1129 & 350 & & 38.3 & 6.43 & $\mathrm{PCL}$ \\
\hline $\mathrm{HCO} 7-7$ & 1129 & 650 & C & 36.1 & 6.36 & PCL \\
\hline $\mathrm{HCO} 7-8$ & 1129 & 750 & & 36.1 & 7 & PCL \\
\hline $\mathrm{HCO} 7-12$ & 1129 & 1150 & & 38 & 6.86 & $P C L$ \\
\hline $\mathrm{HCO} 7-13$ & 1129 & 1250 & C & 28.9 & 5.69 & PCL \\
\hline $\mathrm{HCO} 7-17$ & 1129 & 1650 & & 28.9 & 5.72 & $\mathrm{PCL}$ \\
\hline $\mathrm{HCO} 7-18$ & 1129 & 1750 & & 45.8 & 9.95 & PCL \\
\hline $\mathrm{HCO} 7-2$ & SR90 & 150 & & 1.57 & 0.847 & $\mathrm{PCL}$ \\
\hline $\mathrm{HCO} 7-9$ & SR90 & 850 & & 6.05 & 1.49 & $\mathrm{PCL}$ \\
\hline $\mathrm{HCO} 7-14$ & SR90 & 1350 & & 32.1 & 2.86 & $\mathrm{PCL}$ \\
\hline $\mathrm{HCO} 7-19$ & SR90 & 1850 & & 46.6 & 3.58 & PCL \\
\hline HCO 7-5 & TC99 & 450 & & 115 & 14.6 & PCL \\
\hline $\mathrm{HCO} 7-10$ & TC99 & 950 & & 120 & 17.4 & $\mathrm{PCL}$ \\
\hline $\mathrm{HCO} 7-15$ & TC99 & 1450 & & 111 & 14.1 & $\mathrm{PCL}$ \\
\hline $\mathrm{HCO} 7-20$ & TC99 & 1950 & & 138 & 15.3 & $\mathrm{PCL}$ \\
\hline
\end{tabular}

Notes: $\mathrm{J}=\mathrm{LT}$ reporting limit $\begin{array}{ll}\mathrm{U}=\mathrm{LT} \text { detection limit } & \mathrm{C}=\text { lab control sample not met } \\ \mathrm{R}=\mathrm{ICP} \text { interference check not met } & \mathrm{V}=\text { lab blank contaminated }\end{array}$ $E=$ value between sample specific $E Q L$ and detection limit Accuracy Reported at $2 \delta$ 


\begin{tabular}{|c|c|c|c|c|c|c|}
\hline \multicolumn{7}{|c|}{ H-Area WTU Clearwell } \\
\hline \multicolumn{7}{|c|}{ SR-Treat Resin } \\
\hline & & & & & & \\
\hline Lab ID & Analyte & Avg Bedvol & Anal Qual & Anal Resuit & Accuracy & Result Units \\
\hline $\mathrm{HCO} 2-1$ & ALPHAG & 50 & & 0.731 & 0.671 & $\mathrm{PCL}$ \\
\hline $\mathrm{HCO} 2-6$ & ALPHAG & 550 & C & 0.329 & 0.679 & $P C L$ \\
\hline $\mathrm{HCO} 2-11$ & ALPHAG & 1050 & & 0.605 & 1.35 & $\mathrm{PCL}$ \\
\hline $\mathrm{HCO} 2-16$ & ALPHAG & 1550 & & 0.796 & 0.625 & $\mathrm{PCL}$ \\
\hline $\mathrm{HCO} 2-5$ & ALTOT & 450 & & 50 & NR & UGL \\
\hline $\mathrm{HCO} 2-10$ & ALTOT & 950 & & 50 & NR & UGL \\
\hline $\mathrm{HCO} 2-15$ & ALTOT & 1450 & & 50 & NR & UGL \\
\hline $\mathrm{HCO} 2-20$ & ALTOT & 1950 & & 50 & NR & UGL \\
\hline $\mathrm{HCO} 2-1$ & BETAG & 50 & & 7.07 & 0.977 & $\mathrm{PCL}$ \\
\hline $\mathrm{HCO} 2-6$ & BETAG & 550 & $\underline{V}$ & 4.04 & 0.711 & $\mathrm{PCL}$ \\
\hline $\mathrm{HCO} 2-11$ & BETAG & 1050 & & 5.75 & 2.15 & $\mathrm{PCL}$ \\
\hline $\mathrm{HCO} 2-16$ & BETAG & 1550 & & 6.83 & 1.28 & $\mathrm{PCL}$ \\
\hline $\mathrm{HCO} 2-3$ & C14 & 250 & & 90.7 & 16.2 & $\mathrm{PCL}$ \\
\hline $\mathrm{HCO} 2-4$ & $\mathrm{C} 14$ & 350 & & 65.7 & 15.8 & $\mathrm{PCL}$ \\
\hline $\mathrm{HCO} 2-7$ & C14 & 650 & & 62.5 & 15.9 & $\mathrm{PCL}$ \\
\hline $\mathrm{HCO} 2-8$ & C14 & 750 & & 74.2 & 7.5 & $\mathrm{PCL}$ \\
\hline $\mathrm{HCO} 2-12$ & C14 & 1150 & & 77.6 & 18.9 & $\mathrm{PCL}$ \\
\hline $\mathrm{HCO} 2-13$ & $\mathrm{C}_{14}$ & 1250 & & 76.4 & 15.5 & $\mathrm{PCL}$ \\
\hline $\mathrm{HCO} 2-17$ & $\mathrm{C} 14$ & 1650 & C & 40.2 & 15.2 & $\mathrm{PCL}$ \\
\hline $\mathrm{HCO} 2-18$ & C14 & 1750 & & 58.9 & 15.8 & $\mathrm{PCL}$ \\
\hline $\mathrm{HCO} 2.5$ & FETOT & 450 & & 92.6 & NR & UGL \\
\hline $\mathrm{HCO} 2-10$ & FETOT & 950 & & 129 & $\mathrm{NR}$ & UGL \\
\hline $\mathrm{HCO} 2-15$ & FETOT & 1450 & & 50 & NR & UGL \\
\hline $\mathrm{HCO} 2-20$ & FETOT & 1950 & & 73 & $\mathrm{NR}$ & UGL \\
\hline $\mathrm{HCO} 2-3$ & 1129 & 250 & & 37.3 & 6.5 & PCL \\
\hline $\mathrm{HCO} 2.4$ & 1129 & 350 & & 35.5 & 5.11 & $\mathrm{PCL}$ \\
\hline $\mathrm{HCO} 2-7$ & 1129 & 650 & & 31.1 & 6.27 & $\mathrm{PCL}$ \\
\hline $\mathrm{HCO} 2-8$ & 1129 & 750 & & 32.9 & 5.36 & PCL \\
\hline $\mathrm{HCO} 2-12$ & 1129 & 1150 & & 33.7 & 6.11 & $\mathrm{PCL}$ \\
\hline $\mathrm{HCO} 2-13$ & 1129 & 1250 & & 44.5 & 6.84 & $\mathrm{PCL}$ \\
\hline $\mathrm{HCO} 2-17$ & 1129 & 1650 & & 32.3 & 5.91 & PCL \\
\hline $\mathrm{HCO} 2-18$ & 1129 & 1750 & & 35.2 & 5.66 & PCL \\
\hline $\mathrm{HCO} 2-2$ & SR90 & 150 & C & 59.2 & 3.49 & $P C L$ \\
\hline $\mathrm{HCO} 2-9$ & SR90 & 850 & & 0.202 & 0.739 & $\mathrm{PCL}$ \\
\hline $\mathrm{HCO} 2-14$ & SR90 & 1350 & & 1.09 & 0.751 & PCL \\
\hline $\mathrm{HCO} 2-19$ & SR90 & 1850 & C & 2.8 & 1.02 & $\mathrm{PCL}$ \\
\hline $\mathrm{HCO} 2-5$ & TC99 & 450 & & 106 & 16.5 & $\mathrm{PCL}$ \\
\hline $\mathrm{HCO} 2-10$ & TC99 & 950 & & 109 & 16.8 & PCL \\
\hline $\mathrm{HCO} 2-15$ & TC99 & 1450 & & 104 & 16.5 & PCL \\
\hline $\mathrm{HCO} 2-20$ & TC99 & 1950 & & 115 & 17 & $\mathrm{PCL}$ \\
\hline
\end{tabular}

Notes: $J=L T$ reporting limit

NR $=$ Not Reported

$U=L T$ detection limit

$\mathrm{C}=$ lab control sample not met

$\mathrm{R}=\mathrm{ICP}$ interference check not met $\mathrm{V}=\mathrm{lab}$ blank contaminated

$E=$ value between sample specific $E Q L$ and detection limit

Accuracy Reported at $2 \delta$

Page A39 of A39

WSRC-TR-99-00020, Rev. 0 


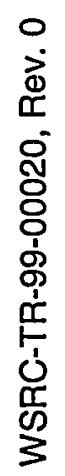

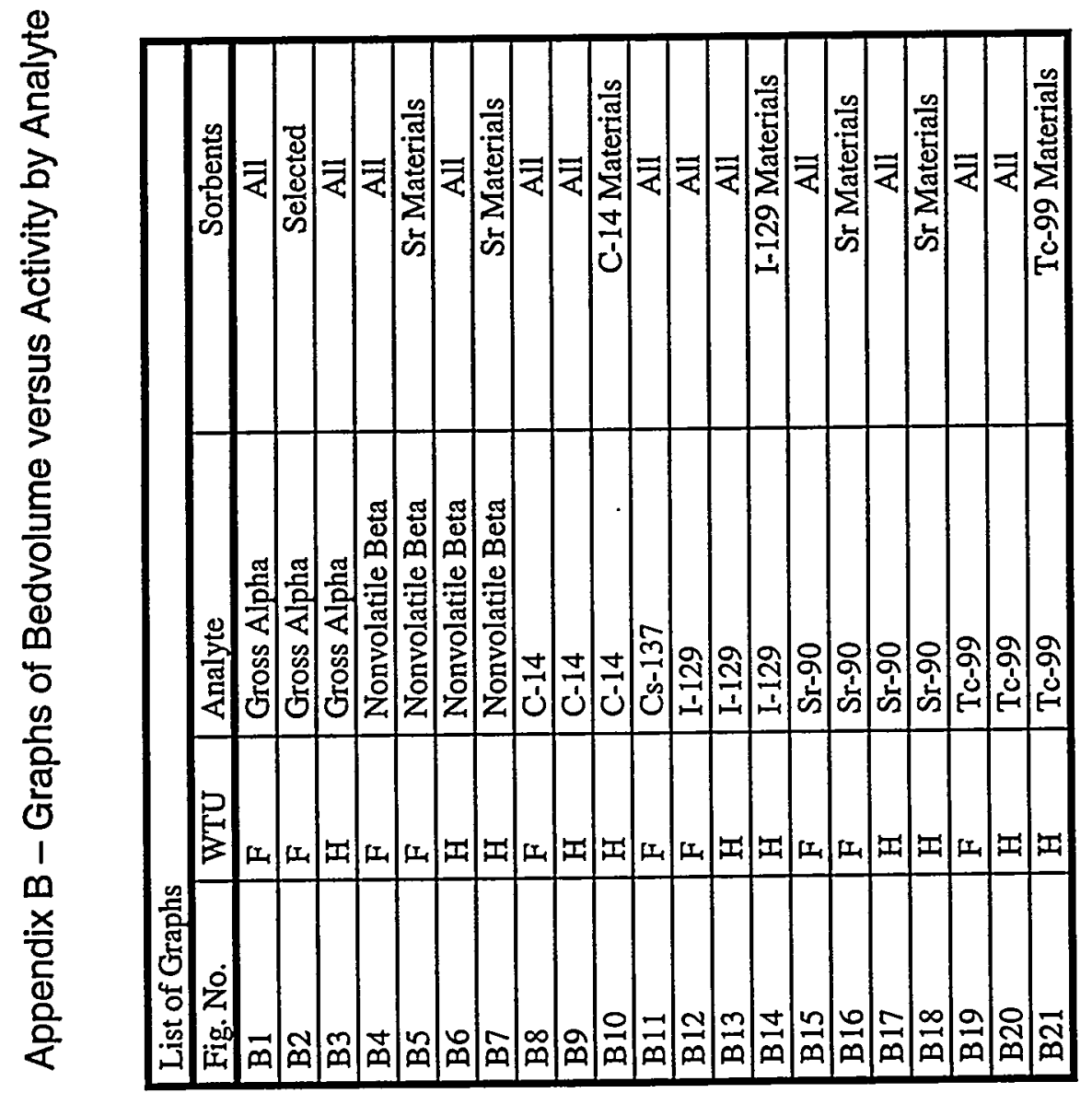

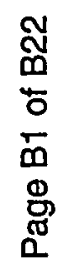



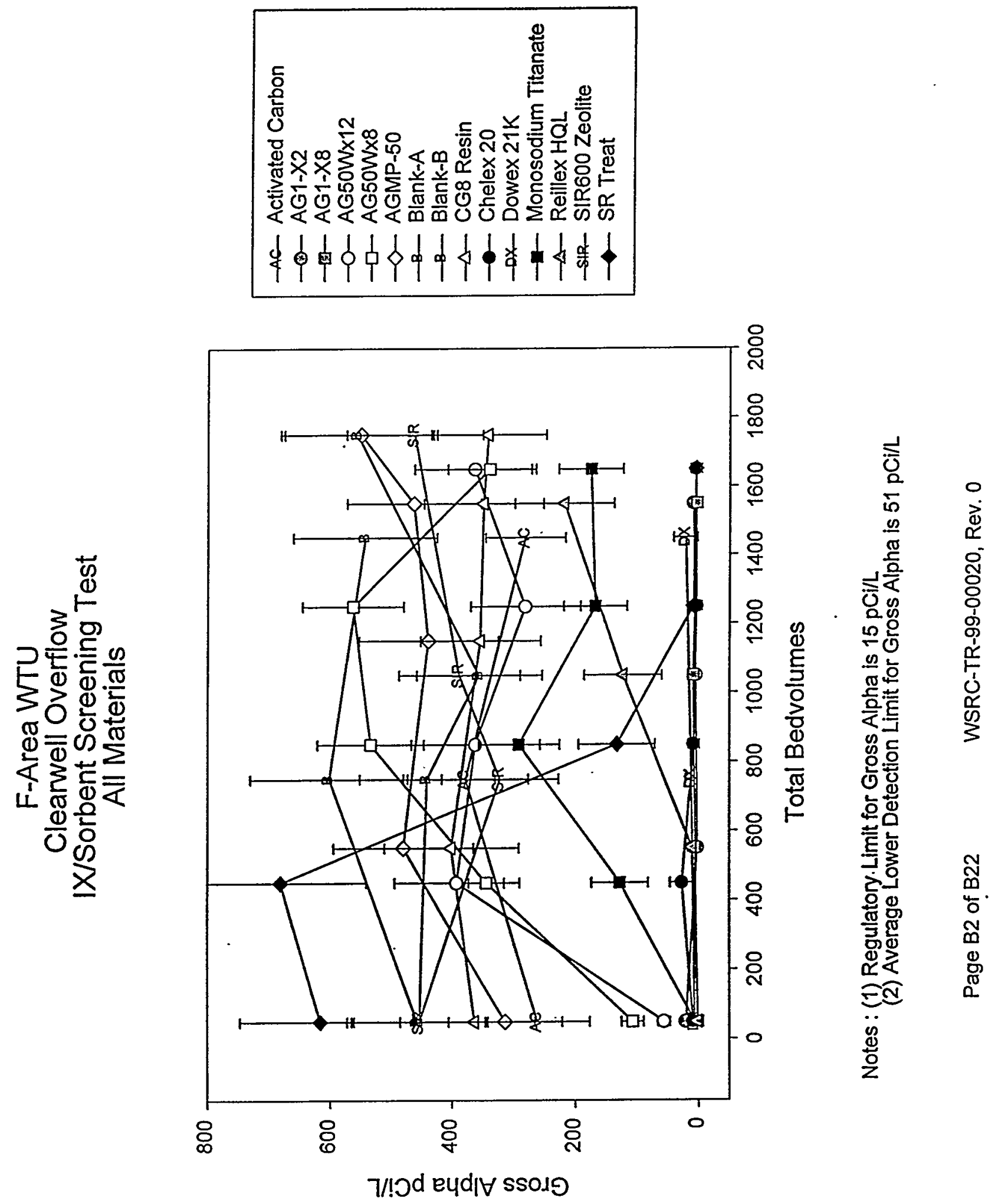

$\frac{5}{\infty}$
$\frac{0}{3}$
$i \frac{1}{i}$ 


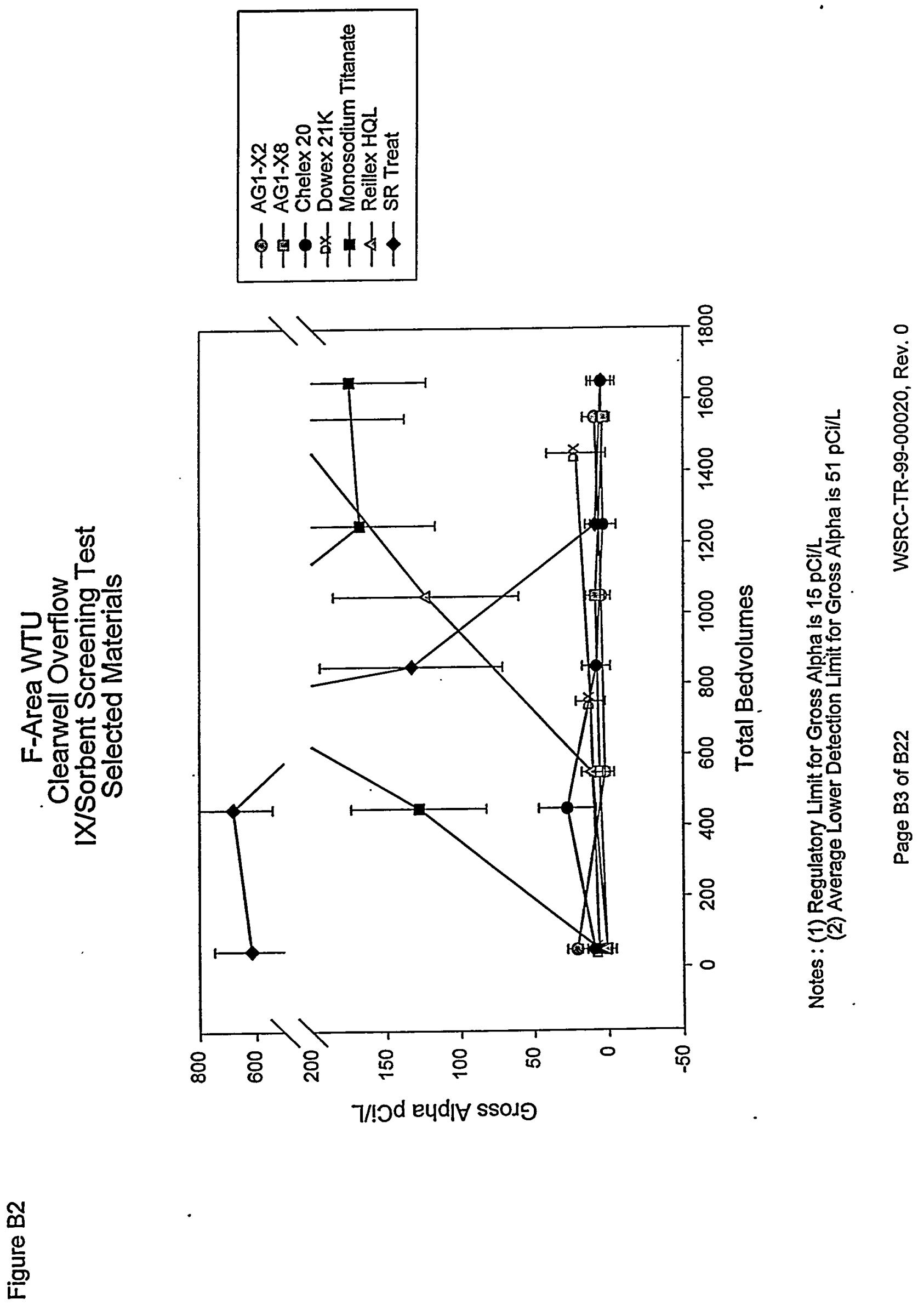


Figure B3

H-Area WTU

Clearwell Overflow

IX/Sorbent Screening Test

All Materials

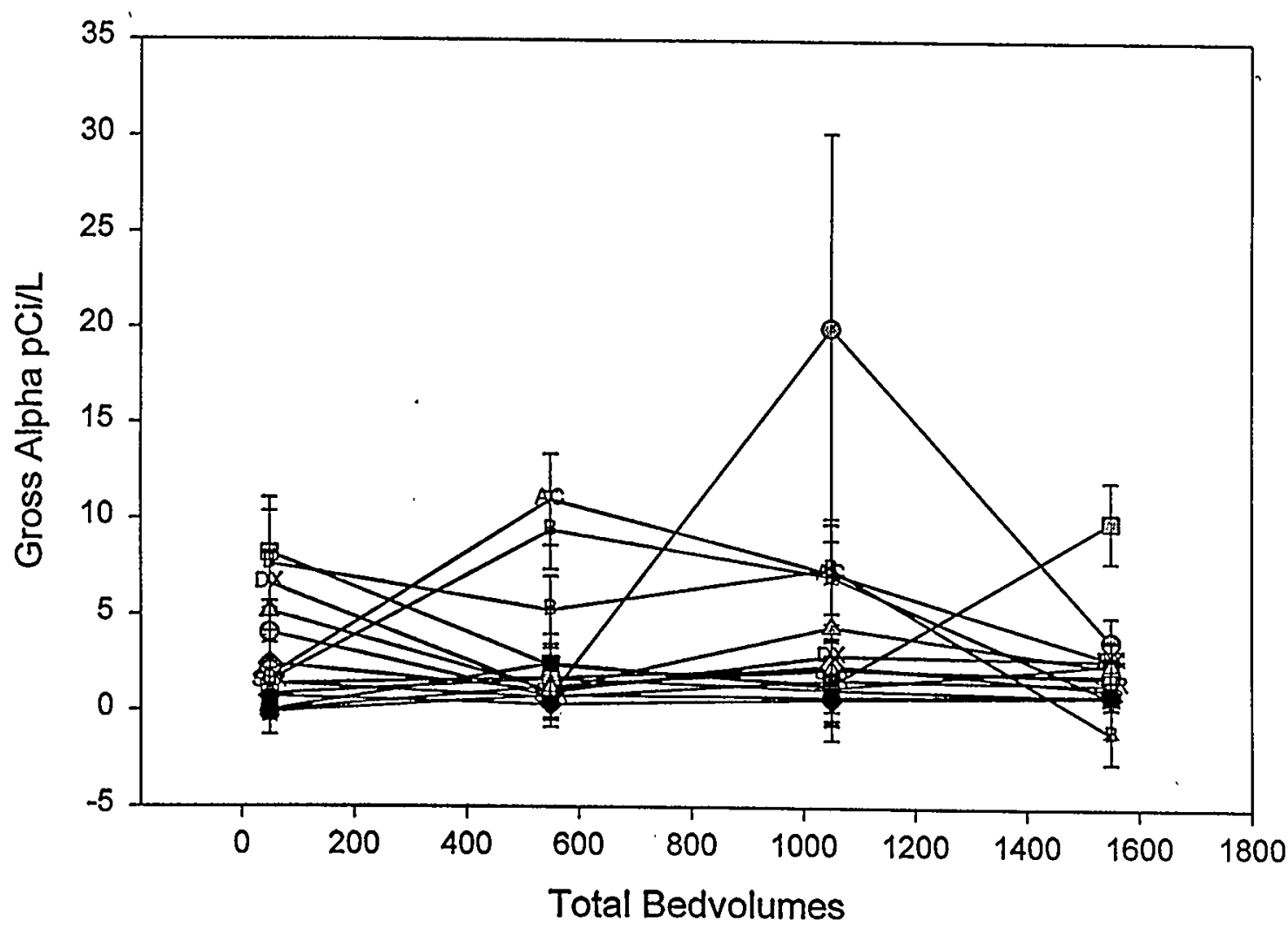

AG Activated Carbon

-1)- AG1-X2

$\rightarrow-A G 1-X 8$

-O- AG50W $\times 12$

$\rightarrow-A G 50 W \times 8$

$\multimap$ AGMP-50

$-\triangle$ CG8 Resin

$\rightarrow-$ Chelex 20

Dx- Dowex 21K

- Iron Powder

- Monosodium Titanate

$\triangle$ Reillex HQL

-SIR - SIR600 Zeolite

$\leadsto$ SR Treat

- B Blank A

$\rightarrow$ B Blank B

Notes : (1) Regulatory Limit for Gross Alpha is $15 \mathrm{pCi} / \mathrm{L}$

(2) Average Lower Detection Limit for Gross Alpha is $2 \mathrm{pCi} / \mathrm{L}$ 
Figure B4

\section{F-Area WTU \\ Clearwell Overflow \\ IX/Sorbent Screening Test \\ All Materials}

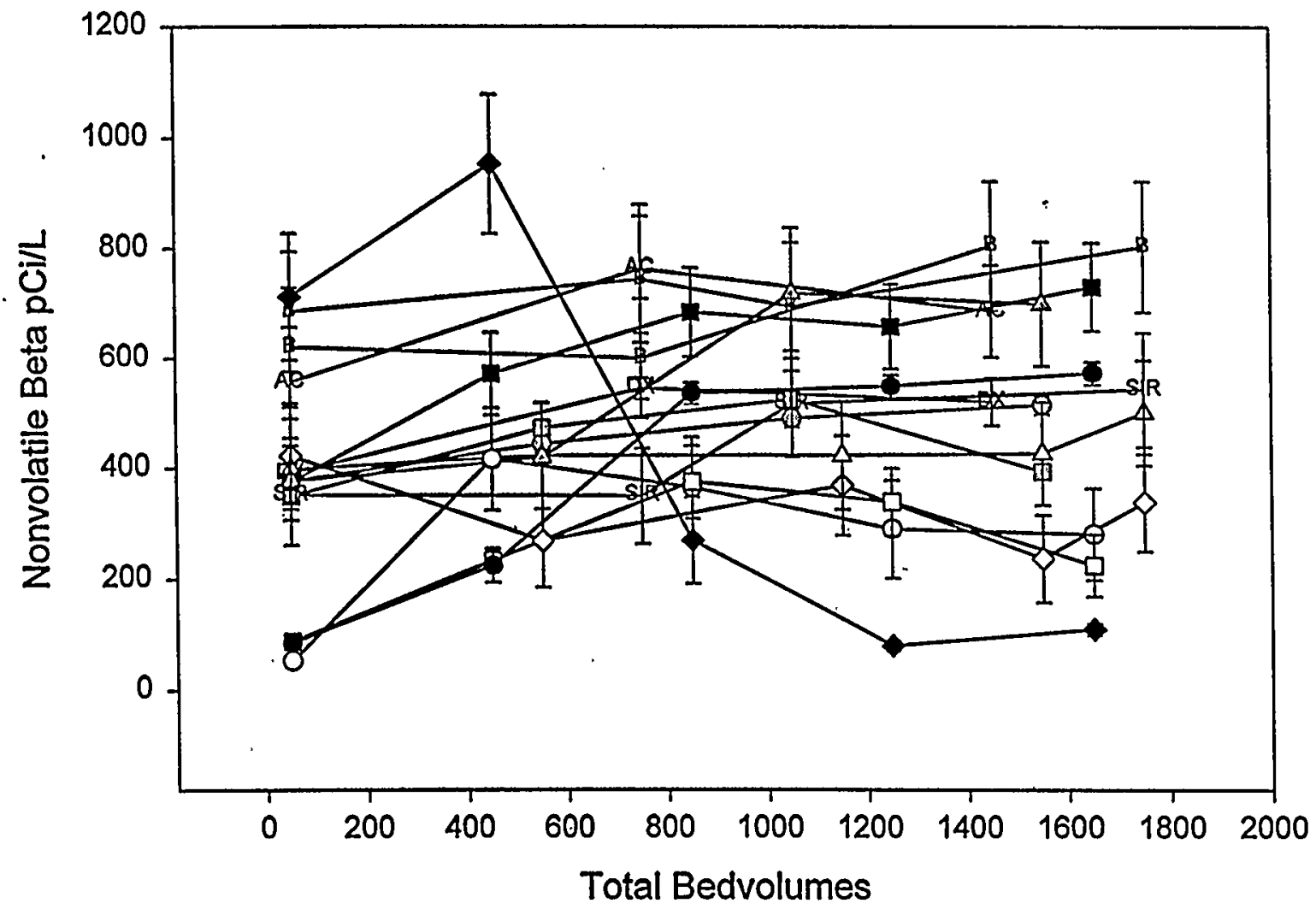

Notes : (1) Regulatory Limit for Nonvolatile Beta is Sum of Beta $<50 \mathrm{pCi} / \mathrm{L}$

(2) Average Lower Detection Limit for Nonvolatile Beta is $85 \mathrm{pCi} / \mathrm{L}$

Page B5 of B22

WSRC-TR-99-00020, Rev. 0
-AC Activated Carbon

- 2 - AG1-X2

$\rightarrow-A G 1-X 8$

$-0-A G 50 W \times 12$

$\rightarrow-A G 50 W \times 8$

$\multimap$ AGMP.50

$\rightarrow$ - Blank-A

-B- Blank-B

$\triangle-$ CG8 Resin

- C Chelex 20

Dx Dowex $21 \mathrm{~K}$

$\rightarrow-$ Monosodium Titanate

$\rightarrow-$ Reillex HQL

StR-SIR600 Zeolite

$\leadsto$ SR Treat 


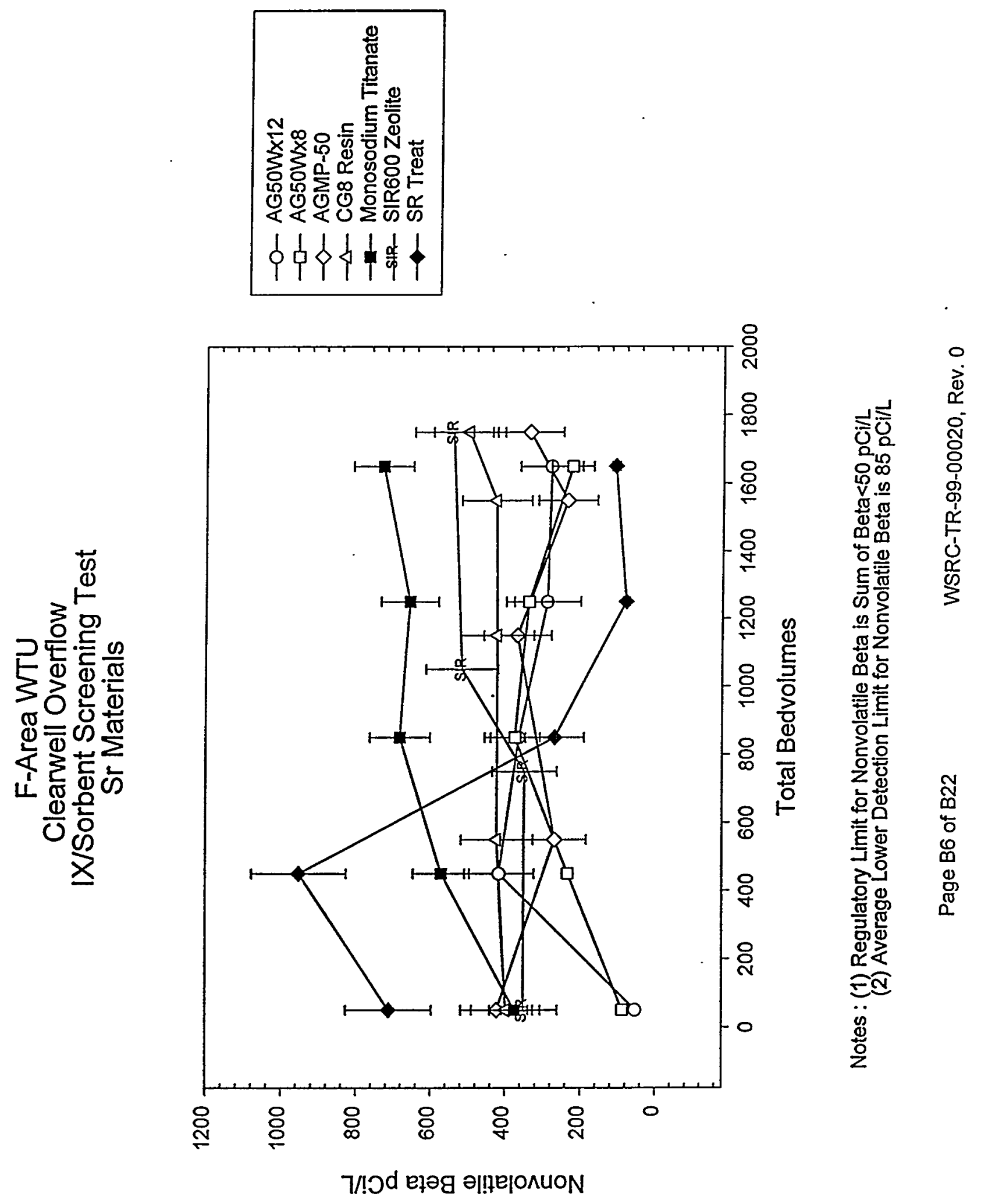

요
은
은 
Figure B6

\author{
H-Area WTU \\ Clearwell Overflow \\ IX/Sorbent Screening Test \\ All Materials
}

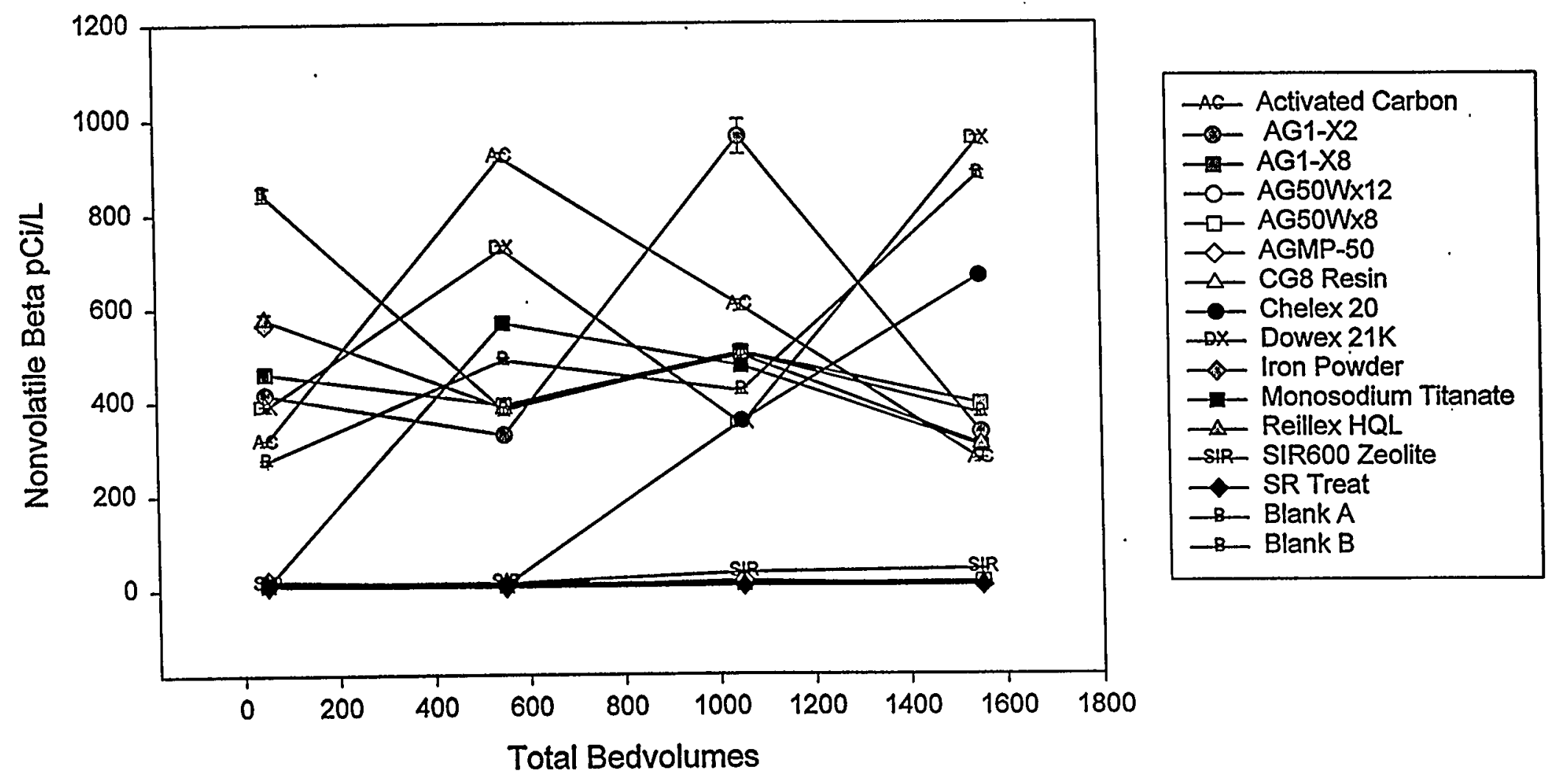

Notes : (1) Regulatory Limit for Nonvolatile Beta is Sum of Beta $<50 \mathrm{pCi} / \mathrm{L}$

(2) Average Lower Detection Limit for Nonvolatile Beta is $2 \mathrm{pCi} / L$ 
Figure B7

$$
\begin{gathered}
\text { H-Area WTU } \\
\text { Clearwell Overflow } \\
\text { IX/Sorbent Screening Test } \\
\text { Sr-90. Materials }
\end{gathered}
$$

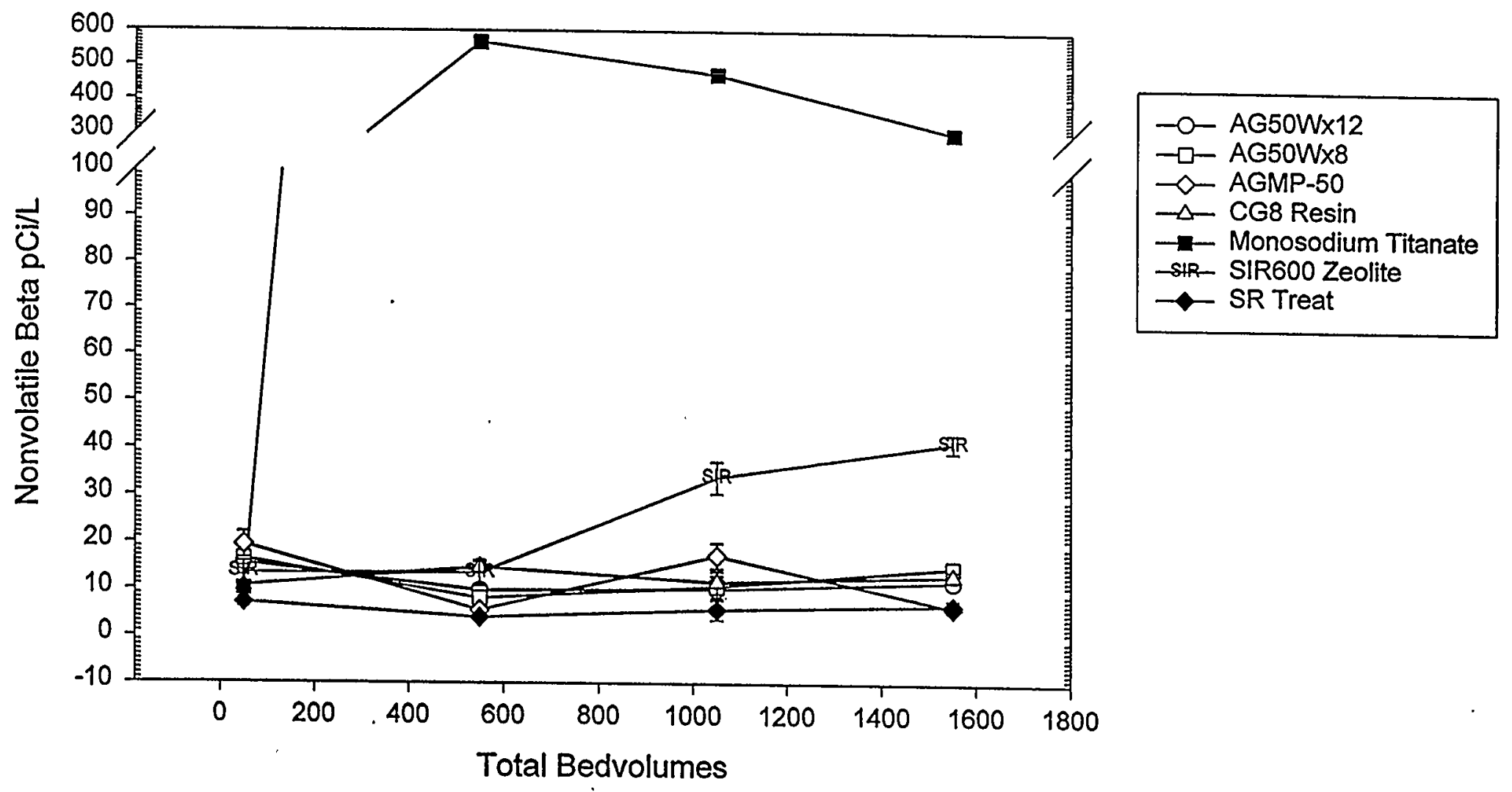

Notes : (1) Regulatory Limit for Nonvolatile Beta is Sum of Beta $<50 \mathrm{pCi} / \mathrm{L}$

(2) Average Lower Detection Limit for Nonvolatile Beta is $2 \mathrm{pCi} / \mathrm{L}$

Page $B 8$ of $B 22$

WSRC-TR-99-00020, Rev. 0 

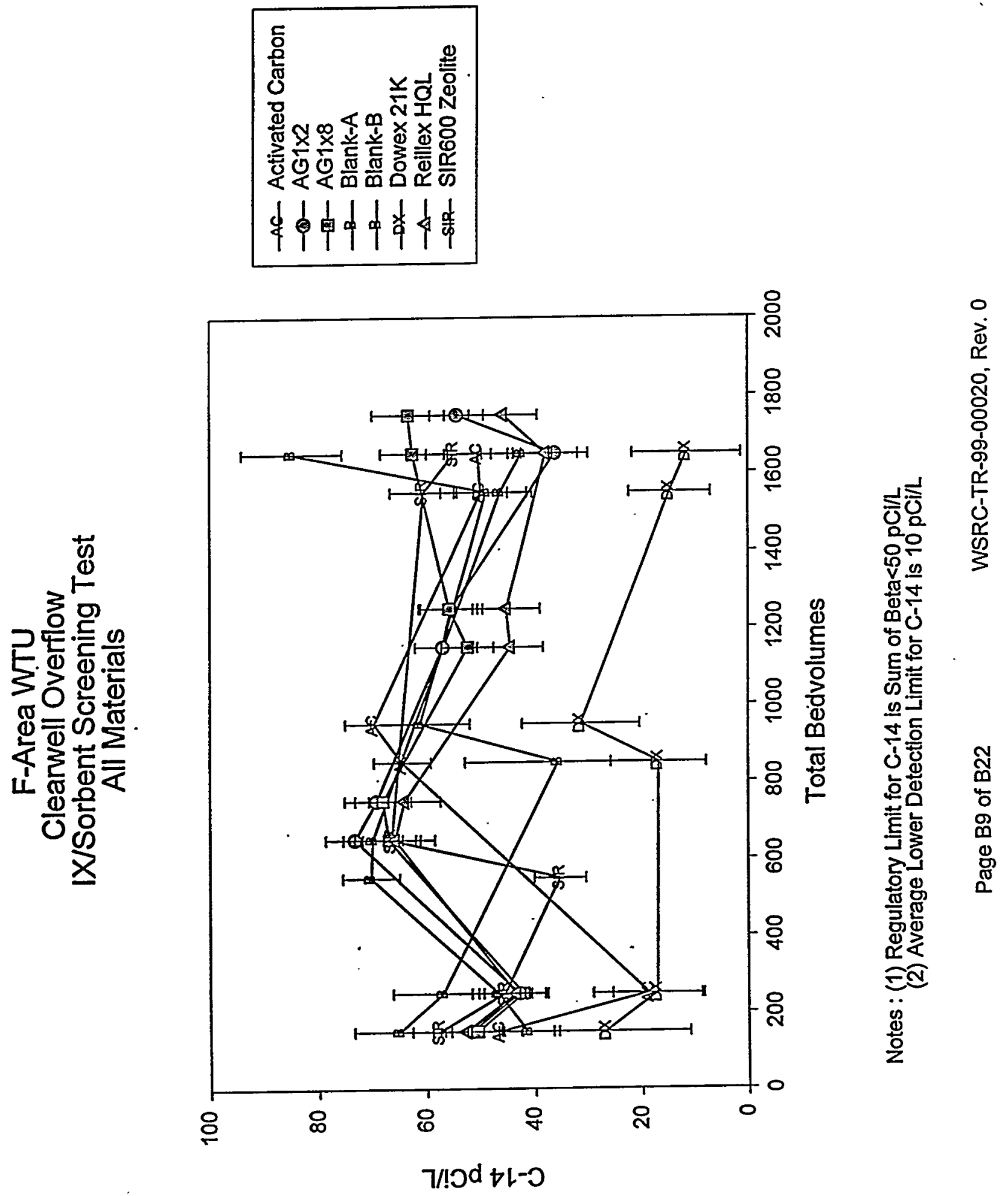

$\stackrel{\infty}{m}$
$\stackrel{0}{5}$
迥 
Figure B9

\author{
H-Area WTU \\ Clearwell Overflow \\ IX/Sorbent Screening Test \\ All Materials
}

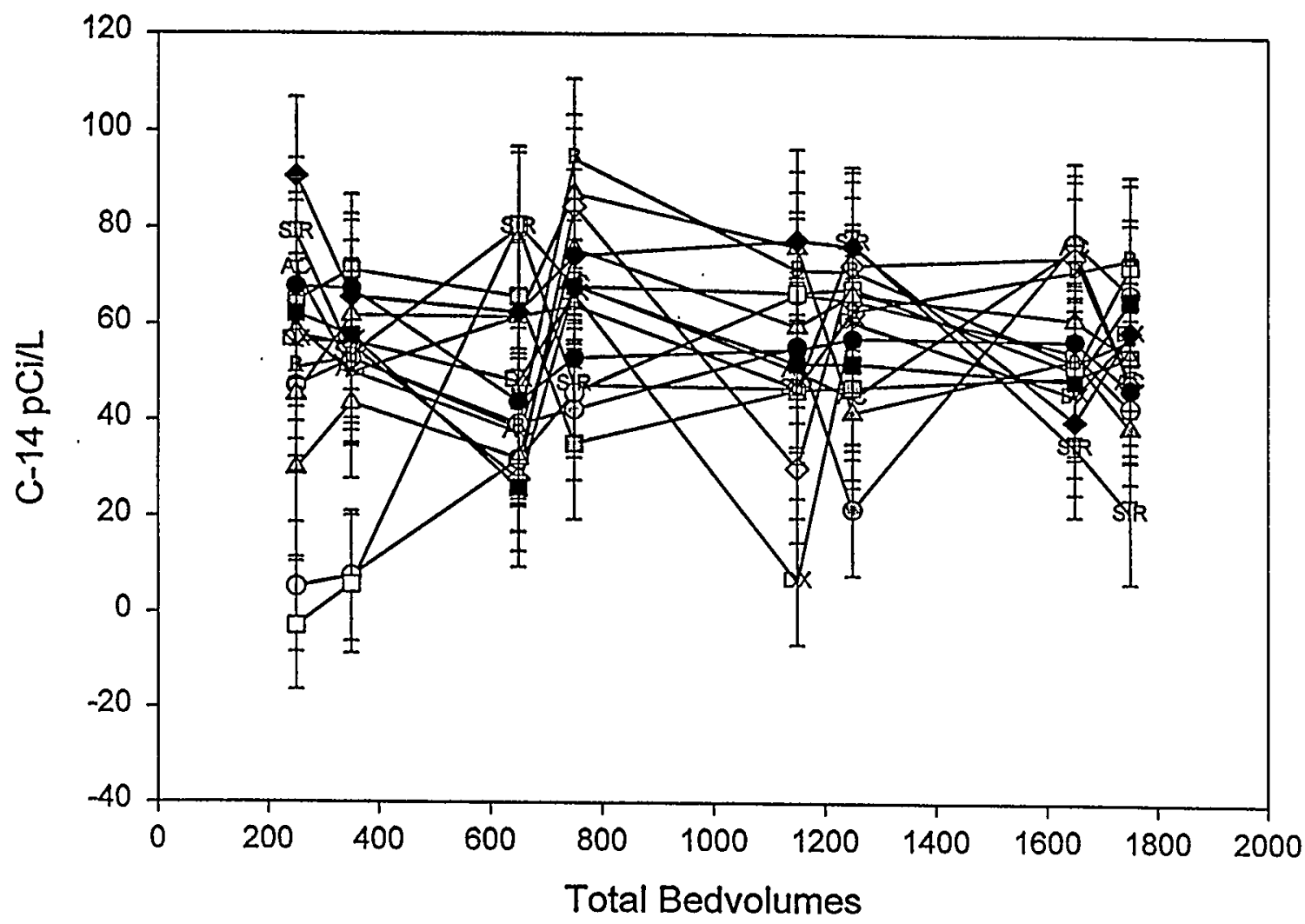

AC Activated Carbon

-0- $A G 1-X 2$

$-\infty-A G 1-\times 8$

-O- AG50W $\times 12$

$-\square-A G 50 W \times 8$

$\approx$ AGMP-50

$\triangle \triangle$ CG8 Resin

-C Chelex 20

Dx Dowex 21k

- Iron Powder

$\rightarrow$ - Monosodium Titanate

$\rightarrow$ Reillex HQL

SIR- SIR600 Zeolite

- SR Treat

-B Blank A

$\rightarrow$ Blank $B$

Notes : (1) Regulatory Limit for C-14 is Sum of Beta $<50 \mathrm{pCi} / \mathrm{L}$

(2) Average Lower Detection Limit for $\mathrm{C}-14$ is $23 \mathrm{pCi} / \mathrm{L}$ 
Figure B10
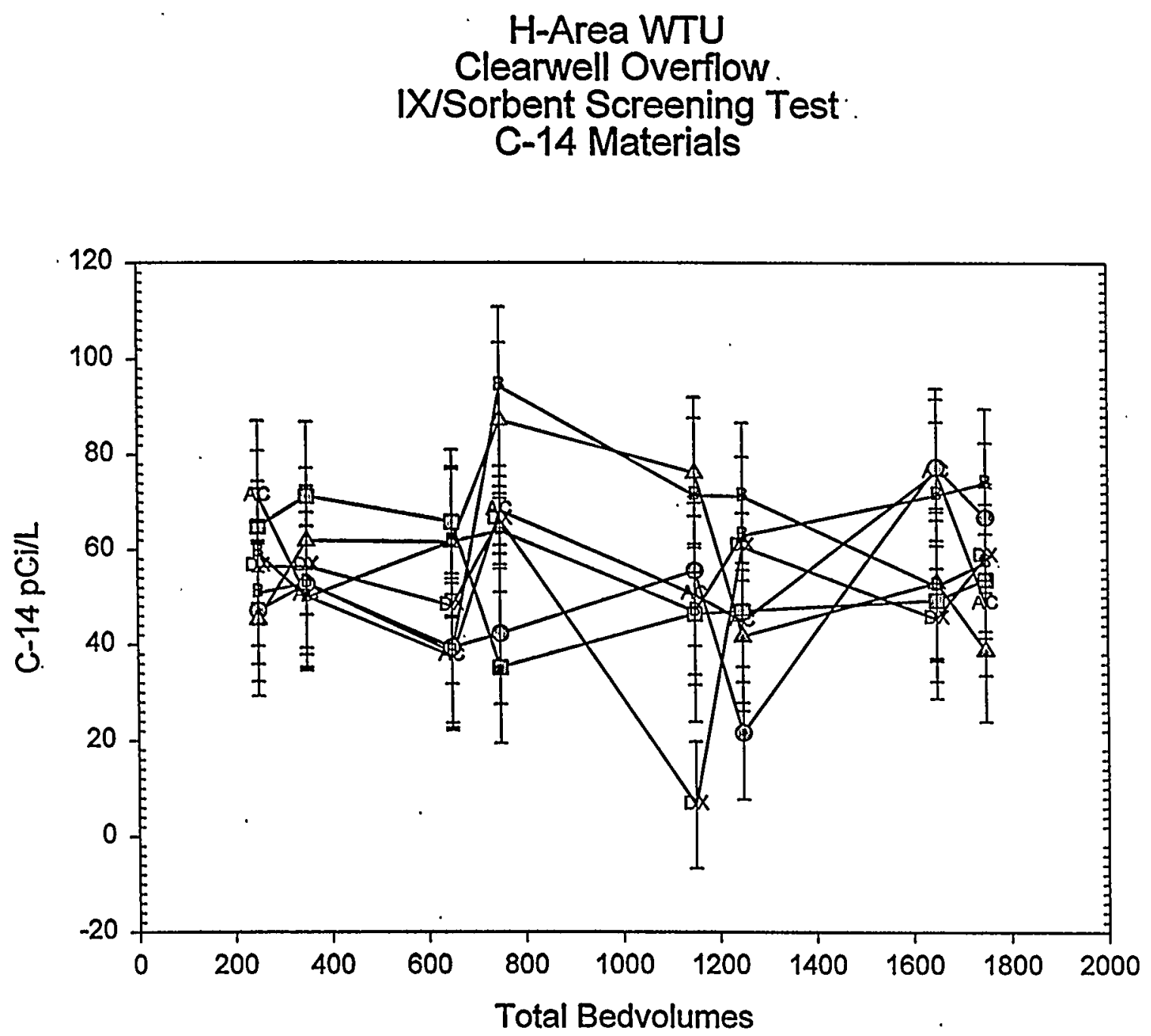

AG- Activated Carbon

-0- AG1-X2

-11- AG1-X8

$\rightarrow$ DX Dowex 21K

$\rightarrow$ Reillex HQL

B- Blank A

$\rightarrow$ - Blank B

Notes : (1) Regulatory Limit for $\mathrm{C}-14$ is Sum of Beta $<50 \mathrm{pCi} / \mathrm{L}$

(2) Average Lower Detection Limit for $\mathrm{C}-14$ is $23 \mathrm{pCi} / \mathrm{L}$ 
Figure B11

\author{
F-Area WTU \\ Clearwell Overflow \\ IX/Sorbent Screening Test \\ All Materials
}

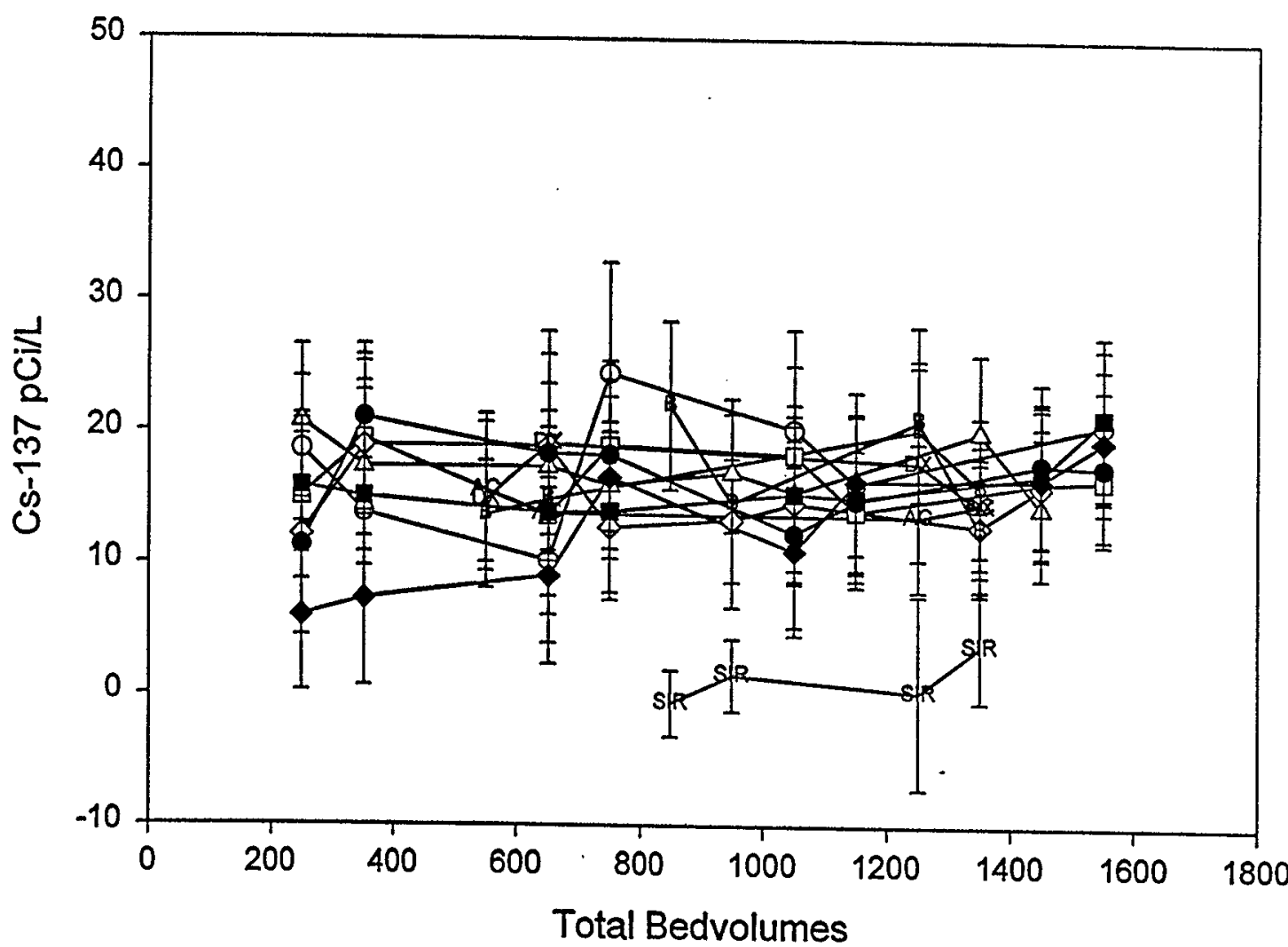

Ac- Activated Carbon

-O- AG50W $\times 12$

$\rightarrow-A G 50 W \times 8$

$\curvearrowright$ AGMP-50

$\rightarrow-$ Blank-A

$\rightarrow$ Blank-B

$\triangle-$ CG8 Resin

$\rightarrow$ Chelex 20

Dx Dowex 21K

$\rightarrow-$ Monosodium Titanate

SIR-SIR600 Zeolite

$\rightarrow$ SR Treat

Notes : (1) Regulatory Limit for Cs-137 is Sum of Beta $<50 \mathrm{pCi} / \mathrm{L}$

(2) Average Lower Detection Limit for $\mathrm{Cs}-137$ is $5 \mathrm{pCilL}$ 


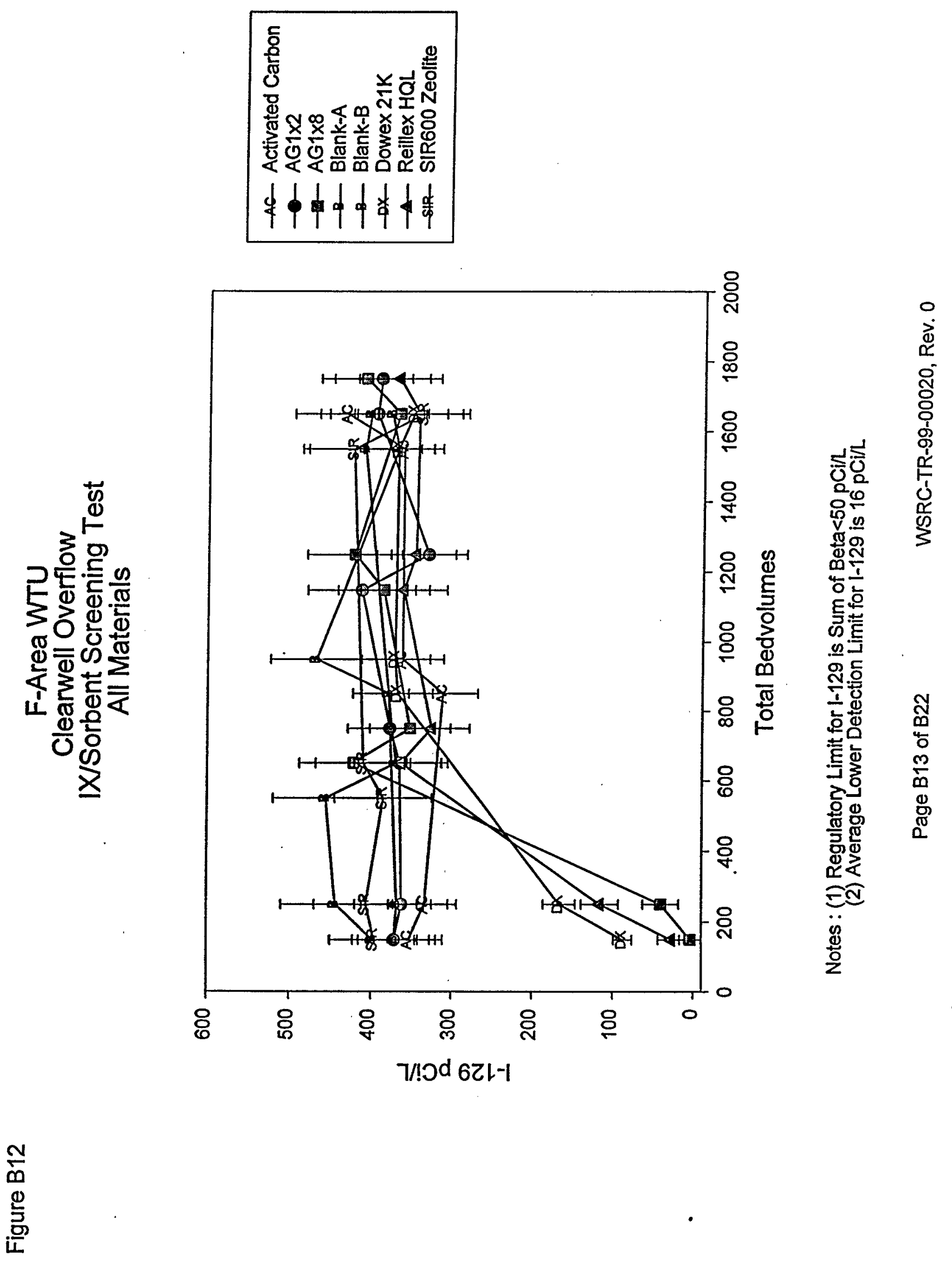


Figure B13

\section{H-Area WTU \\ Clearwell Overflow \\ IX/Sorbent Screening Test \\ All Materials}

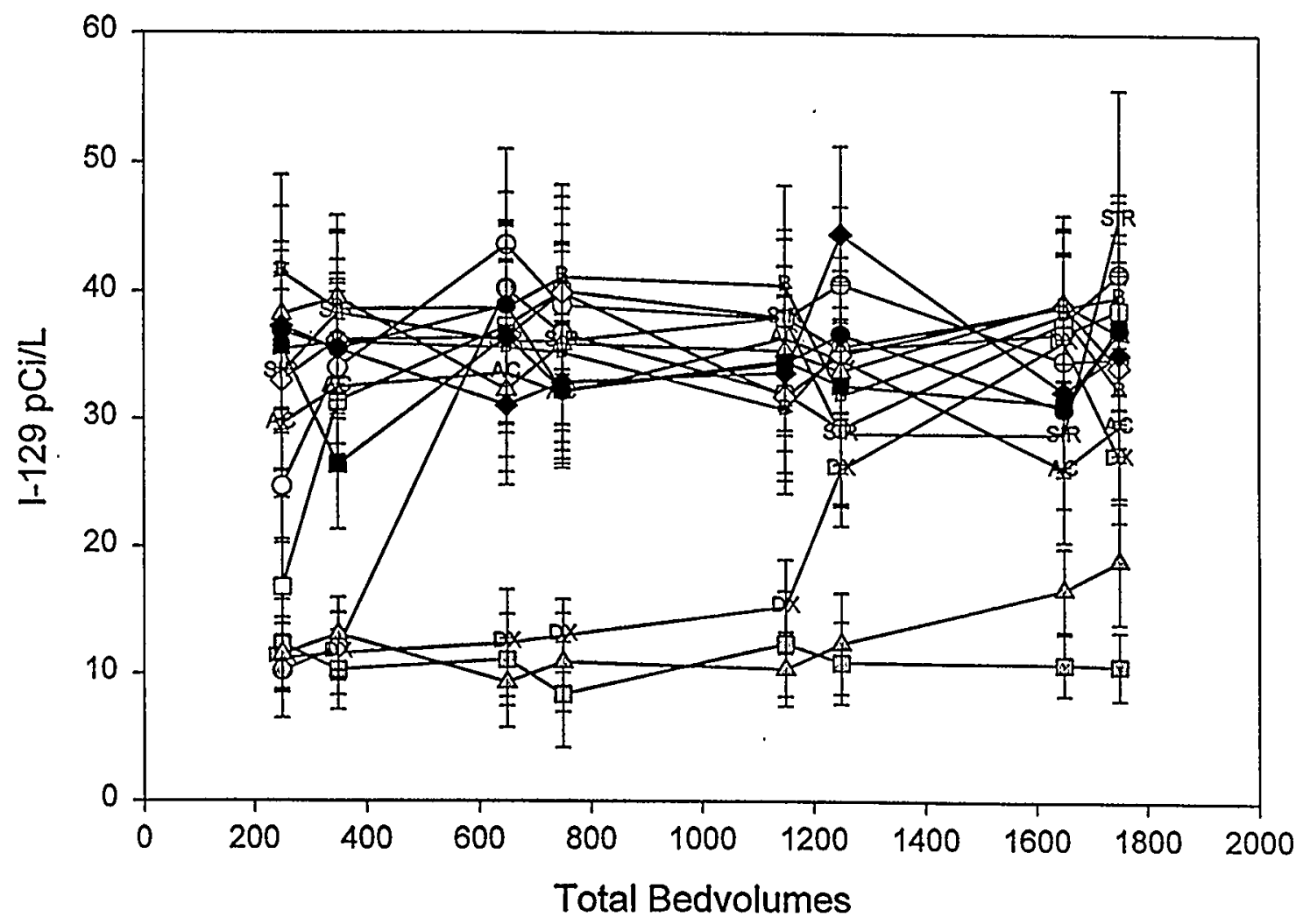

AC Activated Carbon

-1)- AG1-X2

- 1 - AG1-X8

$-0-A G 50 W \times 12$

$\rightarrow-A G 50 W \times 8$

$\approx$ AGMP-50

$\triangle-$ CG8 Resin

- Chelex 20

$\rightarrow x$ Dowex 21k

- Iron Powder

$\rightarrow$ - Monosodium Titanate

- $\triangle$ - Reillex HQL

-SIR- SIR600 Zeolite

- SR Treat

$\rightarrow$ Blank A

-B Blank B

Notes : (1) Regulatory Limit for $1-129$ is Sum of Beta $<50 \mathrm{pCi} / \mathrm{L}$

(2) Average Lower Detection Limit for I-129 is $2 \mathrm{pCi} / \mathrm{L}$ 


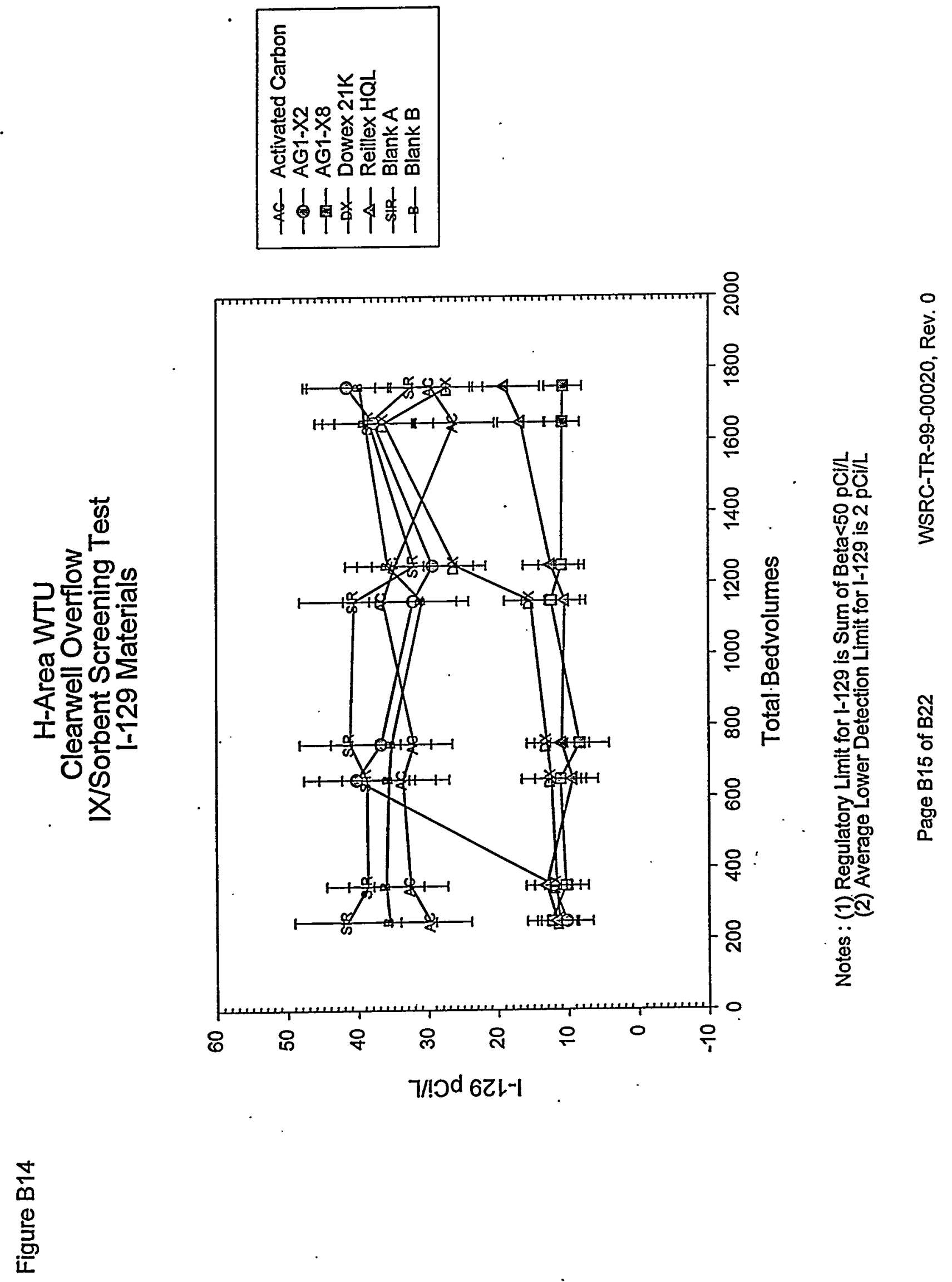


Figure B15

\section{F-Area WTU \\ Clearwell Overflow \\ IX/Sorbent Screening Test \\ All Materials}

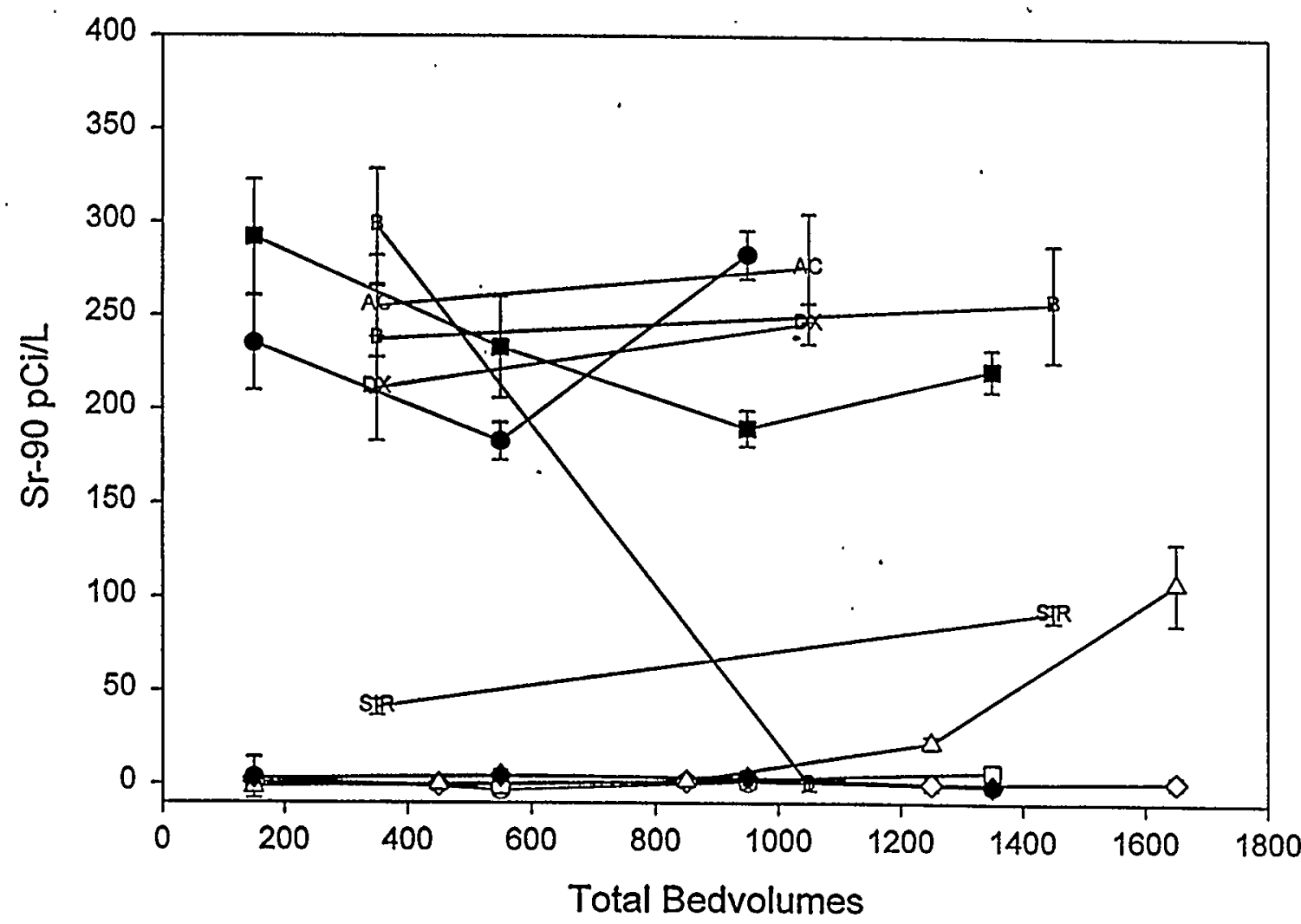

AG Activated Carbon

-O- AG50W $\times 12$

$\rightarrow-A G 50 W \times 8$

$\infty$ AGMP-50

- B- Blank-A

$\rightarrow$ Blank-B

$\triangle-$ CG8 Resin

$\rightarrow$ Chelex 20

Dx Dowex $21 \mathrm{~K}$

$\rightarrow-$ Monosodium Titanate

-SIR- SIR600 Zeolite

$\multimap$ SR Treat

Notes : (1) Regulatory Limit for $\mathrm{Sr}-90$ is $8 \mathrm{pCi} / \mathrm{L}$

(2) Average Lower Detection Limit for Sr-90 is $16 \mathrm{pCi} / \mathrm{L}$ 
Figure B16

\author{
F-Area WTU \\ Clearwell Overflow \\ IX/Sorbent Screening Test \\ Sr Materials
}

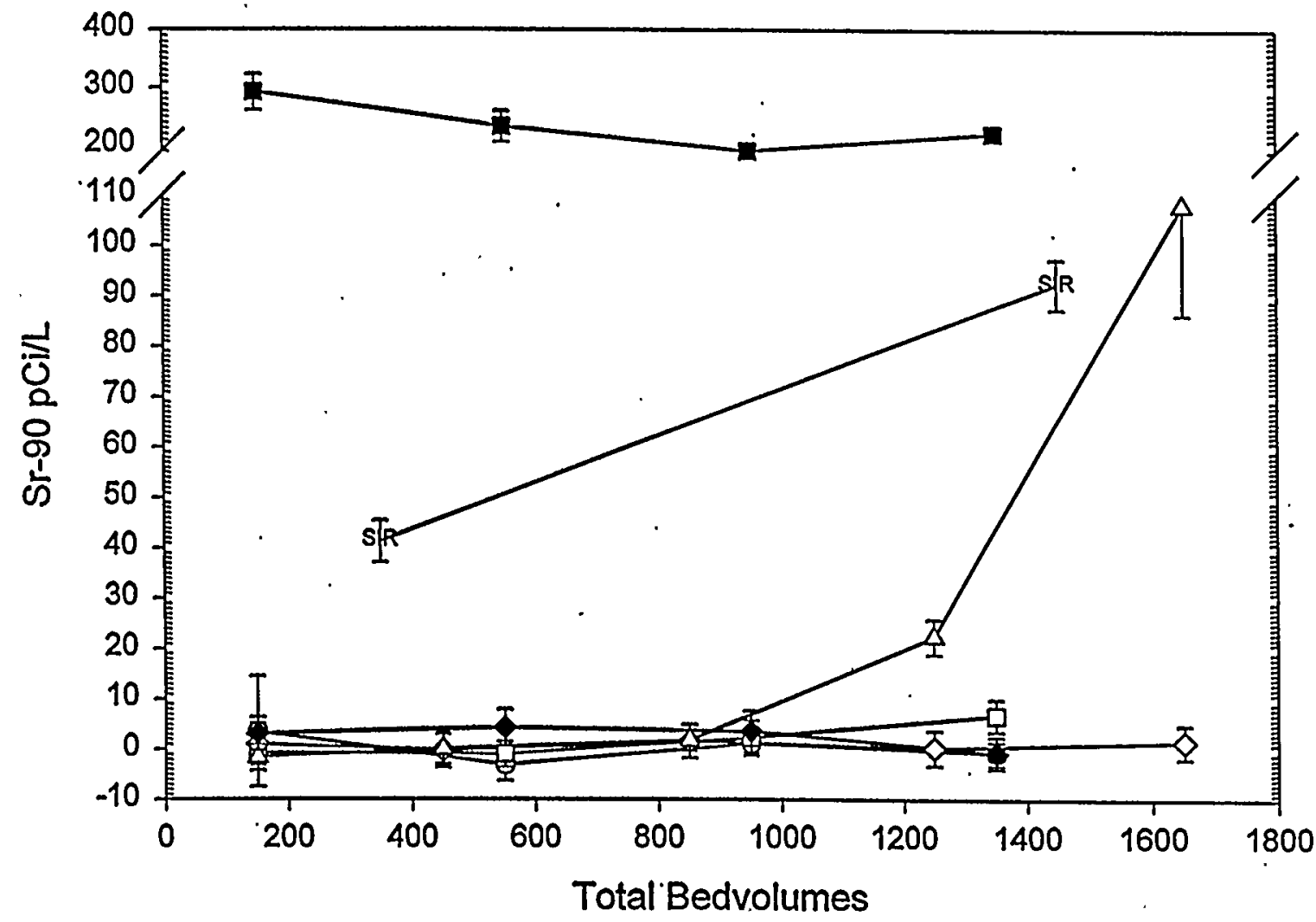

$-\infty$ AG50W $\times 12$

$\rightarrow-A G 50 W \times 8$

$\sim$ AGMP-50

$\triangle-$ CG8 Resin

$\rightarrow$ - Monosodium Titanate

-SIR- SIR600 Zeolite

$\rightarrow$ SR Treat

Notes : (1) Regulatory Limit for Sr-90 is $8 \mathrm{pCl} / \mathrm{L}$

(2) Average Lower Detection Limit for $\mathrm{Sr}-90$ is $16 \mathrm{pCi} / \mathrm{L}$

Page $B 17$ of $B 22$

WSRC-TR-99-00020, Rev. 0 

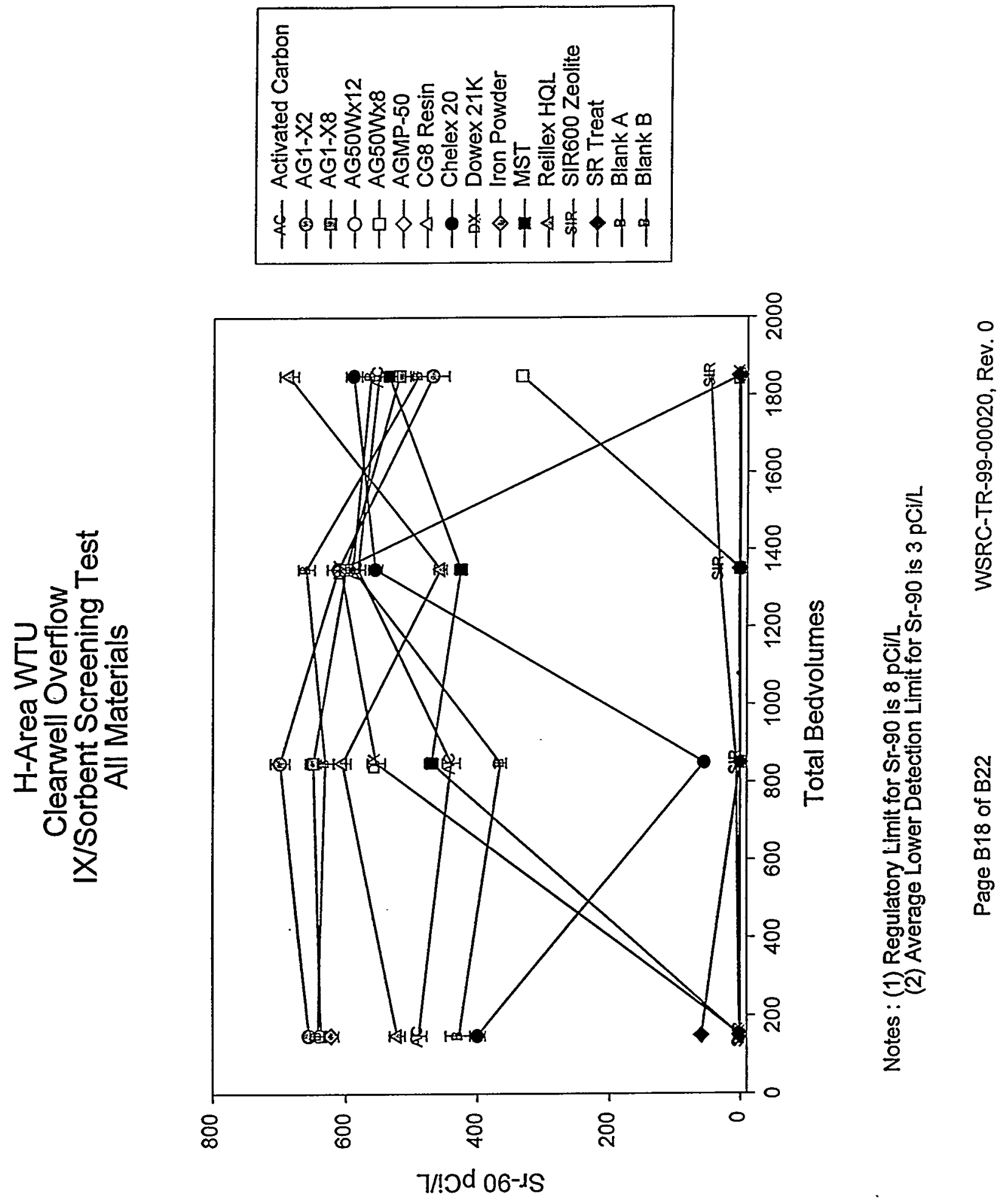

$\frac{N}{\infty}$ 
Figure B18

\section{H-Area WTU \\ Clearwell Overflow \\ IX/Sorbent Screening Test \\ Sr Materials}

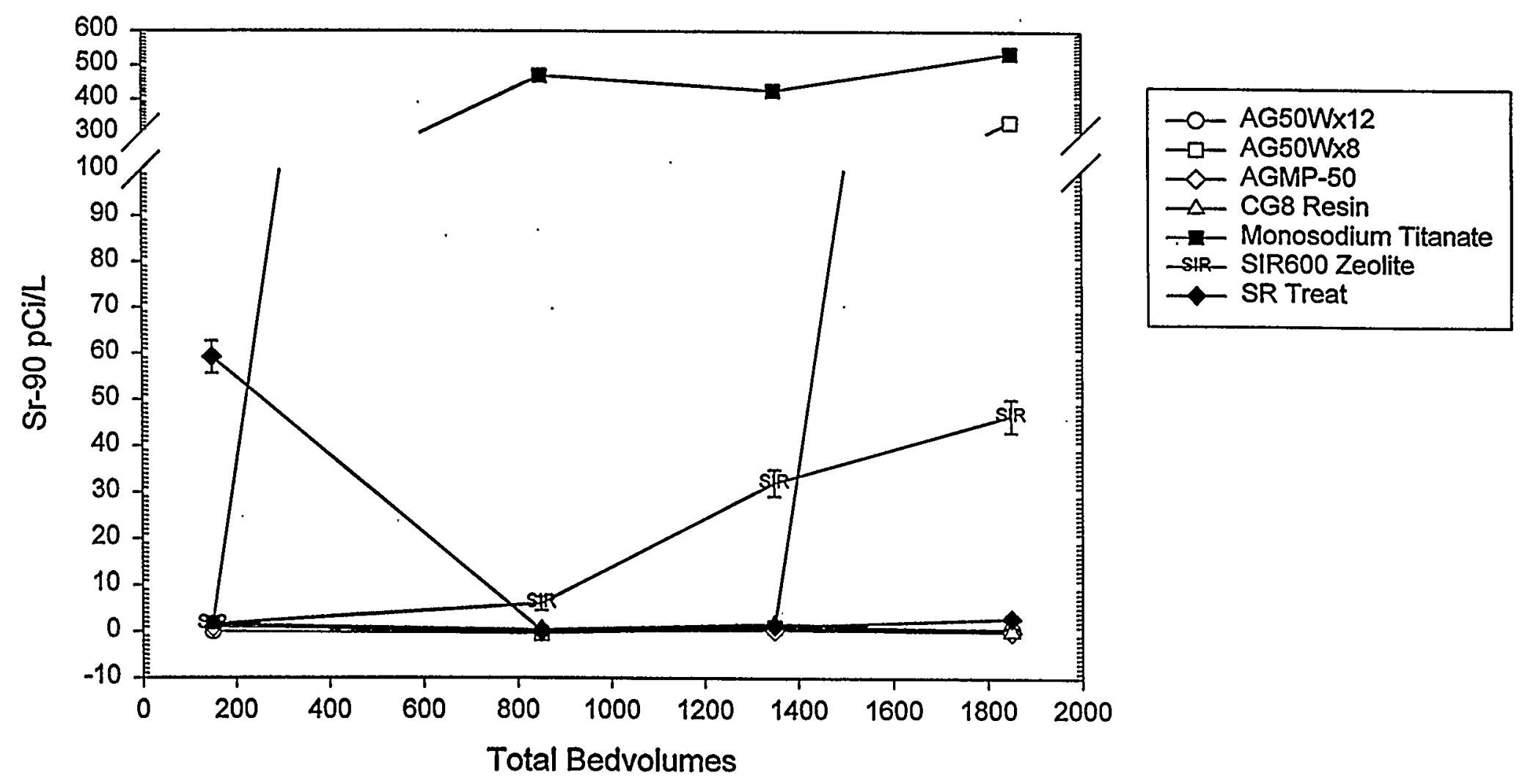

Notes : (1) Regulatory Limit for Sr-90 is $8 \mathrm{pCl} / \mathrm{L}$

(2) Average Lower Detection Limit for Sr-90 is $3 \mathrm{pCi} / \mathrm{L}$

Page $\mathrm{B} 19$ of $\mathrm{B} 22$

WSRC-TR-99-00020, Rev. 0 

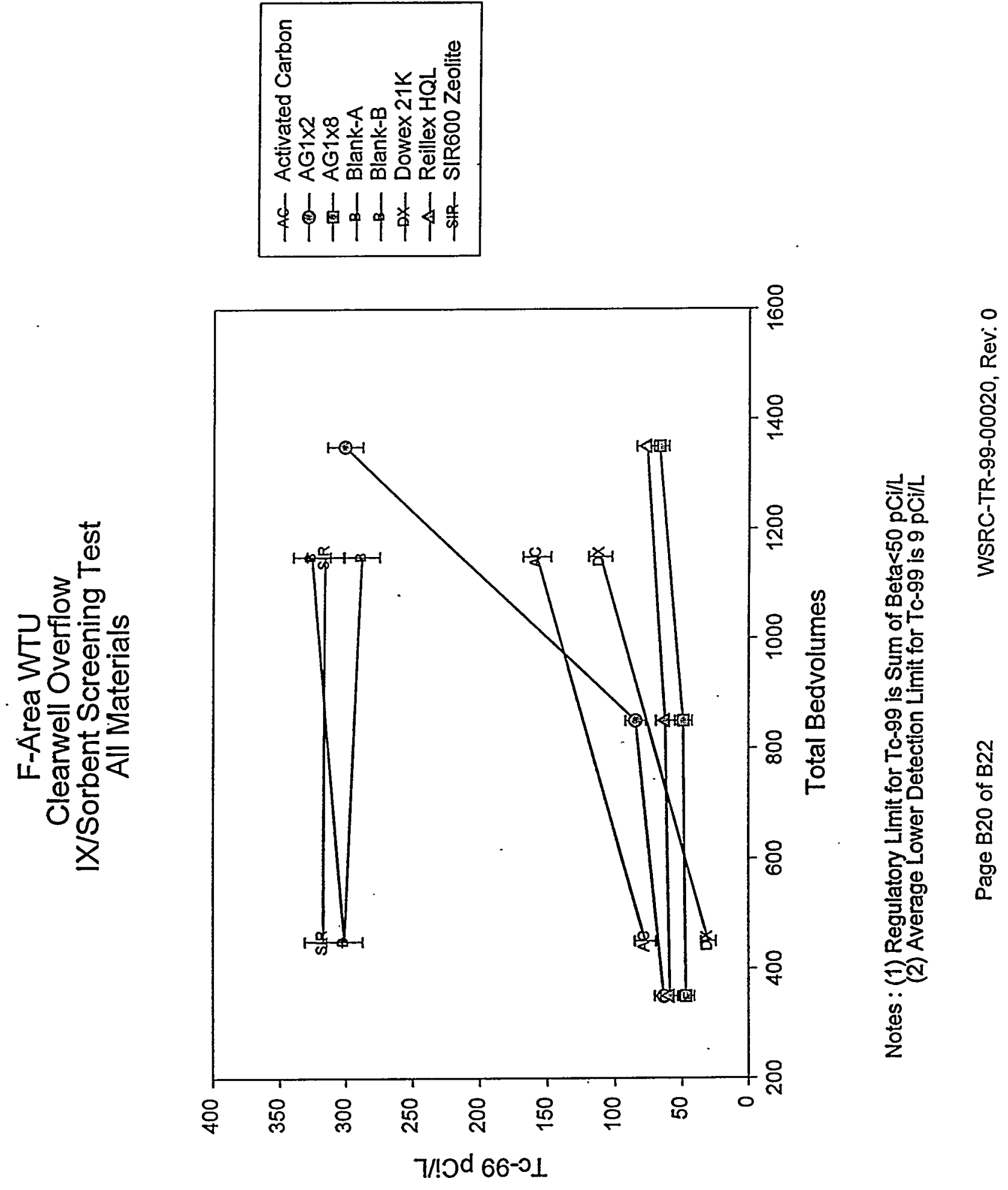

$\frac{\frac{0}{m}}{\frac{0}{5}}$ 
Figure B20

\author{
H-Area WTU \\ Clearwell Overflow \\ IX/Sorbent Screening Test \\ All Materials
}

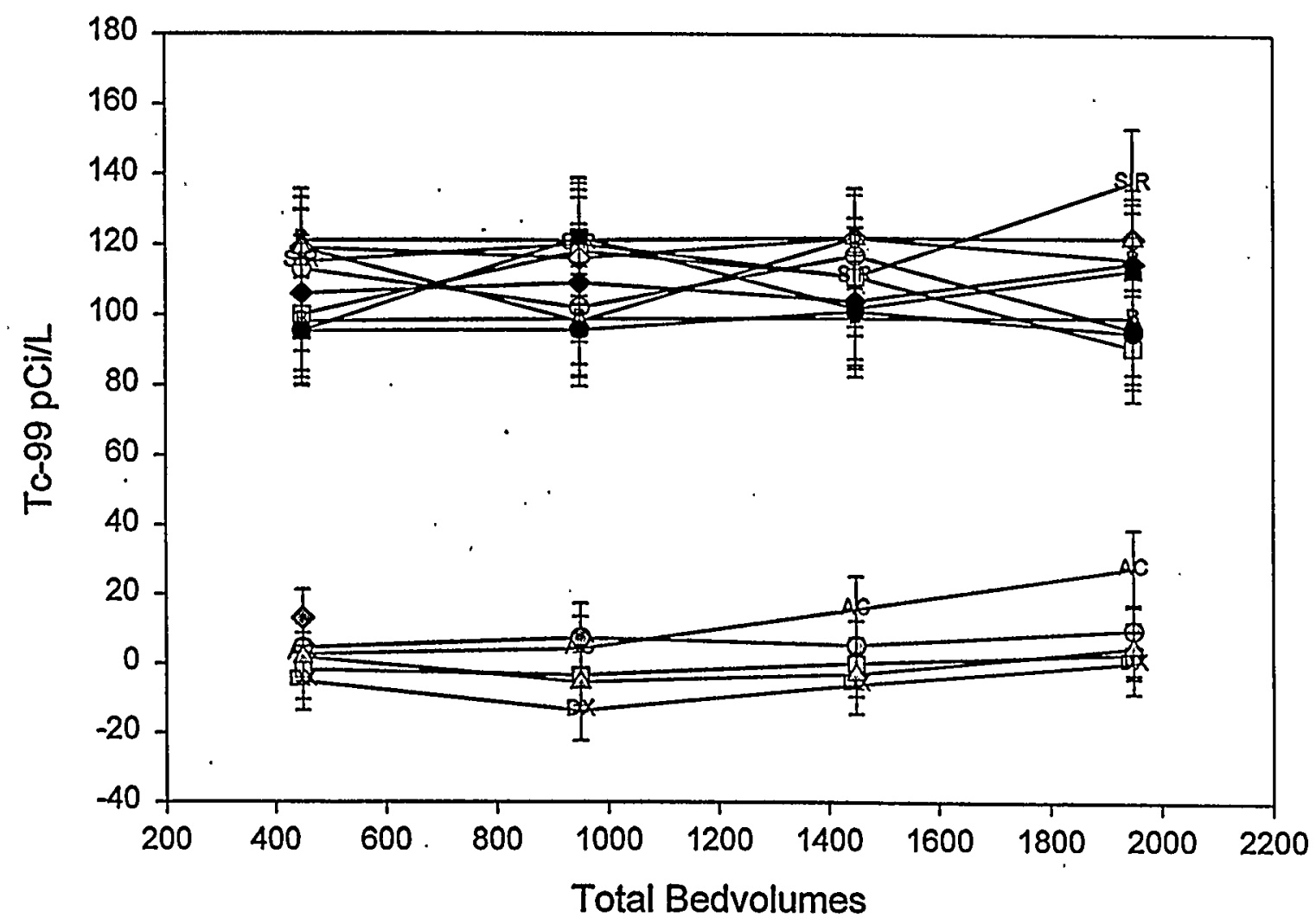

-AC - Activated Carbon

-0- AG1-X2

一国- $A G 1-\times 8$

-O- AG50W $\times 12$

$\rightarrow \square-A G 50 W \times 8$

$\curvearrowright$ AGMP-50

$\triangle-$ CG8 Resin

-C Chelex 20

Dx - Dowex 21K

- Iron Powder

$\rightarrow$ - Monosodium Titanate

-A- Reillex HQL

-SIR SIR600 Zeolite

- SR Treat

$\rightarrow$ Blank $A$

-B B Blank B

Notes : (1) Regulatory Limit for Tc-99 is Sum of Beta $<50 \mathrm{pCi} / \mathrm{L}$

(2) Average Lower Detection Limit for Tc-99 is $20 \mathrm{pCi} / \mathrm{L}$ 


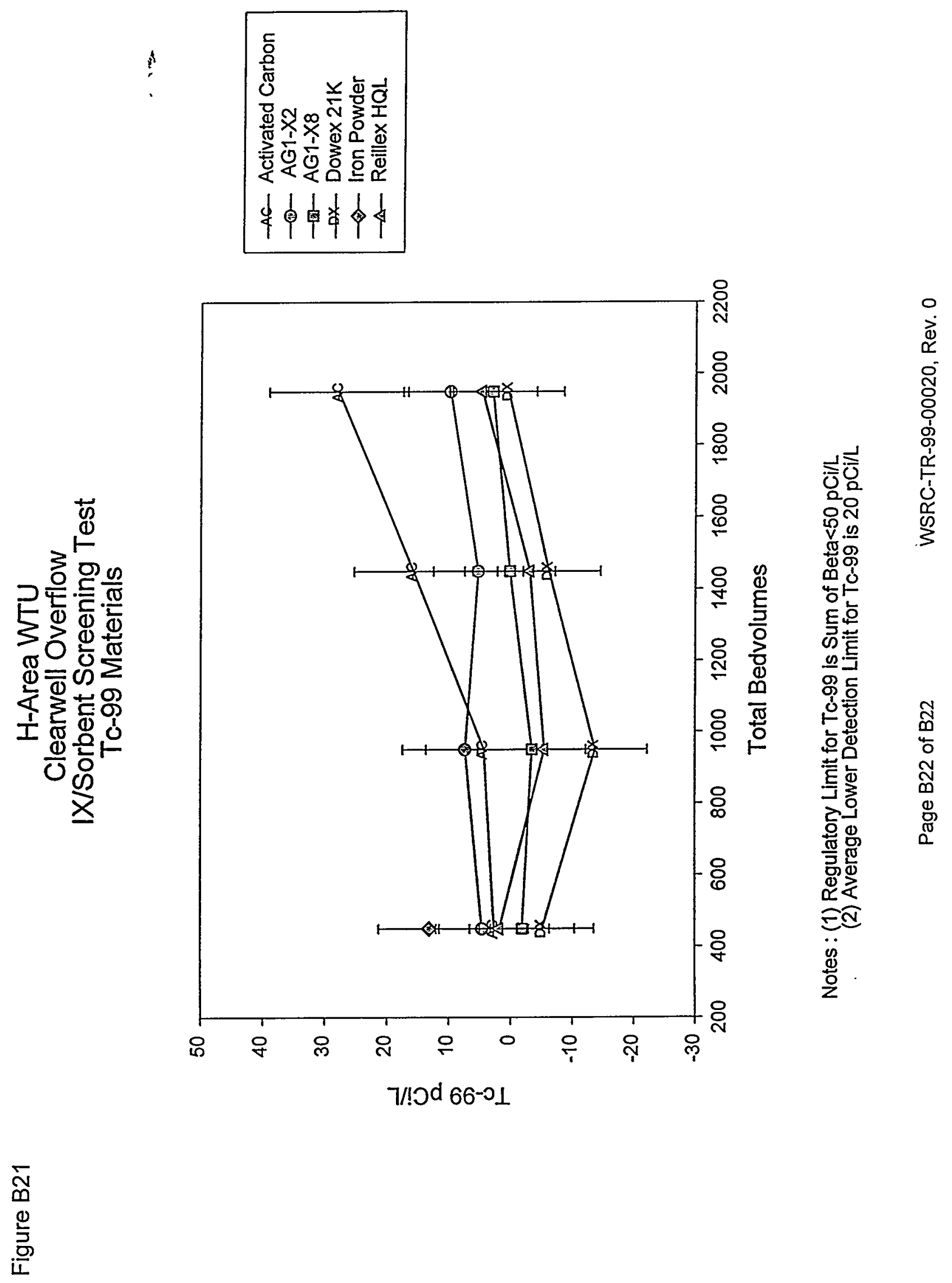



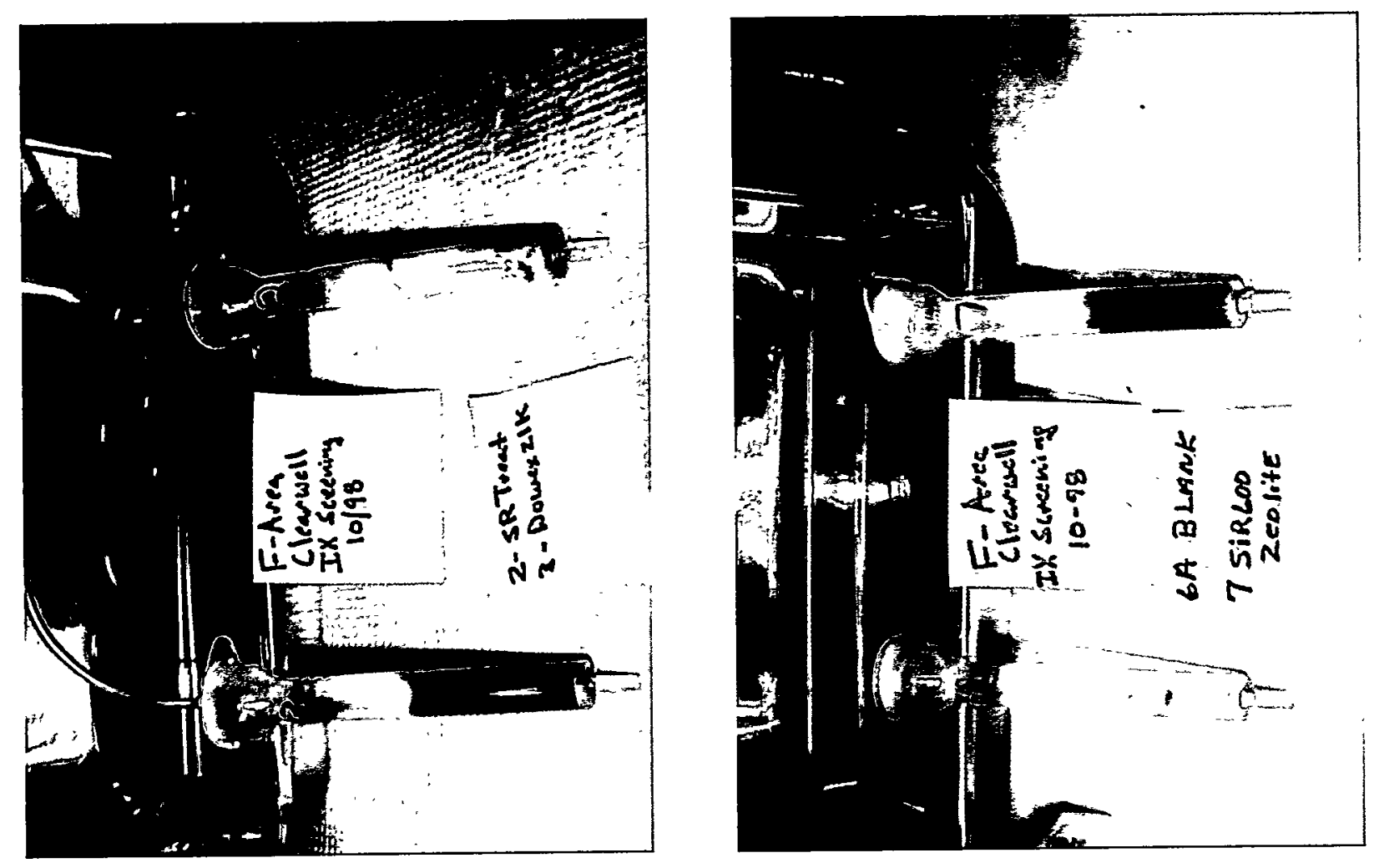

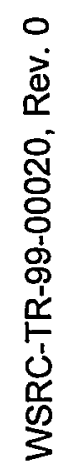
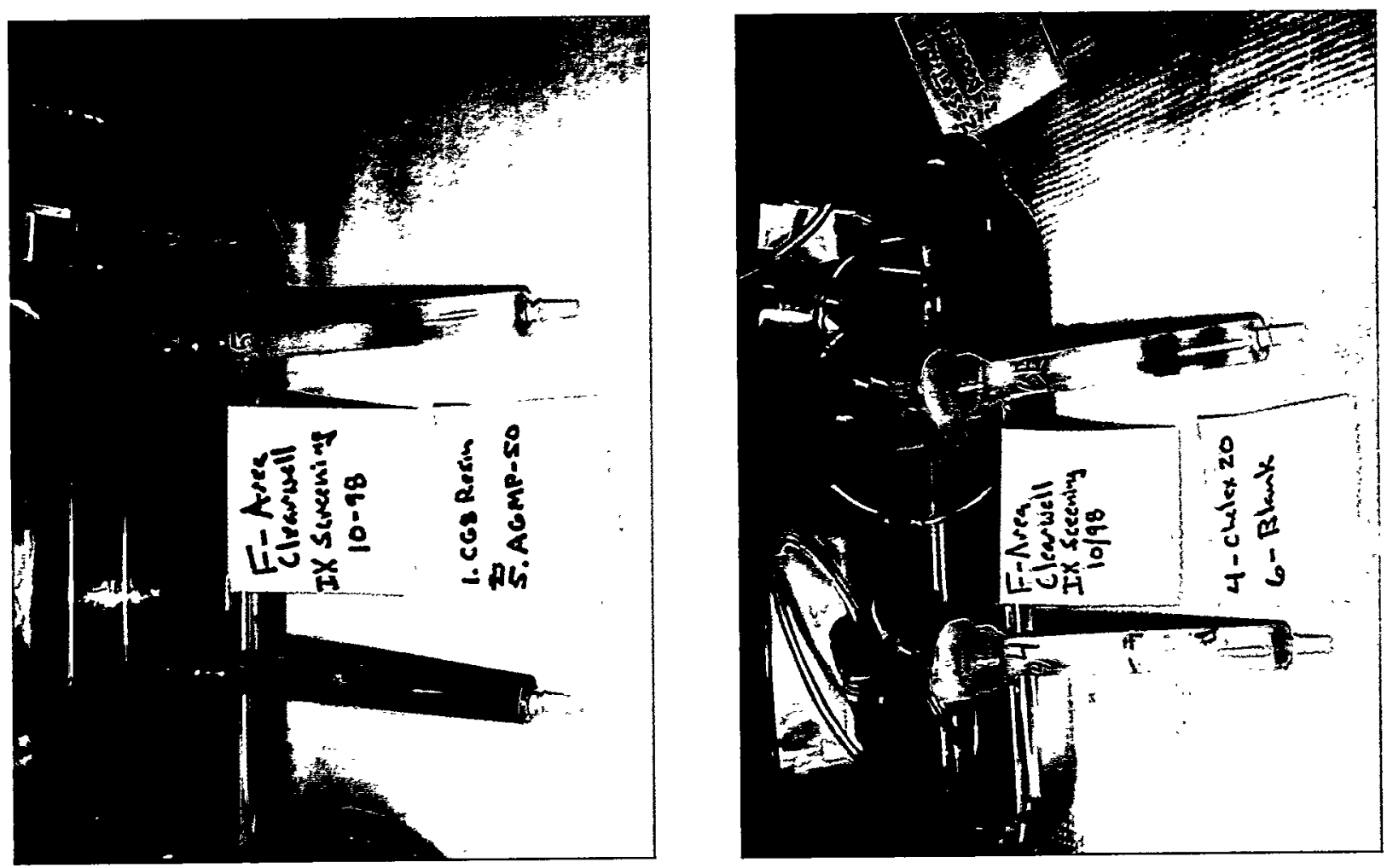

0
4
0
0
0
0
0 

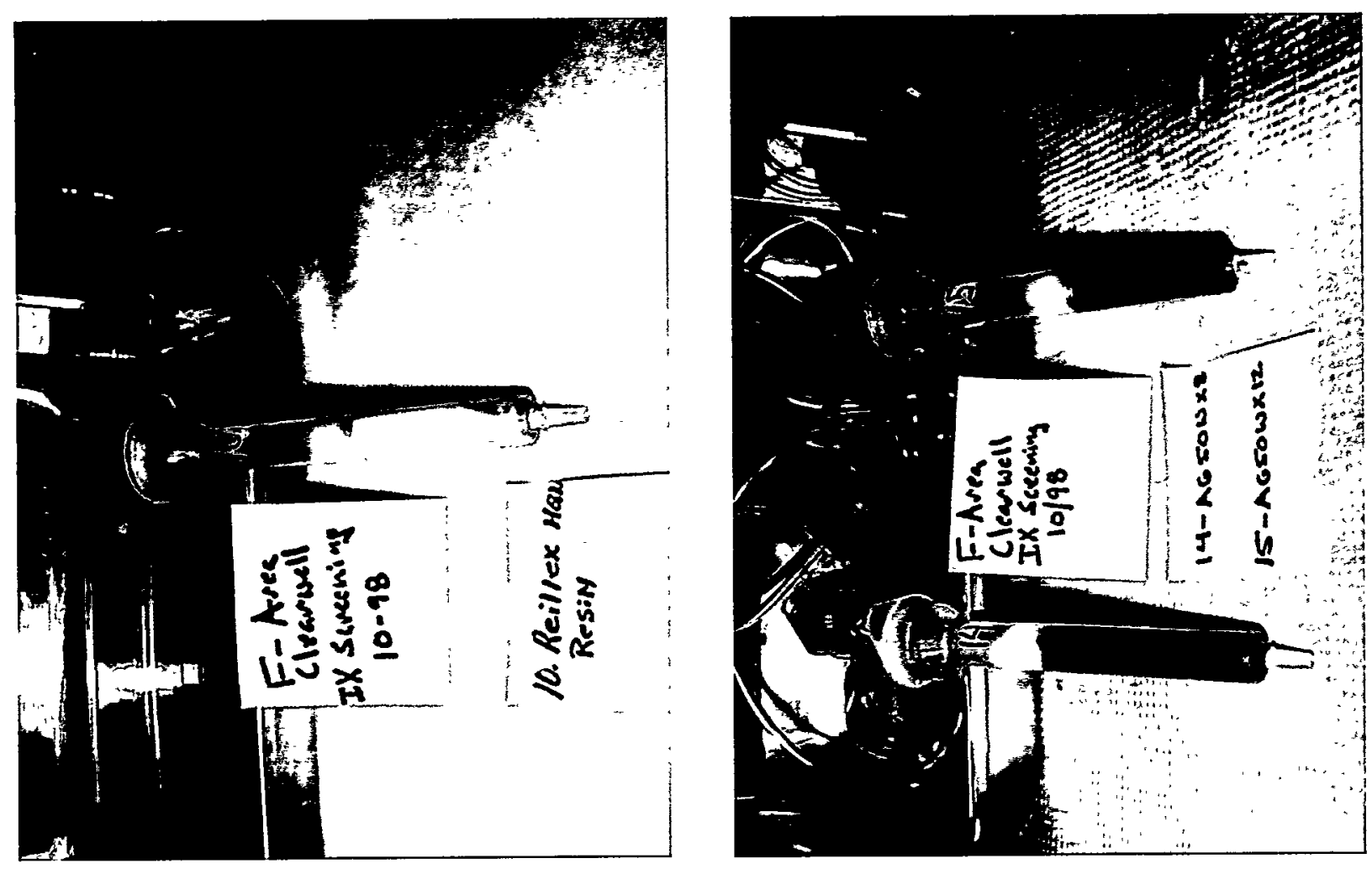

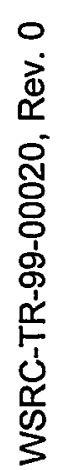
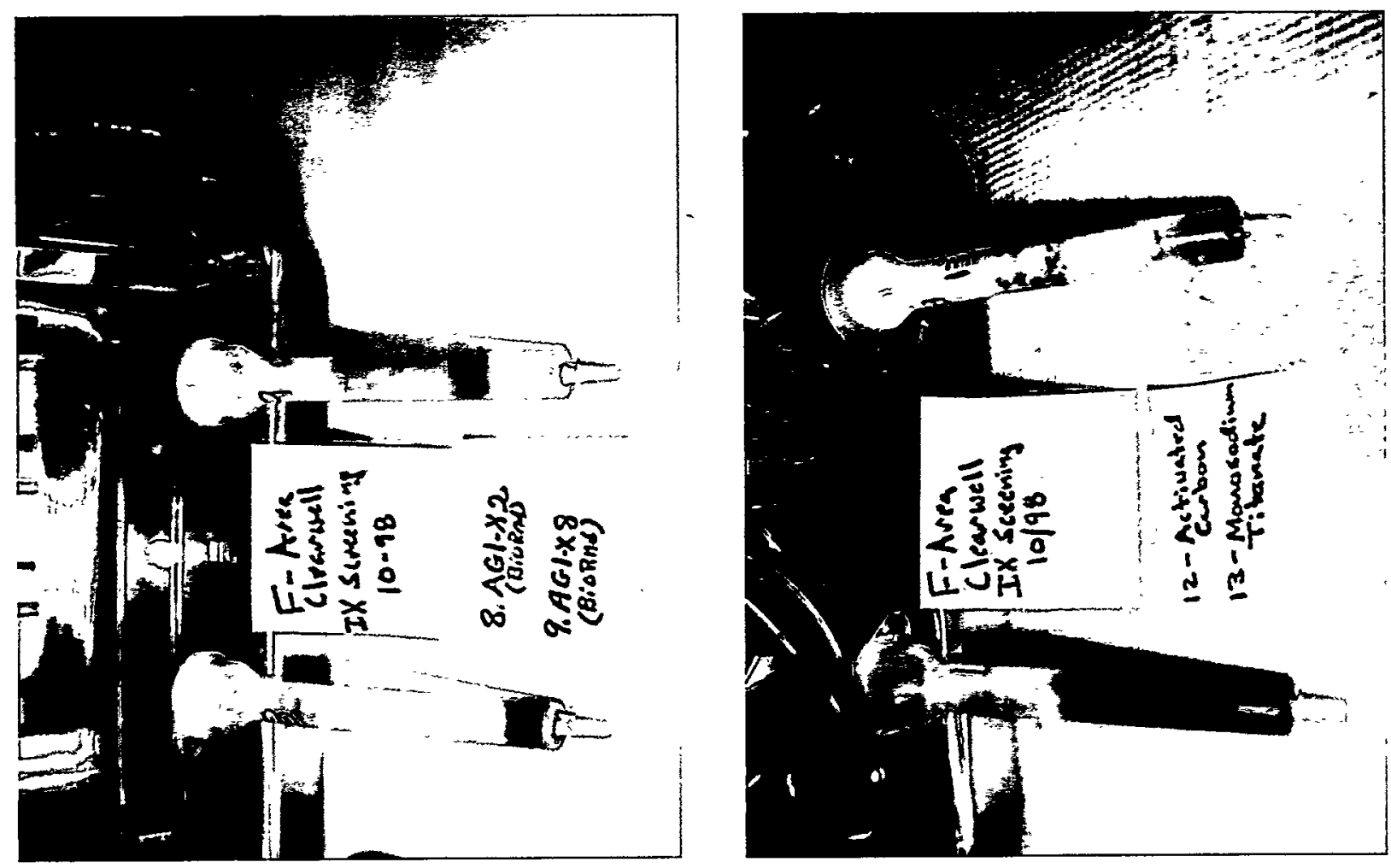

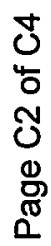



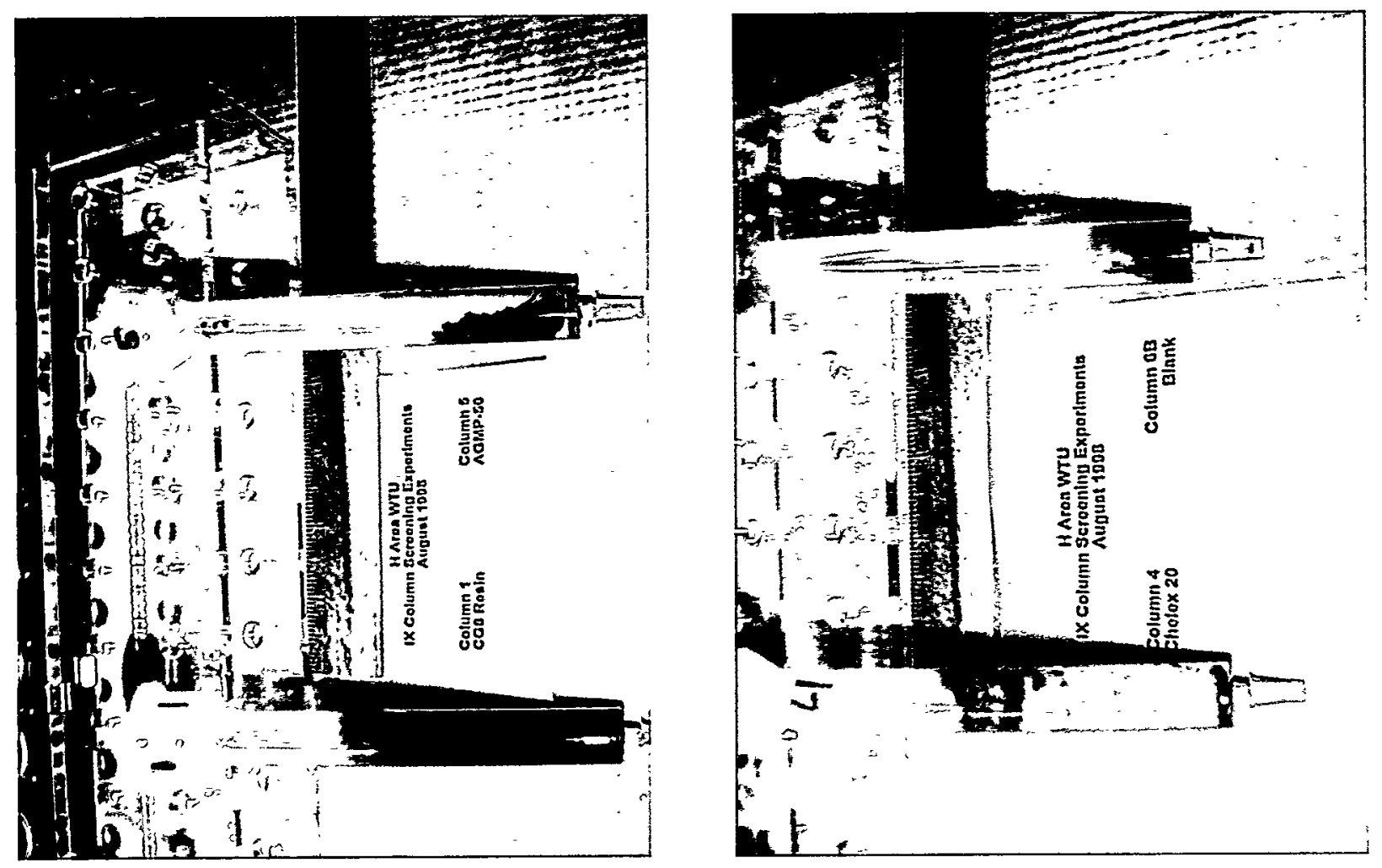

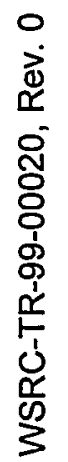
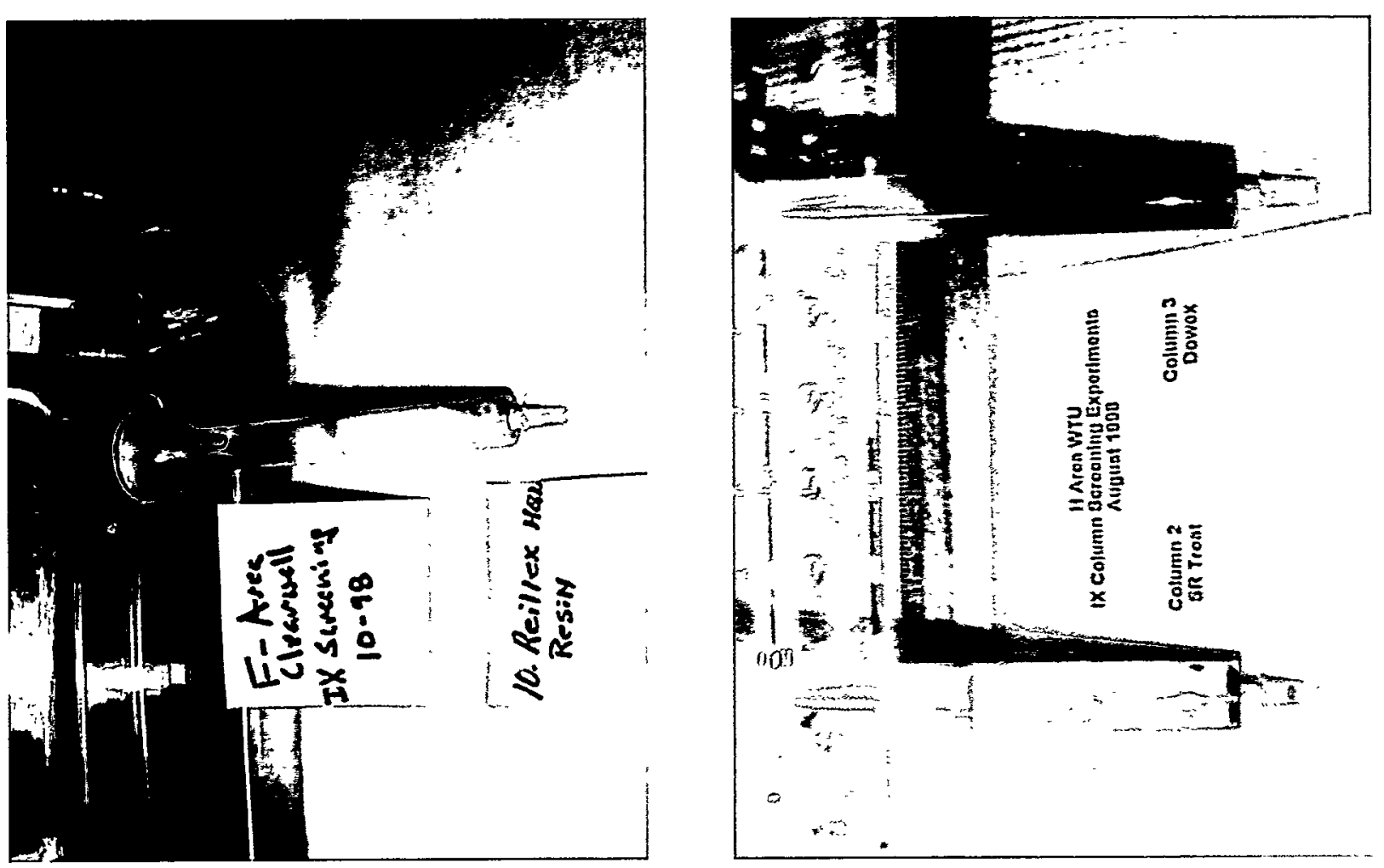

J
40
8
0
0
0
0
0 

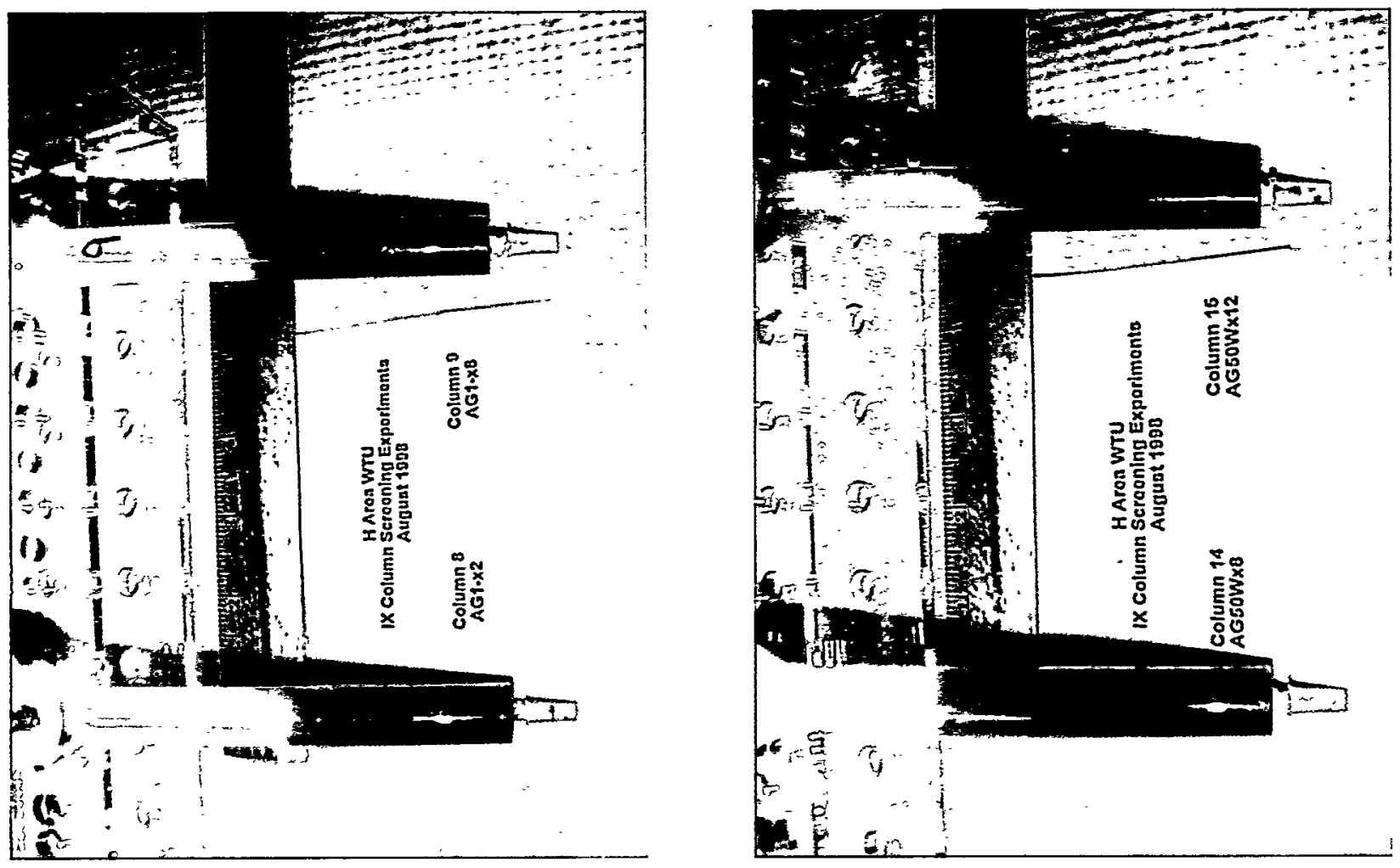

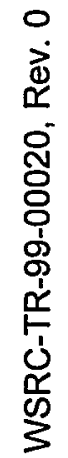
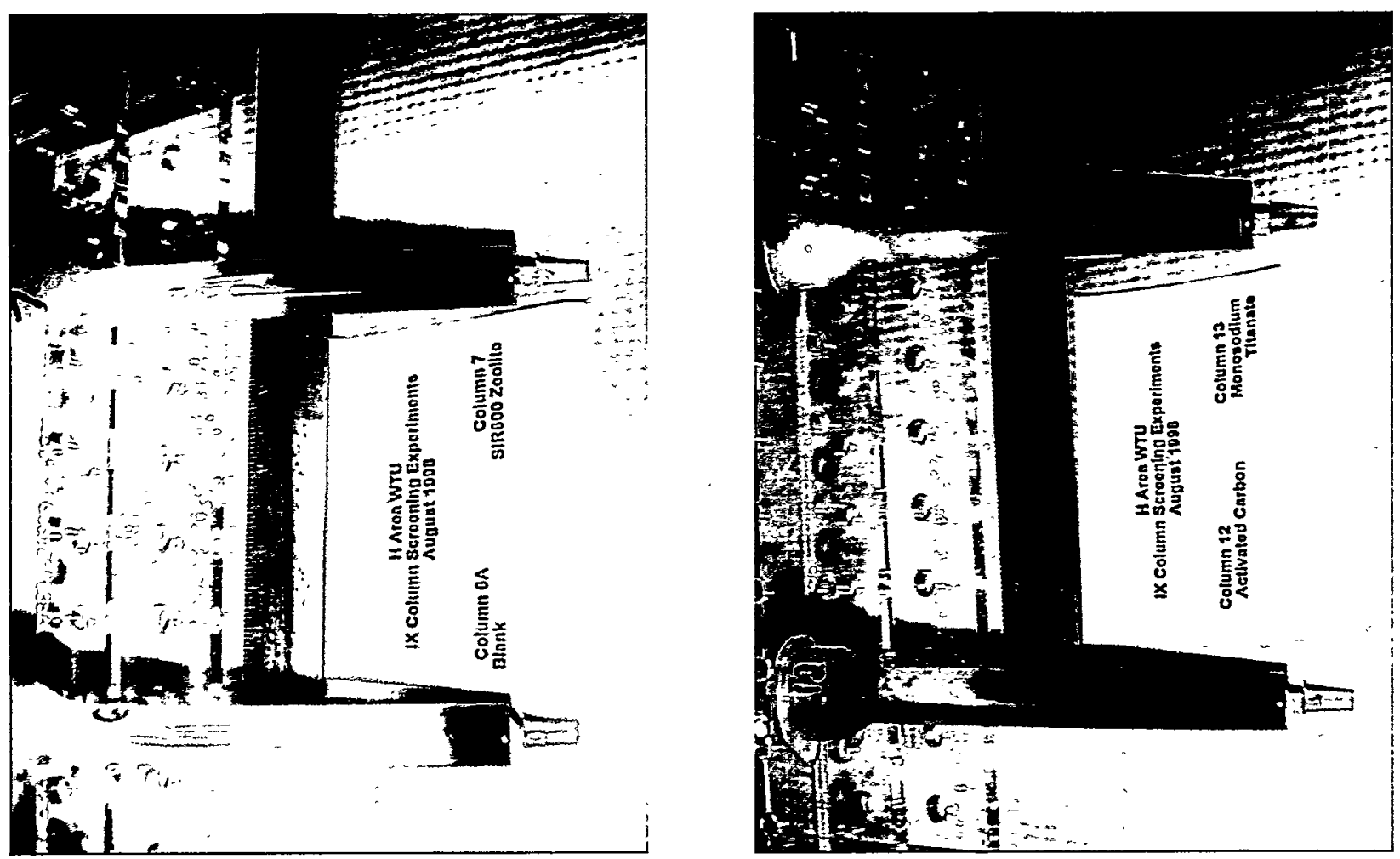

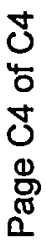




\section{Distribution:}

W. E. Stevens, 773A

Lynn V. Ehrke, 730-2B

Timothy W. Lewis, 730-2B w/o Attachments

Sean R. Bohrer, 730-2B

Michael J. Hartz, 730-2B w/o Attachments

Bruce G. Schappell, 730-2B

D. B. Moore-Shedrow, 773A w/o Attachments

Tom Butcher, 773-43A

STRC/WPT file, 773-A
Tech. Info. Mgmt, 703-43A

Edward M. McNamee, 730-2B

Alvin A. Siddall, 730-2B

James M. Lovekamp, 730-2B

James M. Clark, 730-2B

Joseph P. Kanzleiter , 730-2B

Scott Reboul, 730-2B

Walter Tamosaitis, 773A

WSRC-TR-99-00020, Rev. 0 